UNIVERSIDADE DE SÃO PAULO

INSTITUTO DE QUÍMICA DE SÃO CARLOS

DEPARTAMENTO DE FÍSICO-QUÍMICA

\title{
Atividade eletrocatalítica e estabilidade de nanopartículas de platina suportadas em óxidos de molibdênio e carbono frente à reação de redução de oxigênio
}

PEDRO FARINAZZO BERGAMO DIAS MARTINS

Dissertação apresentada ao Instituto de

Química de São Carlos, da Universidade de São Paulo, como parte dos requisitos para a obtenção do título de mestre em ciências.

Área de concentração: Físico-química Orientador: Prof. Dr. Edson Antonio Ticianelli

\section{Exemplar revisado}

$\mathrm{O}$ exemplar original encontra-se em acervo reservado na Biblioteca do IQSC-USP

São Carlos 
Autorizo a reprodução e divulgação total ou parcial deste trabalho, por qualquer meio convencional ou eletrônico para fins de estudo e pesquisa, desde que citada a fonte.

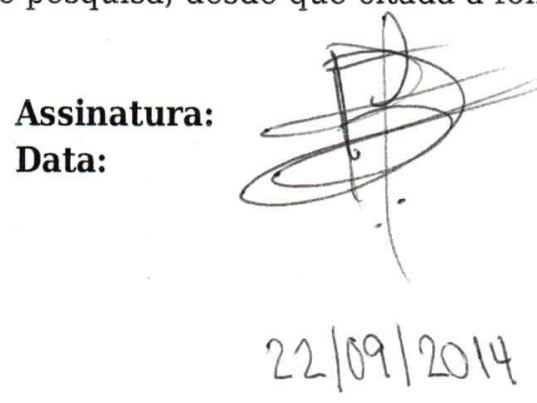

Ficha Catalográfica elaborada pela Seção de Referência e Atendimento ao Usuário do SBI/IQSC

Martins, Pedro Farinazzo Bergamo Dias

Atividade eletrocatalítica e estabilidade de nanopartículas de platina suportadas em óxidos de molibdênio e carbono frente à reação de redução de oxigênio. / Pedro Farinazzo Bergamo Dias Martins. - São Carlos, 2014. $98 \mathrm{f}$.

Dissertação (Mestrado em Físico-Química) - Instituto de Química de São Carlos / Universidade de São Carlos, 2014.

Edição revisada

Orientador: Prof. Dr. Edson Antonio Ticianelli

1. Reação de redução de oxigênio. 2. Célula a combustível de eletrólito polimérico. 3. Eletrocatálise. 4. Nanopartículas. I. Título. 



\section{DEDICATÓRIA}

Aos meus pais, Francisco e Débora, por sempre terem acreditado em mim, me dado apoio nas horas e decisões difíceis. E ao meu irmão, Francisco Júnior, que sempre esteve ao meu lado, como um grande companheiro. Muito obrigado por todos os momentos que passamos juntos. 



\section{AGRADECIMENTOS}

Agradeço aos meus familiares, em especial aos meus avós, Marciano e Olga, pelo apoio que me deram ao longo de minha vida pessoal e profissional.

À Maria Isabella Sapia, pela força nos momentos mais difíceis, pela enorme ajuda durante essa etapa, por todos os momentos que passamos juntos e por sempre estar ao meu lado ao longo da minha formação.

Ao Instituto de Química de São Carlos - USP, pelas facilidades oferecidas.

Ao Prof. Dr. Edson Ticianelli pela inestimável orientação acadêmica, pela paciência e atenção dada, e pelo exemplo de profissionalismo.

Ao Dr. Valdecir A. Paganin, pelo apoio e presteza sempre oferecidos.

Aos funcionários do IQSC, Dr. Mauro e Jonas, ao do IFSC José Augusto e a todos os demais que, direta ou indiretamente, colaboram para o andamento deste trabalho.

Aos colegas de laboratório, Adriana, Elenice, Amanda, Waldemir, Nyccolas, Drielly Oliveira, Orlando Lima, Aniélli, Thairo, Rafael Marinho, Amaury, Vanessa Oliveira, Edvan, Jose Luiz Bott, Rashida Parveen, Guilherme Saglietti, Patricia Corradini, Gabriel da Silva, Ayaz Hassan, Rafael Reis, Flávio Nikkuni, Pietro Lopes, pelo auxílio, pelos momentos de descontração e pelo companheirismo.

Ao Laboratório Nacional de Luz Síncontron, pela disponibilização das medidas de XPS e XAS.

Aos colegas Gabriel da Silva, Patricia Corradini e Prof ${ }^{a}$. Dra. Joelma Perez, pelas medidas de XPS realizadas.

Aos colegas Guilherme Saglietti, Ayaz Hassan e Rafael Reis, pelo auxílio durante as medidas de XAS.

À todos do Grupo de Eletroquímica pelo suporte e disposição em ajudar.

À todos os professores do IQSC.

À CAPES pela bolsa concedida.

Aos meus amigos Anderson Luis, Thais Pacifico, Ricardo Nomiyama, Elias Paiva, Juliana Tamara, Glauco Leal, Natan Costa, Michelle Peixoto, Giorgio Morbioli, Jéssica Albuquerque, Guilherme Castelano, Isaías Silva, Lucas Quintal, Lucas Sponton, Luis Felipe, Marcus Vinicius, Mateus Simões, Giulianna Denari, Pedro Barrenha, Marcio Bocelli e Maurício Daniel, pelos grandes momentos de descontração, por tornar esta jornada menos tensa, mais divertida e marcante.

À todos que de alguma forma me ajudaram. 



\section{RESUMO}

O envelhecimento dos eletrocatalisadores utilizados em cátodos de células a combustível de eletrólito polimérico (PEMFCs) é um dos principais fatores que restringem sua aplicação como conversores de energia em larga escala. Esse trabalho visa contribuir para o aprimoramento da estabilidade de nanopartículas de platina (NPs de Pt) por meio da modificação do suporte catalítico aos quais encontram-se impregnadas. Desse modo, foram realizadas sínteses de suportes catalíticos baseados em óxidos de molibdênio $\left(\mathrm{MoO}_{3}\right.$ e $\left.\mathrm{MoO}_{2}\right)$ ancorados em carbono Vulcan ${ }^{\circledR} \mathrm{XC72-R}$, sendo os materiais produzidos caracterizados física, estrutural e eletroquimicamente antes e após a impregnação de NPs de Pt. Para investigar a estabilidade dos eletrocatalisadores, foi realizado um teste de degradação eletroquímico acelerado, o qual consistiu em aplicar os ciclos de potenciais entre 0,6 e 1,0 V vs. ERH por curto período de tempo. Os resultados mostraram que os métodos de síntese utilizados foram satisfatórios, levando a formação dos catalisadores com as proporções bem próximas das requeridas. $\mathrm{O}$ catalisador $\mathrm{Pt} / \mathrm{MoO}_{3}-\mathrm{C}$ apresentou a maior atividade específica frente a reação de redução de oxigênio (RRO), atribuída a efeitos sinérgicos metal/suporte. Quando investigada a estabilidade dos materiais frente ao teste de degradação eletroquímico acelerado, observou-se que, a princípio, nenhum dos óxidos de molibdênio diminui a extensão da degradação da platina. Analisando-se as atividades específicas frente à RRO para cada catalisador antes e após o envelhecimento eletroquímico, foi observado que $\mathrm{Pt} / \mathrm{MoO}_{2}-\mathrm{C}$ apresentou-se como o material mais estável dentre os demais. 



\begin{abstract}
The aging of Pt based electrocatalysts used in the polymer electrolyte fuel cell (PEMFC) cathodes is one of the main issues that restrict its wide application as energy converters. This work aims to contribute to the improvement of the stability of platinum nanoparticles (Pt NPs) by modification of the catalyst support at which they are impregnated. Thus, syntheses of catalyst supports based on molybdenum oxide $\left(\mathrm{MoO}_{3}\right.$ and $\left.\mathrm{MoO}_{2}\right)$ anchored on Vulcan ${ }^{\circledR}$ $\mathrm{XC72-R}$ carbon were carried out and the produced materials were characterized physically, structurally and electrochemically prior and after impregnation of the Pt NPs. To investigate their stability, an electrochemical accelerated degradation test was performed, which consisted of applying a large number of short duration potential cycling steps between 0.6 and $1.0 \mathrm{~V}$ vs. RHE. The results showed that the synthetic methods used here were satisfactory, leading to the formation of catalysts with compositions near to those expected. The $\mathrm{Pt} / \mathrm{MoO}_{3}-$ $\mathrm{C}$ catalyst showed the highest specific activity toward the oxygen reduction reaction (ORR), and this was attributed to metal/support synergistic effects. When the stability against electrochemical accelerated degradation test of the materials was investigated, it was observed that, in principle, none of the molybdenum oxides really decreases the extent of platinum degradation. However, comparing the specific activities towards the ORR for each catalyst, before and after electrochemical aging, it is concluded that $\mathrm{Pt} / \mathrm{MoO}_{2}-\mathrm{C}$ is the most stable material among all others.
\end{abstract}




\section{LISTA DE FIGURAS}

Figura 1 - Dados sobre a produção de células a combustível destinadas a portáteis, estacionárias e transportes. 21

Figura 2 - Principais tipos de células a combustível produzidas e em constante desenvolvimento tecnológico.

Figura 3 - Distribuição dos tipos de células a combustível em termos de (a) megawatts, e (b) de unidades produzidas.

Figura 4 - Secção transversal de uma célula a combustível de membrana de troca protônica (PEMFC) operando com $\mathrm{H}_{2} / \mathrm{O}_{2}$ 27

Figura 5 - Esquema geral dos possíveis caminhos reacionais para RRO. 29

Figura 6 - Modelos de adsorção de $\mathrm{O}_{2}$ na superfície eletródica e possíveis rotas reacionais da reação de redução de oxigênio em eletrólitos ácidos. 30

Figura 7 - Mecanismos propostos para processos de degradação dos eletrocatalisadores baseados em nanopartículas de platina suportadas em carbono nas células a combustível, (a) Ostwald Ripening eletroquímico, (b) Migração e coalescência de cristalitos de Pt, (c) Afastamento das NPs de Pt do suporte de carbono, e (d) Dissolução e reprecipitação de cristalitos de Pt na membrana ionomérica........ 34

Figura 8 - Fotografia do arranjo montado para realização das medidas de XAS in situ nos catalisadores recém-preparados e comercial...... 44

Figura 9 - Protocolo do teste de degradação por ciclo de potencial acelerado. 47

Figura 10 - Difratogramas obtidos para os suportes catalíticos recém-preparados $\mathrm{MoO}_{3}-\mathrm{C}$ (a) e $\mathrm{MoO}_{2}-\mathrm{C}(\mathrm{b})$.

Figura 11 - Voltametria cíclica do suporte $\mathrm{MoO}_{2}-\mathrm{C}$ recém-preparado, realizada em solução $0,50 \mathrm{M}$ de $\mathrm{H}_{2} \mathrm{SO}_{4}$ saturada com gás $\mathrm{N}_{2}$, com velocidade de varredura de $20 \mathrm{mV}$ $\mathrm{s}^{-1}$, à temperatura ambiente $\left(25^{\circ} \mathrm{C}\right)$. As flechas indicam a direção de varredura no intervalo $0,05-1,0 \mathrm{~V}$. 51

Figura 12 - Diagrama de Pourbaix (potencial-pH) para um sistema Mo- $\mathrm{H}_{2} \mathrm{O}$..................... 53

Figura 13 - Difratogramas obtidos para os eletrocatalisadores recém-preparados, comercial e também o padrão cristalográfico de platina metálica. Os asteriscos (*) representam picos remanescentes referentes ao trióxido de molibdênio.............54

Figura 14 - Micrografias dos eletrocatalisadores recém-preparado e comercial obtidas por TEM. Os histogramas de distribuição de tamanho de partículas correspondentes 
estão inseridos abaixo das micrografias. Os insertos presentes são histogramas

referentes à esfericidade das NPs de Pt. ................................................... 56

Figura 15 - Espectros dos catalisadores recém-preparados obtidos por XPS....................... 57

Figura 16 - Espectros de XPS para Mo 3d para os catalisadores $\mathrm{Pt} / \mathrm{MoO}_{3}-\mathrm{C}$ (a) e $\mathrm{Pt} / \mathrm{MoO}_{2}-\mathrm{C}$

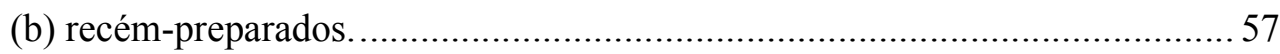

Figura 17 - Espectros de XPS para Pt 4f para os catalisadores $\mathrm{Pt} / \mathrm{MoO}_{3}-\mathrm{C}$ (a) e $\mathrm{Pt} / \mathrm{MoO}_{2}-\mathrm{C}(\mathrm{b})$ recém-preparados.

Figura 18 - Espectros de XANES in situ dos catalisadores $\mathrm{Pt} / \mathrm{MoO}_{3}-\mathrm{C}$ e $\mathrm{Pt} / \mathrm{MoO}_{2}-\mathrm{C}$ recémpreparados e Pt/C ETEK comercial polarizados em (a) 0,5 V, e (b) 0,9 V vs. ERH, em eletrólito de $0,5 \mathrm{M}$ de $\mathrm{H}_{2} \mathrm{SO}_{4}$, a temperatura ambiente e atmosfera de ar.

Figura 19 - Voltametrias cíclicas dos catalisadores $\mathrm{Pt} / \mathrm{MoO}_{3}-\mathrm{C}, \mathrm{Pt} / \mathrm{MoO}_{2}-\mathrm{C}$ recém-preparados e Pt/C comercial realizadas em $0,5 \mathrm{M}$ de $\mathrm{H}_{2} \mathrm{SO}_{4}$, com velocidade de varredura de $50 \mathrm{mV} \mathrm{s}^{-1}$, no intervalo de $0,05-1,2 \mathrm{~V} v s$. ERH, em atmosfera inerte de Ar e a temperatura ambiente de $\sim 25^{\circ} \mathrm{C}$.

Figura 20 - Voltametria cíclica de oxidação de CO adsorvido na superfície da platina no catalisador $\mathrm{Pt} / \mathrm{MoO}_{2}-\mathrm{C}$ seguida pelo segundo ciclo onde nota-se o perfil voltamétrico típico de NPs de Pt suportadas. Medidas realizadas em 0,5 M de $\mathrm{H}_{2} \mathrm{SO}_{4}$. Eletroadsorção em $50 \mathrm{mV}$ com $\mathrm{CO}$ (em atmosfera de $\mathrm{CO}$ ) por $10 \mathrm{~min}$ seguido pela saturação da atmosfera por Ar por $30 \mathrm{~min}$, e por fim a varredura de potencial com velocidade de varredura de $50 \mathrm{mV} \mathrm{s}^{-1}$, no intervalo de $0,05-1,2$ $\mathrm{V} v s$. ERH e a temperatura ambiente de $\sim 25^{\circ} \mathrm{C}$. 64

Figura 21 - Curvas de polarização para a RRO obtida potenciodinamicamente sobre o catalisador $\mathrm{Pt} / \mathrm{MoO}_{2}-\mathrm{C}$ em solução $0,5 \mathrm{M} \mathrm{H}_{2} \mathrm{SO}_{4}$, com atmosfera saturada com gás $\mathrm{O}_{2}$, a uma velocidade de varredura de $5 \mathrm{mV} \mathrm{s}^{-1}$ e à temperatura ambiente de $\sim 25^{\circ} \mathrm{C}$. (a) efeito de histerese na RRO, e (b) curvas em diferentes velocidades de rotação. As correntes foram normalizadas pela área geométrica do eletrodo, $0,196 \mathrm{~cm}^{2}$. 66

Figura 22 - Curvas de Levich para a RRO nos catalisadores $\mathrm{Pt} / \mathrm{MoO}_{2}-\mathrm{C}$, Pt/MoO3-C recémpreparados e Pt/C comercial. As curvas de RRO foram obtidas em solução $0,5 \mathrm{M} \mathrm{H}_{2} \mathrm{SO}_{4}$, com atmosfera saturada com gás $\mathrm{O}_{2}$, a uma velocidade de varredura de $5 \mathrm{mV} \mathrm{s}^{-1}$, em diversas velocidades de rotação e à temperatura ambiente de $\sim 25^{\circ} \mathrm{C}$. 
Figura 23 - Diagrama de Tafel dos eletrocatalisadores $\mathrm{Pt} / \mathrm{MoO}_{2}-\mathrm{C}$, Pt/MoO3-C recémpreparados e $\mathrm{Pt} / \mathrm{C}$ comercial corrigidos por transporte de massa e as correntes normalizadas pela área ativa de $\mathrm{Pt}$, para a $\mathrm{RRO}$ em solução $0,5 \mathrm{M}_{\text {de }} \mathrm{H}_{2} \mathrm{SO}_{4}, \omega=$ $1600 \mathrm{rpm}$, à temperatura de $25^{\circ} \mathrm{C}$. 69

Figura 24 - Voltametrias cíclicas a velocidade de $50 \mathrm{mV} \mathrm{s}^{-2}$, em $0,5 \mathrm{M} \mathrm{H}_{2} \mathrm{SO}_{4}$, dos catalisadores $\mathrm{Pt} / \mathrm{MoO}_{3}-\mathrm{C}, \mathrm{Pt} / \mathrm{MoO}_{2}-\mathrm{C}$ e $\mathrm{Pt} / \mathrm{C}$ ETEK novos e em definidos números de ciclagens do teste de envelhecimento acelerado aplicado. 73

Figura 25 - Micrografias de cada eletrocatalisador novo e após 12000 ciclos de 0,6 - 1,0 V em $0,5 \mathrm{M} \mathrm{H}_{2} \mathrm{SO}_{4}$, atmosfera de ar e temperatura de $25^{\circ} \mathrm{C}$. Micrografias obtidas por TEM 75

Figura 26 - Histogramas globais para cada eletrocatalisador novo e após 12000 ciclos. Os insertos presentes são histogramas referentes à esfericidade das NPs de Pt presentes em cada catalisador. 75

Figura 27 - Micrografias obtidas após o envelhecimento eletroquímico do catalisador $\mathrm{Pt} / \mathrm{MoO}_{3}$-C. O esquema também apresentado ilustra mecanismo de degradação responsável pela formação das nanopartículas de platina equiaxiais. 77

Figura 28 - Curvas de polarização para a RRO obtida potenciodinamicamente a velocidade de $5 \mathrm{mV} \mathrm{s}^{-2}$, em 0,5 $\mathrm{M} \mathrm{H}_{2} \mathrm{SO}_{4}, \omega=1600 \mathrm{rpm}$, dos catalisadores $\mathrm{Pt} / \mathrm{MoO}_{3}-\mathrm{C}$, $\mathrm{Pt} / \mathrm{MoO}_{2}-\mathrm{C}$ e Pt/C ETEK novos e em definidos números de ciclagens do teste de envelhecimento acelerado aplicado. As correntes foram normalizadas pela área geométrica do eletrodo, $0,196 \mathrm{~cm}^{2}$.Os insertos são aproximações da região de transferência de carga e possuem intervalo de potenciais de $0,83-0,92 \mathrm{~V}$ vs. ERH. 79

Figura 29 - Diagrama de Tafel dos eletrocatalisadores $\mathrm{Pt} / \mathrm{MoO}_{2}-\mathrm{C}, \mathrm{Pt} / \mathrm{MoO}_{3}-\mathrm{C}$ e Pt/C ETEK corrigidos por transporte de massa e as correntes normalizadas pela área ativa de Pt dos respectivos eletrodos, para a RRO em solução 0,5 $\mathrm{M}$ de $\mathrm{H}_{2} \mathrm{SO}_{4}, \omega=1600$ rpm, à temperatura de $25^{\circ} \mathrm{C}$, após o envelhecimento eletroquímico. 81 



\section{LISTA DE TABELAS}

Tabela 1 - Proporção em massa dos elementos Mo e C presentes no suporte catalítico recémpreparado obtidas por EDX.

Tabela 2 - Tamanho médio dos cristalitos e parâmetros de rede dos suportes catalíticos $\mathrm{MoO}_{2}-\mathrm{C}$ e $\mathrm{MoO}_{3}-\mathrm{C}$ calculados por dados obtidos por DRX

Tabela 3 - Porcentagens mássicas entre Pt, Mo e C presente nos eletrocatalisadores recémpreparados e comercial 52

Tabela 4 - Proporções mássicas dos elementos Mo e C presentes nos suportes catalíticos antes e após o MAF 53

Tabela 5 - Diâmetro médio dos cristalitos e parâmetros de rede padrões e dos eletrocatalisadores $\mathrm{Pt} / \mathrm{MoO}_{2}-\mathrm{C}, \mathrm{Pt} / \mathrm{MoO}_{3}-\mathrm{C}$ e $\mathrm{Pt} / \mathrm{C}$ ETEK calculados por dados obtidos por DRX. Também estão inseridos os diâmetros médios dos cristalitos obtidos por TEM. 55

Tabela 6 - Energias de ligação dos componentes Mo 3d $\mathrm{d}_{5 / 2}$ e Mo 3d $\mathrm{d}_{3 / 2}$ nos catalisadores recémpreparados e porcentagem atômica calculada para cada sinal. Dados obtidos por XPS 58

Tabela 7 - Energias de ligação dos componentes Pt 4f nos catalisadores recém-preparados e comercial, e porcentagem atômica calculada para cada sinal. (*) Dados retirados de Corradini et al. [117]

60

Tabela 8 - Carga mássica de Pt e área eletroquimicamente ativa para os eletrodos $\mathrm{Pt} / \mathrm{MoO}_{3}-\mathrm{C}$, $\mathrm{Pt} / \mathrm{MoO}_{2}-\mathrm{C}$ recém-preparados e $\mathrm{Pt} / \mathrm{C}$ comercial determinadas pelos métodos $\mathrm{H}_{\text {upd }}$ e CO-stripping.

Tabela 9 - Número de elétrons envolvidos, densidades de correntes cinéticas obtidas em potencial de $0,9 \mathrm{~V}$ e coeficientes de Tafel $b_{1}$ e $b_{2}$ obtidos para a RRO nos eletrodos $\mathrm{Pt} / \mathrm{MoO}_{3}-\mathrm{C}, \mathrm{Pt} / \mathrm{MoO}_{2}-\mathrm{C}$ recém-preparados e $\mathrm{Pt} / \mathrm{C}$ comercial. 68

Tabela 10 - Área eletroquimicamente ativa dos eletrodos $\mathrm{Pt} / \mathrm{MoO}_{3}-\mathrm{C}, \mathrm{Pt} / \mathrm{MoO}_{2}-\mathrm{C}$ recémpreparados e $\mathrm{Pt} / \mathrm{C}$ comercial novos e após diversos ciclos de teste de degradação

Tabela 11 - Número de elétrons envolvidos, correntes cinéticas (normalizadas pela área eletroativa de $\mathrm{Pt}$ ) obtidas em potencial de $0,9 \mathrm{~V}$ e coeficientes de Tafel $b_{1}$ e $b_{2}$ obtidos para a RRO nos eletrodos $\mathrm{Pt} / \mathrm{MoO}_{3}-\mathrm{C}, \mathrm{Pt} / \mathrm{MoO}_{2}-\mathrm{C}$ recém-preparados e $\mathrm{Pt} / \mathrm{C}$ comercial em intervalos definidos de ciclagem eletroquímica 



\section{LISTA DE SÍMBOLOS}

$d=$ média dos tamanhos dos cristalitos / $\AA$

$k=$ coeficiente igual a 0,90 , assumindo que os cristalitos possuem a forma esférica

$\lambda=$ comprimento de onda do raio $\mathrm{X}$ utilizado $\left(\mathrm{Cu} \mathrm{K}_{\alpha} 1,5406 \AA\right)$

$\beta=$ largura do pico de difração à meia altura / rad

$\theta=$ ângulo da posição máxima do pico de difração

$a=$ parâmetro de rede / $\AA$

$i_{d}=$ densidade de corrente limite-difusional $/ \mathrm{mA} \mathrm{cm}^{-2}$

$B=$ coeficiente de Levich $/ \mathrm{mA} \mathrm{cm}^{-2} \mathrm{rpm}^{-1 / 2}$

$\omega=$ velocidade angular $/ \mathrm{rpm}$

$n=$ número de elétrons envolvidos por molécula de espécie reagente $/ \mathrm{mol}^{-1}$

$F=$ constante de Faraday $/ \mathrm{C} \mathrm{mol}^{-1}$

$D=$ coeficiente de difusão da espécie reagente $/ \mathrm{cm}^{2} \mathrm{~s}^{-1}$

$v=$ viscosidade cinemática do meio $/ \mathrm{cm}^{2} \mathrm{~s}^{-1}$

$C^{0}=$ concentração da espécie reagente no seio da solução $/ \mathrm{mol} \mathrm{cm}^{-3}$

$i=$ densidade de corrente obtida diretamente das curvas de polarização $/ \mathrm{mA} \mathrm{cm}^{-2}$

$i_{0}=$ densidade de corrente de troca $/ \mathrm{mA} \mathrm{cm}^{-2}$

$\alpha=$ coeficiente de simetria

$f=$ constante $\mathrm{F} / \mathrm{RT}$

$\eta=$ sobrepotencial / Volts

$R=$ constante universal dos gases

$T=$ temperatura

$i_{k}=$ densidade de corrente cinética $/ \mathrm{mA} \mathrm{cm}^{-2}$ 



\section{SUMÁRIO}

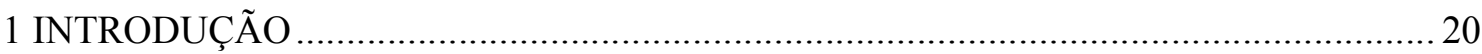

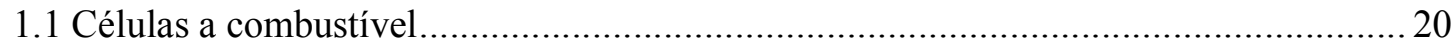

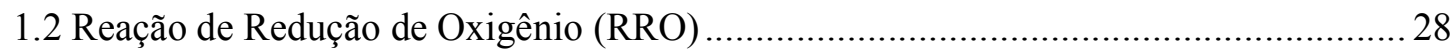

1.3 Estabilidade e durabilidade de células a combustível de membrana de troca protônica

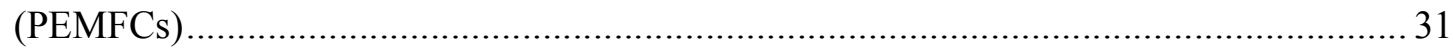

1.3.1 Modelos de degradação do grupamento catalisador/suporte presente nos eletrodos

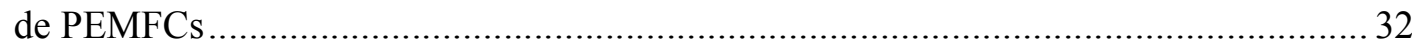

1.3.2 Utilização de óxidos de molibdênio/carbono como suporte catalítico para cátodos

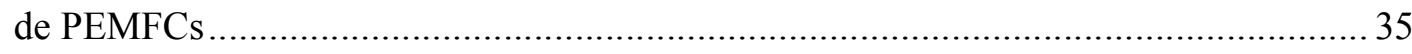

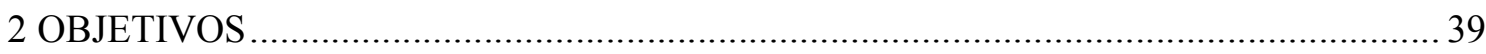

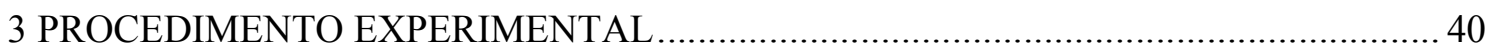

3.1 Síntese dos suportes baseados em óxidos de molibdênio suportados em carbono

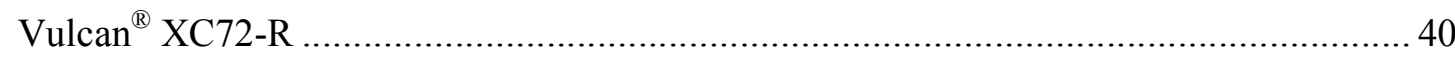

3.1.1 Dióxido de molibdênio suportado em carbono ……………………..................... 40

3.1.2 Trióxido de molibdênio suportado em carbono ……………………………….... 40

3.2 Impregnação de nanopartículas de platina nos suportes recém-preparados.................... 41

3.3 Caracterização física e estrutural dos suportes e eletrocatalisadores recém-preparados 41

3.3.1 Espectroscopia por dispersão de energia de raios X .............................................. 41

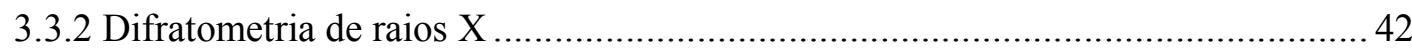

3.3.3 Microscopia eletrônica de transmissão ………………………………………...... 42

3.3.4 Espectroscopia fotoeletrônica de raios X........................................................... 43

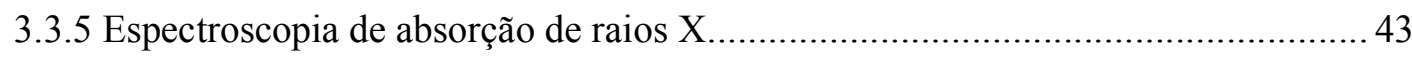

3.4 Caracterização eletroquímica dos suportes e eletrocatalisadores recém-preparados..... 44

3.5 Teste de degradação eletroquímico acelerado ................................................................ 46

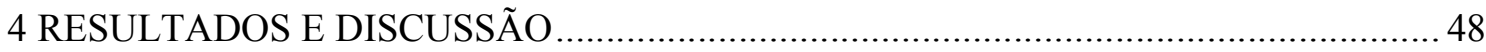

4.1 Caracterização física e estrutural dos suportes catalíticos............................................ 48 
4.2 Caracterização dos eletrocatalisadores recém-preparados e comercial.........................51

4.2.1 Caracterização física e estrutural.................................................................. 51

4.2.2 Caracterização eletroquímica: determinação da área superficial ativa................... 62

4.2.3 Caracterização eletroquímica: atividade frente à reação de redução de oxigênio

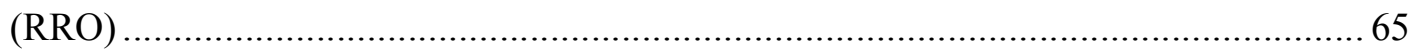

4.3 Investigação da estabilidade dos eletrocatalisadores $\mathrm{Pt} / \mathrm{MoO}_{3}-\mathrm{C}, \mathrm{Pt} / \mathrm{MoO}_{2}-\mathrm{C}$ e $\mathrm{Pt} / \mathrm{C}$

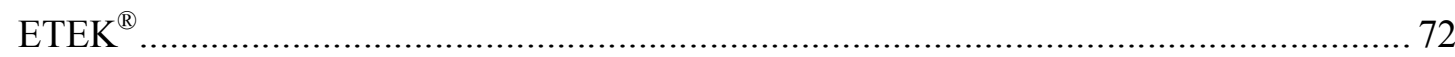

5 CONCLUSÕES

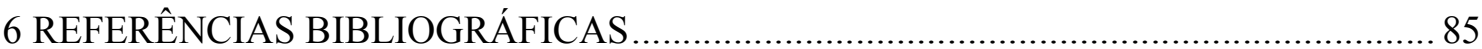




\section{INTRODUÇÃ̃O}

\subsection{Células a combustível}

As células a combustível foram inventadas no meio do séc. XIX por Sir Willian Grove. Entretanto, Christian Friedrich Schönbein, um professor da Universidade de Basle no período de 1829 a 1868, foi o descobridor do princípio de funcionamento de uma célula a combustível como um sistema de conversão de energia química em elétrica. Eles mantinhamse constantemente em contato trocando informações sobre o tema [1]; enquanto Schönbein focava-se mais na parte fundamental da descoberta, Grove era o engenheiro. Em 1842, em uma apresentação privada para Michael Faraday, John Peter Gassiot e Edward William Brayley, seu editor científico, Willian Grove fez sua primeira demonstração de uma célula a combustível [2]. Até meados do séc. XX, o desenvolvimento das células a combustível manteve-se estagnado devido a grande abundância de fontes de energia primárias e seu baixo custo. Atualmente um dos principais fatores que influenciam o aprimoramento das células a combustível é a preocupação com as consequências para o meio ambiente causadas pelo uso de combustíveis fósseis para a produção de eletricidade e para propulsão de veículos. Ademais, com a crise do petróleo, os países, altamente dependentes deste, viram-se forçados a encontrar dispositivos alternativos para produção de energia elétrica [1].

Atualmente, as células a combustível estão se estabelecendo como uma melhor opção tecnológica comparada com as máquinas convencionais de combustão interna ou baterias. Como tal, remessas de sistemas de células a combustível continuaram a crescer em 2012, tendo seu número praticamente dobrado comparado ao ano anterior, chegando a um total de 45.700 unidades (Figura 1). Considerando as principais aplicações de uma célula a combustível, as destinadas a aplicações estacionárias e em transportes foram as responsáveis pelo crescimento de megawatts distribuídos ao redor do mundo, chegando a 166,7 MW (Figura 1). Em pesquisa realizada pela Fuel Cell Today em meados de 2013, considerando a constância da demanda de células a combustível até o primeiro semestre de 2013, foi estimado que até final de 2013 ocorreria um crescimento de cerca de $46 \%$ neste setor da indústria, que chegaria a aproximadamente 67.000 unidades, equivalente a valores de potência excedendo 215 MW (Figura 1) [3]. 
Figura 1 - Dados sobre a produção de células a combustível destinadas a portáteis, estacionárias e transportes.
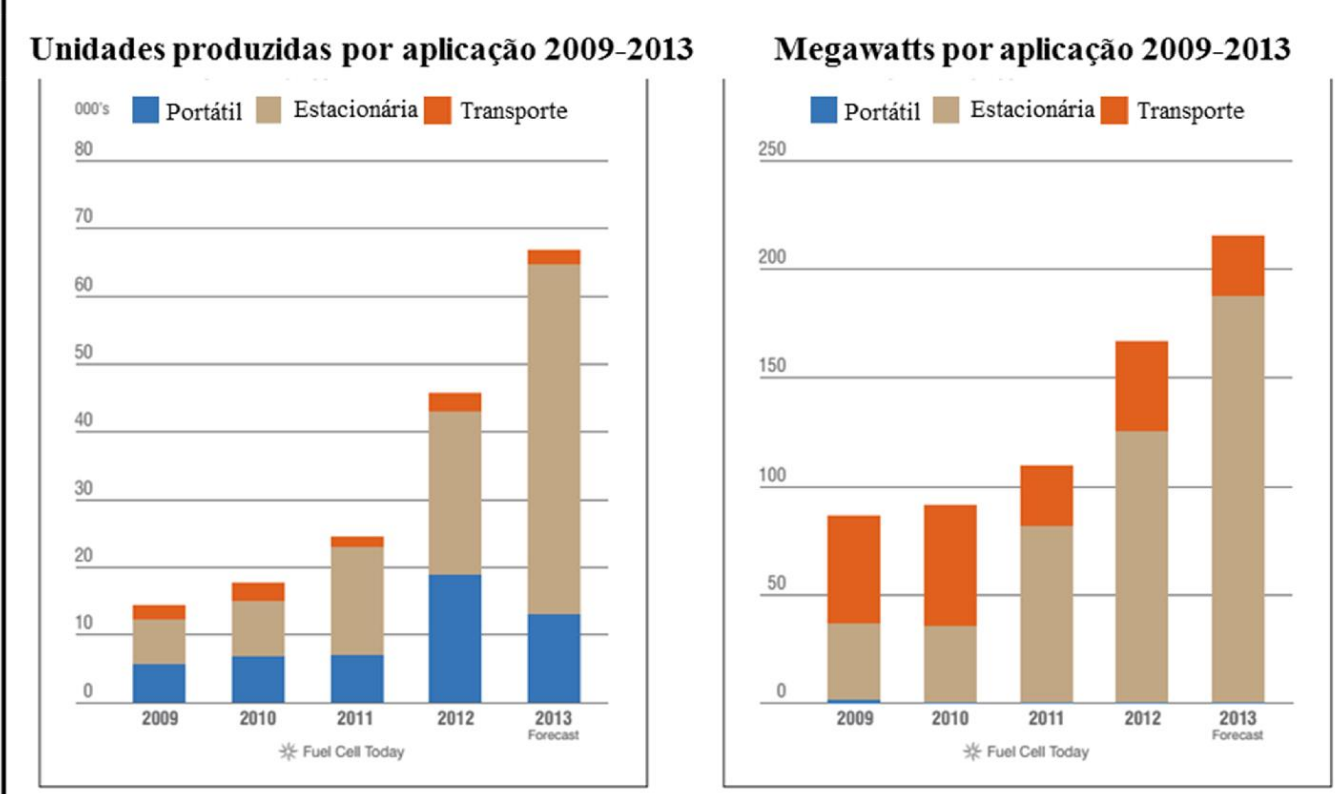

Fonte: Figura adaptada de CARTER, D.; WING, J. Fuel Cell Today, 2013 [3].

As células a combustível são classificadas de acordo com o tipo de eletrólito utilizado, que determina a temperatura de operação. Basicamente elas são compostas por um cátodo e um ânodo separados por um dado eletrólito e ligados através de um circuito externo. Os principais tipos de células a combustível estão sintetizados na Figura 2.

Figura 2 - Principais tipos de células a combustível produzidas e em constante desenvolvimento tecnológico.

\begin{tabular}{|c|c|c|c|c|c|c|}
\hline & $\begin{array}{c}\text { AFC } \\
\text { (Alcalina) }\end{array}$ & $\begin{array}{c}\text { PEMFC } \\
\text { (Membrana de } \\
\text { troca protônica) }\end{array}$ & $\begin{array}{c}\text { DMFC } \\
\text { (Metanol } \\
\text { Direto) } \\
\end{array}$ & $\begin{array}{l}\text { PAFC (Ácido } \\
\text { Fosfórico) }\end{array}$ & $\begin{array}{c}\text { MCFC } \\
\text { (Carbonato } \\
\text { Fundido) }\end{array}$ & SOFC (Óxido Sólido) \\
\hline $\begin{array}{c}\text { Temp. } \\
\text { Operação }\left({ }^{\circ} \mathrm{C}\right)\end{array}$ & $<100$ & $60-120$ & $60-120$ & $160-220$ & $600-800$ & $\begin{array}{c}800-1000 \\
\text { Possivel operar em } \\
\text { temperatura menor } \\
\quad(500-600)\end{array}$ \\
\hline Reação anódica & $\begin{array}{c}\mathrm{H}_{2}+2 \mathrm{OH}^{-} \\
\rightarrow 2 \mathrm{H}_{2} \mathrm{O}+ \\
2 \mathrm{e}^{-} \\
\end{array}$ & $\mathrm{H}_{2} \rightarrow 2 \mathrm{H}^{+}+2 \mathrm{e}^{-}$ & $\begin{array}{c}\mathrm{CH}_{3} \mathrm{OH}+ \\
\mathrm{H}_{2} \mathrm{O} \rightarrow \mathrm{CO}_{2} \\
+6 \mathrm{H}^{+}+6 \mathrm{e}^{-}\end{array}$ & $\begin{array}{c}\mathrm{H}_{2} \rightarrow \underset{2 \mathrm{e}^{-}}{2 \mathrm{H}^{+}+} \\
\end{array}$ & $\begin{array}{c}\mathrm{H}_{2}+\mathrm{CO}_{3}^{2-} \rightarrow \\
\mathrm{H}_{2} \mathrm{O}+\mathrm{CO}_{2}^{+} \\
2 \mathrm{e}^{-} \\
\end{array}$ & $\mathrm{H}_{2}+\mathrm{O}^{2-} \rightarrow \mathrm{H}_{2} \mathrm{O}+2 \mathrm{e}^{-}$ \\
\hline $\begin{array}{l}\text { Reação } \\
\text { catódica }\end{array}$ & $\begin{array}{l}1 / 2 \mathrm{O}_{2}+\mathrm{H}_{2} \mathrm{O} \\
+2 \mathrm{e}^{-} \rightarrow 2 \mathrm{OH}^{-}\end{array}$ & $\begin{array}{c}1 / 2 \mathrm{O}_{2}+2 \mathrm{H}^{+}+2 \mathrm{e}^{-} \\
\rightarrow \mathrm{H}_{2} \mathrm{O}\end{array}$ & $\begin{array}{c}3 / 2 \mathrm{O}_{2}+6 \mathrm{H}^{+} \\
+6 \mathrm{e}^{-} \rightarrow \\
3 \mathrm{H}_{2} \mathrm{O}\end{array}$ & $\begin{array}{c}1 / 2 \mathrm{O}_{2}+2 \mathrm{H}^{+}+ \\
2 \mathrm{e}^{-} \rightarrow \mathrm{H}_{2} \mathrm{O}\end{array}$ & $\begin{array}{l}1 / 2 \mathrm{O}_{2}+\mathrm{CO}_{2} \\
+2 \mathrm{e}^{-} \stackrel{\mathrm{CO}_{3}{ }^{2-}}{ }\end{array}$ & $1 / 2 \mathrm{O}_{2}+2 \mathrm{e}^{-} \rightarrow \mathrm{O}^{2-}$ \\
\hline $\begin{array}{l}\text { Transportador } \\
\text { de carga no } \\
\text { eletrólito }\end{array}$ & $\mathrm{OH}^{-}$ & $\mathrm{H}^{+}$ & $\mathrm{H}^{+}$ & $\mathrm{H}^{+}$ & $\mathrm{CO}_{3}{ }^{2-}$ & $\mathrm{O}^{2-}$ \\
\hline
\end{tabular}

Fonte: Figura adaptada de CARRETTE, L. Fuel Cells, v. 1, 2001 [2]. 
As células a combustível alcalinas (AFC, Alkaline Fuel Cell) é um dos tipos mais antigos de células a combustível. A AFC foi desenvolvida primeiramente para missões Apollo, e uma versão otimizada desta continua a ser aplicada como fonte de energia elétrica para missões espaciais [4]. O eletrólito destas células é o hidróxido de potássio $(\mathrm{KOH})$, e as principais reações que ocorrem na célula são as que seguem:

Ânodo:

$\mathrm{H}_{2}+2 \mathrm{OH}^{-} \rightarrow 2 \mathrm{H}_{2} \mathrm{O}+2 \mathrm{e}^{-}$

Cátodo:

$\mathrm{O}_{2}+\mathrm{H}_{2} \mathrm{O}+2 \mathrm{e}^{-} \rightarrow \mathrm{HO}_{2}^{-}+\mathrm{OH}^{-}$

$\mathrm{HO}_{2}^{-}+\mathrm{H}_{2} \mathrm{O}+2 \mathrm{e}^{-} \rightarrow 3 \mathrm{OH}^{-}$

Ou: $\mathrm{O}_{2}+2 \mathrm{H}_{2} \mathrm{O}+4 \mathrm{e}^{-} \rightarrow 4 \mathrm{OH}^{-}$

As AFCs tem a vantagem de gerar potenciais de células mais elevados em relação às células que utilizam eletrólito ácido, pois a cinética da reação de oxidação de redução de oxigênio é mais facilitada em $\mathrm{KOH}$. Metais nobres são bastante ativos para ambos os eletrodos das AFCs. O eletrólito alcalino também permite que sejam utilizados eletrodos baseados em catalisadores de metais não nobres, tais como níquel de Raney para o ânodo [5], e óxidos do tipo espinel e prata em conjunto com ftalocianinas de ferro e outras porfirinas para o eletrodo de oxigênio/ar (cátodo). Uma desvantagem das AFCs é a necessidade de se utilizar gases com elevada pureza para uma operação satisfatória. Essa é considerada a principal restrição na maioria das aplicações [2]. A AFC é susceptível a contaminação por $\mathrm{CO}_{2}$ no eletrólito (obstrução dos poros) quando o hidrogênio obtido por reforma e o ar são utilizado no ânodo ou no cátodo, respectivamente, ou pela corrosão do suporte catalítico de carbono, pois ocorre a formação de carbonatos segundo a seguinte reação:

$\mathrm{CO}_{2}+2 \mathrm{OH}^{-} \rightarrow\left(\mathrm{CO}_{3}\right)^{2-}+\mathrm{H}_{2} \mathrm{O}$

Catalisadores baseados em Pt e Ni também podem ser envenenados por impurezas, sulfeto e $\mathrm{CO}$, contidas na matéria-prima ('feedstock'). 
As células a combustível de ácido fosfórico (PAFC, Phosphoric Acid Fuel Cell) são destinadas à aplicações estacionárias, ou seja, são células desenvolvidas para fornecer energia para um local fixo. Plantas de energia estacionárias estão sendo instaladas pelo mundo todo com produção de energia variando de $5-200 \mathrm{~kW}$, suprindo cidades, mercados e hospitais com eletricidade, calor e água quente [6]. As reações eletródicas de uma PAFC são:

Ânodo:

$\mathrm{H}_{2} \rightarrow 2 \mathrm{H}^{+}+2 \mathrm{e}^{-}$

Cátodo:

$\mathrm{O}_{2}+4 \mathrm{H}_{2}+4 \mathrm{e}^{-} \rightarrow 2 \mathrm{H}_{2} \mathrm{O}$

Reação Global: $2 \mathrm{H}_{2}+\mathrm{O}_{2} \rightarrow 2 \mathrm{H}_{2} \mathrm{O}$

As vantagens das PAFCs é a sua arquitetura simples, a estabilidade térmica, química e eletroquímica, e a baixa volatilidade do ácido fosfórico na faixa de temperatura de 150-200 ${ }^{\circ} \mathrm{C}$. Uma das principais desvantagens está no fato dos cátodos das PAFCs possuírem cinética muito lenta para a redução de oxigênio. Devido a este fato, catalisadores com alta carga de $\mathrm{Pt}$ são necessários para a promoção da redução de oxigênio nos cátodos. Outra desvantagem é a restrição de temperatura de operação dessas células: abaixo de $150^{\circ} \mathrm{C}$, a condutividade do eletrólito é reduzida e acima de $220^{\circ} \mathrm{C}$, o ácido fosfórico é muito volátil e sua decomposição é facilitada $[2,4]$.

As células a combustível de carbonato fundido (MCFC, Molten Carbonate Fuel Cell) começaram a ser desenvolvidas aproximadamente na metade do séc. XX para aplicações em armazenamento de energia. A temperatura de operação de uma MCFC típica é de aproximadamente $650^{\circ} \mathrm{C}$, o que possibilita a reforma interna do combustível e que o calor gerado possa ser aproveitado em combinação com uma turbina, para gerar mais eletricidade, além daquela fornecida pela MCFC [2]. Outra consequência do uso da elevada temperatura é o aumento da cinética da redução de oxigênio, que possibilita o não uso de metais nobres no cátodo. Os sistemas de células a combustível de carbonato fundido combinados com turbinas possuem eficiências elétricas da ordem de 50-70\%. O desempenho das MCFCs propriamente ditas é limitado pela resistividade do eletrólito e pelas perdas durante a polarização do eletrodo. Os carbonatos fundidos geralmente utilizados como eletrólito são carbonatos de LiK ou LiNa, sendo estes estabilizados em uma matriz de $\mathrm{LiAlO}_{2}$ suportada com fibras de alumina 
$\left(\mathrm{Al}_{2} \mathrm{O}_{3}\right)$. As reações anódicas e catódicas quando se utiliza gás metano $\left(\mathrm{CH}_{4}\right)$ como combustível são:

Ânodo:

$\mathrm{CH}_{4}+2 \mathrm{H}_{2} \mathrm{O} \rightarrow \mathrm{CO}_{2}+4 \mathrm{H}_{2}$ ou

$\mathrm{CH}_{4}+\mathrm{H}_{2} \mathrm{O} \rightarrow \mathrm{CO}+3 \mathrm{H}_{2}$

$\mathrm{CO}+\mathrm{H}_{2} \mathrm{O} \rightarrow \mathrm{CO}_{2}+\mathrm{H}_{2}$

$\mathrm{H}_{2}+\mathrm{CO}_{3}{ }^{2-} \rightarrow \mathrm{CO}_{2}+\mathrm{H}_{2} \mathrm{O}+2 \mathrm{e}^{-}$(reação principal) ou

$\mathrm{CO}+\mathrm{CO}_{3}{ }^{2-} \rightarrow 2 \mathrm{CO}_{2}$ (reação em menor extensão)

Cátodo:

$\mathrm{O}_{2}+2 \mathrm{CO}_{2}+4 \mathrm{e}^{-} \rightarrow 2 \mathrm{CO}_{3}{ }^{2-}$

As células a combustível de óxido sólido (SOFC, Solid Oxide Fuel Cell) são compostas por um sistema de duas fases gás-sólido de modo que problemas com controle de água, encharcamento das camadas catalíticas e baixa cinética de redução de oxigênio são evitados. Por outro lado, por operarem em temperaturas entre $800-1000{ }^{\circ} \mathrm{C}$, há muita dificuldade em encontrar materiais que possuam estabilidade térmica para operação. Assim como nas MCFCs, a reforma interna dos combustíveis é possibilitada sobre o catalisador anódico, sendo possível, quando combinadas com outros sistemas de geração de energia (e.g., turbinas de gás), gerar uma eficiência elétrica global de até 70\%. As SOFCs podem operar com praticamente qualquer combustível de hidrocarboneto ou hidrogênio, não existindo a necessidade de utilizar metais nobres nos eletrodos. O ânodo consiste de um material composto por catalisador de $\mathrm{Ni}$ ou Co contido em zircônia estabilizada por ítria, e no cátodo utiliza-se $\mathrm{LaSrMnO}_{3}$. O eletrólito também é composto por zircônia estabilizada por ítria. As principais reações que ocorrem neste tipo de célula são:

Ânodo:

$\mathrm{H}_{2}+\mathrm{O}^{2-} \rightarrow \mathrm{H}_{2} \mathrm{O}+2 \mathrm{e}^{-}$ou 
$\mathrm{CO}+\mathrm{O}^{2-} \rightarrow \mathrm{CO}_{2}+2 \mathrm{e}^{-}$ou

$\mathrm{CH}_{4}+4 \mathrm{O}^{2-} \rightarrow 2 \mathrm{H}_{2} \mathrm{O}+\mathrm{CO}_{2}+8 \mathrm{e}^{-}$

Cátodo:

$\mathrm{O}_{2}+4 \mathrm{e}^{-} \rightarrow 2 \mathrm{O}^{2-}$

As células a combustível de membrana de troca protônica (PEMFC, Proton Exchange Membrane Fuel Cell) continuam a ser o tipo de célula mais estudado no mundo e isto pode ser atribuído à possibilidade de um vasto campo de aplicação: portáteis, estacionárias e para o transporte. Diferente dos outros tipos de células, as PEMFCs podem ser usadas tanto para pequenas quanto para grandes escalas. Analisando a Figura 3(a) pode-se notar que, em termos de megawatts, a distribuição das células colocadas em uso é praticamente equivalente entre PEMFCs, MCFCs e SOFCs. Entretanto, as contribuições, em megawatts, dos dois últimos tipos de células devem-se graças às suas aplicações no setor estacionário destinado a implantações em larga-escala de potência. Ou seja, apesar da equivalência desses tipos de células em termos de megawatts, quando investigamos a distribuição dos tipos de células em termos das quantidades de unidades, as PEMFCs disparam em relação às demais, representando 88\% do total de células produzidas no ano de 2012 (Figura 3 (b)). Pesquisa realizada pela Fuel Cell Today em meados de 2013 mostrou que esta tendência continuaria até o final do ano de 2013 [3]. 
Figura 3 - Distribuição dos tipos de células a combustível em termos de (a) megawatts, e (b) de unidades produzidas.

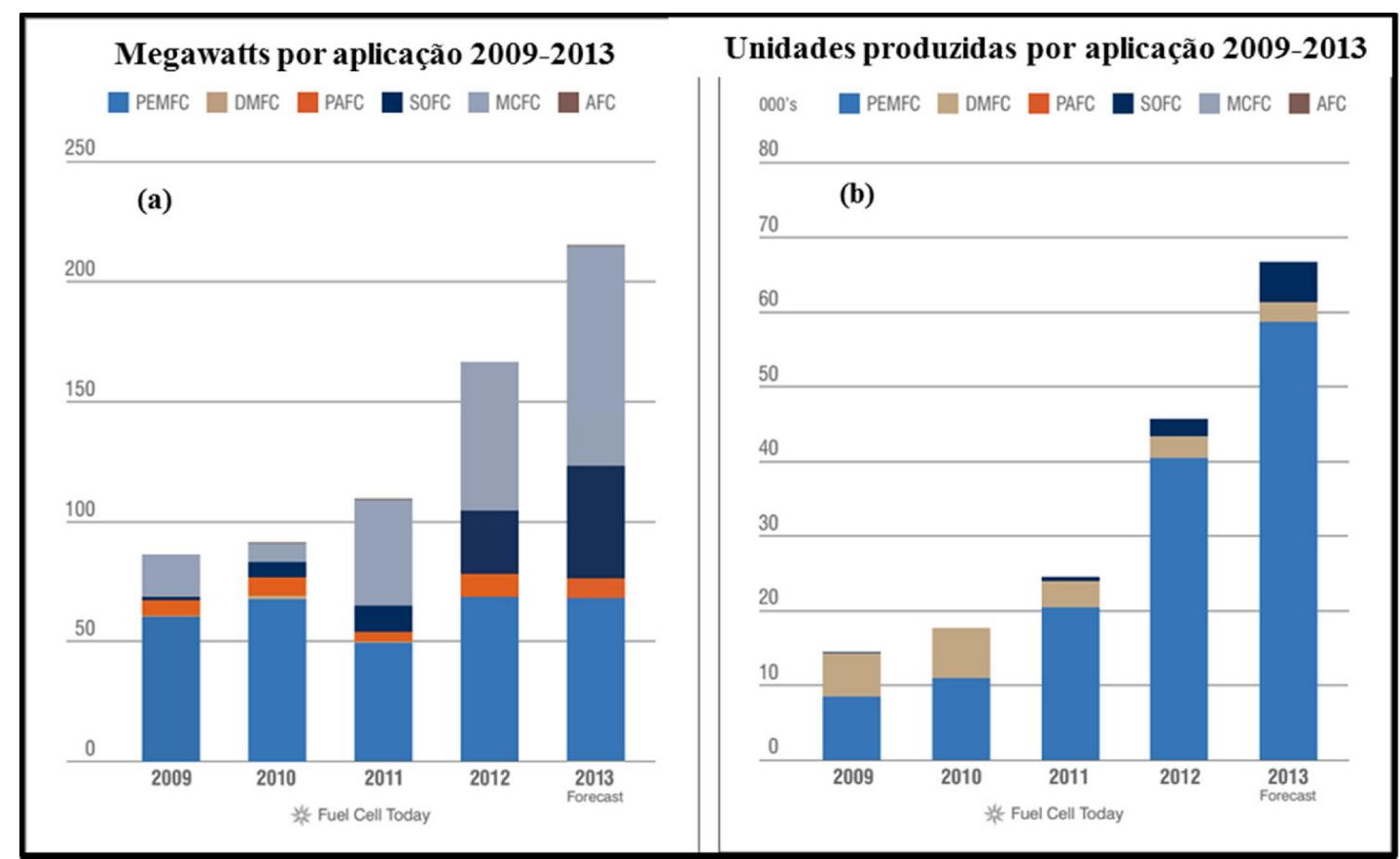

Fonte: Figura adaptada de CARTER, D.; WING, J. Fuel Cell Today, 2013 [3].

As PEMFCs operam em temperaturas relativamente baixas, entre $85-105^{\circ} \mathrm{C}$, onde o gás hidrogênio $\left(\mathrm{H}_{2}\right)$ é oxidado no ânodo e o oxigênio $\left(\mathrm{O}_{2}\right)$ contido no ar é reduzido no cátodo, gerando como produto químico final água $\left(\mathrm{H}_{2} \mathrm{O}\right)$. Vale ressaltar que há outras classes das células a combustível de membrana de troca protônica, por exemplo: as células a combustível de metanol direto (DMFC, Direct Methanol Fuel Cell) operam com metanol como combustível [7-12]. O desenvolvimento de células a combustível para aplicação em veículos de pequeno porte tem focalizado nas células a combustível de membrana de troca protônica devido a elas operarem em temperaturas relativamente baixas e possuírem curto tempo de iniciação e resposta de transiente comparada aos outros tipos de células a combustível que operam a elevadas temperaturas $\left(200^{\circ} \mathrm{C}\right.$ a $\left.1000^{\circ} \mathrm{C}\right)$.

O esquema de uma célula a combustível PEMFC encontra-se na Figura 4. Simplificadamente, os processos que ocorrem durante o funcionamento são: (i) o gás hidrogênio e o ar são bombeados para os canais de fluxo anódico e catódico, respectivamente; (ii) $\mathrm{o} \mathrm{H}_{2}$ e o ar permeiam através das respectivas camadas de difusão de gás (CDG) e a camada micro-porosa (CMP), onde são difundidos para as correspondentes camadas eletrocatalíticas; (iii) $\mathrm{o} \mathrm{H}_{2}$ é continuamente oxidado na camada eletrocatalítica anódica 
gerando prótons e elétrons; (iv) os prótons migram através de uma membrana de troca protônica (também conhecida como membrana de eletrólito polimérico, tendo como exemplo o NAFION ${ }^{\circledR}$, E. I. DuPont de Nemours and Company); (v) os elétrons gerados na oxidação do $\mathrm{H}_{2}$ são conduzidos para o cátodo por meio de um circuito externo; (vi) o $\mathrm{O}_{2}$ contido no ar é reduzido através da reação com os prótons e os elétrons, provenientes da oxidação do hidrogênio, na camada eletrocatalítica catódica, gerando água e calor como produtos finais. As moléculas de água produzidas são transportadas para fora da camada eletrocatalítica catódica através da CDG/CMP catódica, sendo eventualmente removidas do canal de fluxo catódico para fora da célula. As camadas eletrocatalíticas catódica e anódica, e a membrana trocadora de prótons formam o chamado conjunto membrana-eletrodo (MEA, Membrane Electrode Assembly). O conjunto membrana-eletrodo necessita de umidade para garantir que os processos descritos acima sejam cumpridos. Como exposto na Figura 4, a membrana de troca protônica permite o intercâmbio de água entre os eletrodos, mantendo-se constantemente úmida $[13,14]$.

Figura 4 - Secção transversal de uma célula a combustível de membrana de troca protônica (PEMFC) operando com $\mathrm{H}_{2} / \mathrm{O}_{2}$.

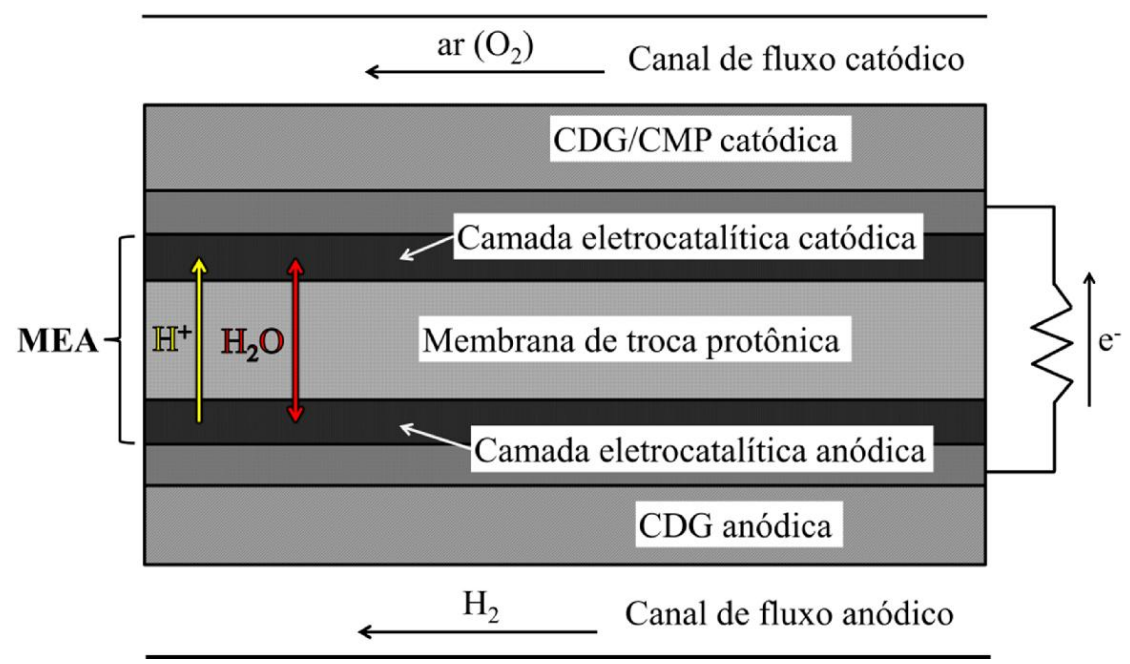

As principais reações que ocorrem nas PEMFCs são idênticas àquelas mencionadas para as PAFCs (reações 1.6 a 1.8). 


\subsection{Reação de Redução de Oxigênio (RRO)}

Uma grande parcela dos fatores que limitam a aplicação de células a combustível em larga-escala está diretamente relacionada com a reação de redução de oxigênio (RRO), devido ao seu mecanismo complexo e cinética lenta, comparada a outras reações eletródicas como a reação de oxidação de hidrogênio. Trata-se de uma reação multieletrônica que pode envolver diversos passos e intermediários reacionais, tornando a elucidação do mecanismo desta reação um enorme desafio. Décadas de estudos direcionados à busca de mecanismos reacionais que mostrem como a RRO é desencadeada nas superfícies metálicas tem sido efetuados, especialmente em superfícies de eletrodos compostas por platina metálica ('Pt-bulk'), nanopartículas de platina dispersas em substratos (carbono, por exemplo) e monocristais de platina de baixo índice, já que dos materiais existentes, o metal platina é o mais estável nas condições experimentais expostas ao eletrodo. Como resultados, diferentes rotas reacionais têm sido propostas, porém não existe ainda um mecanismo completamente resolvido para a RRO tanto para meio ácidos, como para alcalinos.

Dentre os diversos trabalhos descritos na literatura relacionados à $\mathrm{RRO}$, o realizado por Wroblowa et al. merece atenção especial [15]. Eles propõem um esquema de rotas reacionais para a RRO em meio ácido bastante simplificado (Figura 5), onde a molécula de oxigênio pode ser reduzida majoritariamente via dois caminhos alternativos comumente chamados de mecanismo 'direto' (ou mecanismo de 4 elétrons) e mecanismo 'indireto' (ou mecanismo de 2 elétrons). De acordo com o esquema de caminhos reacionais apresentados na Figura 5 verifica-se que:

(i) a molécula de oxigênio que provém do seio da solução eletrolítica $\left(\mathrm{O}_{2}{ }^{\text {bulk }}\right)$ é adsorvida na superfície do eletrodo $\left(\mathrm{O}_{2}{ }^{\text {ads }}\right)$;

(ii) $\mathrm{O}_{2}{ }^{\text {ads }}$ pode ser reduzido diretamente a uma molécula de água $\left(\mathrm{H}_{2} \mathrm{O}\right)$ sem a formação de quaisquer intermediários detectáveis. Trata-se do mecanismo 'direto', onde no total:

$\mathrm{O}_{2}{ }^{\text {ads }}+4 \mathrm{e}^{-}+4 \mathrm{H}^{+} \rightarrow \mathrm{H}_{2} \mathrm{O}$

(iii) $\mathrm{o} \mathrm{O}_{2}{ }^{\text {ads }}$ pode ser reduzido parcialmente, formando uma molécula de peróxido de hidrogênio $\left(\mathrm{H}_{2} \mathrm{O}_{2}{ }^{\text {ads }}\right)$ como intermediário da reação. Trata-se do mecanismo 'indireto', onde 2 elétrons são necessários:

$\mathrm{O}_{2}{ }^{\text {ads }}+2 \mathrm{e}^{-}+2 \mathrm{H}^{+} \rightarrow \mathrm{H}_{2} \mathrm{O}_{2}{ }^{\text {ads }}$

(iv) $\mathrm{o}_{2} \mathrm{O}_{2}$ ads pode, posteriormente, ser reduzido formando $\mathrm{H}_{2} \mathrm{O}$, acarretando um processo de mais 2 elétrons:

$\mathrm{H}_{2} \mathrm{O}_{2}{ }^{\text {ads }}+2 \mathrm{e}^{-}+2 \mathrm{H}^{+} \rightarrow \mathrm{H}_{2} \mathrm{O}$ 
(v) $\mathrm{O} \mathrm{H}_{2} \mathrm{O}_{2}{ }^{\text {ads }}$ pode também ser reoxidado para $\mathrm{O}_{2}{ }^{\text {ads }}$ ou

(vi) ser transportado para o seio da solução $\left(\mathrm{H}_{2} \mathrm{O}_{2}{ }^{\text {bulk }}\right)$;

(vii) ademais, $\mathrm{H}_{2} \mathrm{O}_{2}{ }^{\text {ads }}$ pode ser desproporcionado em $\mathrm{H}_{2} \mathrm{O}$ e $\mathrm{O}_{2}$. Trata-se de uma reação bimolecular não-eletroquímica, ou seja, não há envolvimento de espécies iônicas.

Analisando as reações (1.23) e (1.24) nos processos (iii) e (iv), nota-se que a soma destas resulta exatamente na equação (1.22). Observa-se, portanto, que o mecanismo 'indireto' pode ou não envolver 4 elétrons, enquanto o mecanismo 'direto' obrigatoriamente envolve $4 \mathrm{e}^{\mathrm{e}}$. Portanto, constata-se que a rotulação 'direto' ou 'indireto' está baseada em quando o peróxido de hidrogênio pode ou não ser detectado como um intermediário da reação [16-33].

Figura 5 - Esquema geral dos possíveis caminhos reacionais para RRO.

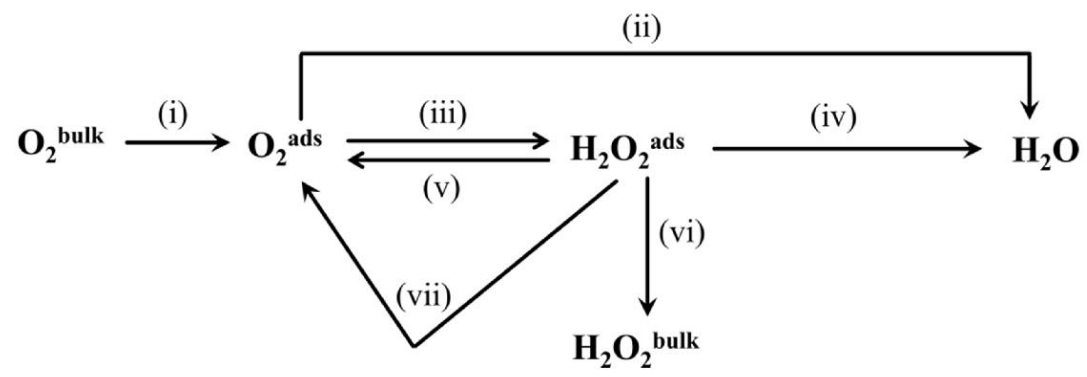

Fonte: Figura adaptada de WROBLOWA et al. J. Electroanal. Chem. Interfacial Electrochem., v. 69, $1976[15]$.

$\mathrm{O}$ modo como o $\mathrm{O}_{2}$ é adsorvido na espécie metálica presente na superfície do eletrodo pode decidir fortemente o tipo de mecanismo reacional que a RRO apresentará. Um quadro apresentando as possíveis formas de adsorção e as rotas reacionais para a redução de oxigênio está ilustrado na Figura 6. Este esquema mostra que há três formas de o $\mathrm{O}_{2}$ se adsorver na superfície eletródica, sendo elas indicadas pelos modelos de adsorção de Griffith, Paulling e de Ponte [34-37]. 
Figura 6 - Modelos de adsorção de $\mathrm{O}_{2}$ na superfície eletródica e possíveis rotas reacionais da reação de redução de oxigênio em eletrólitos ácidos.

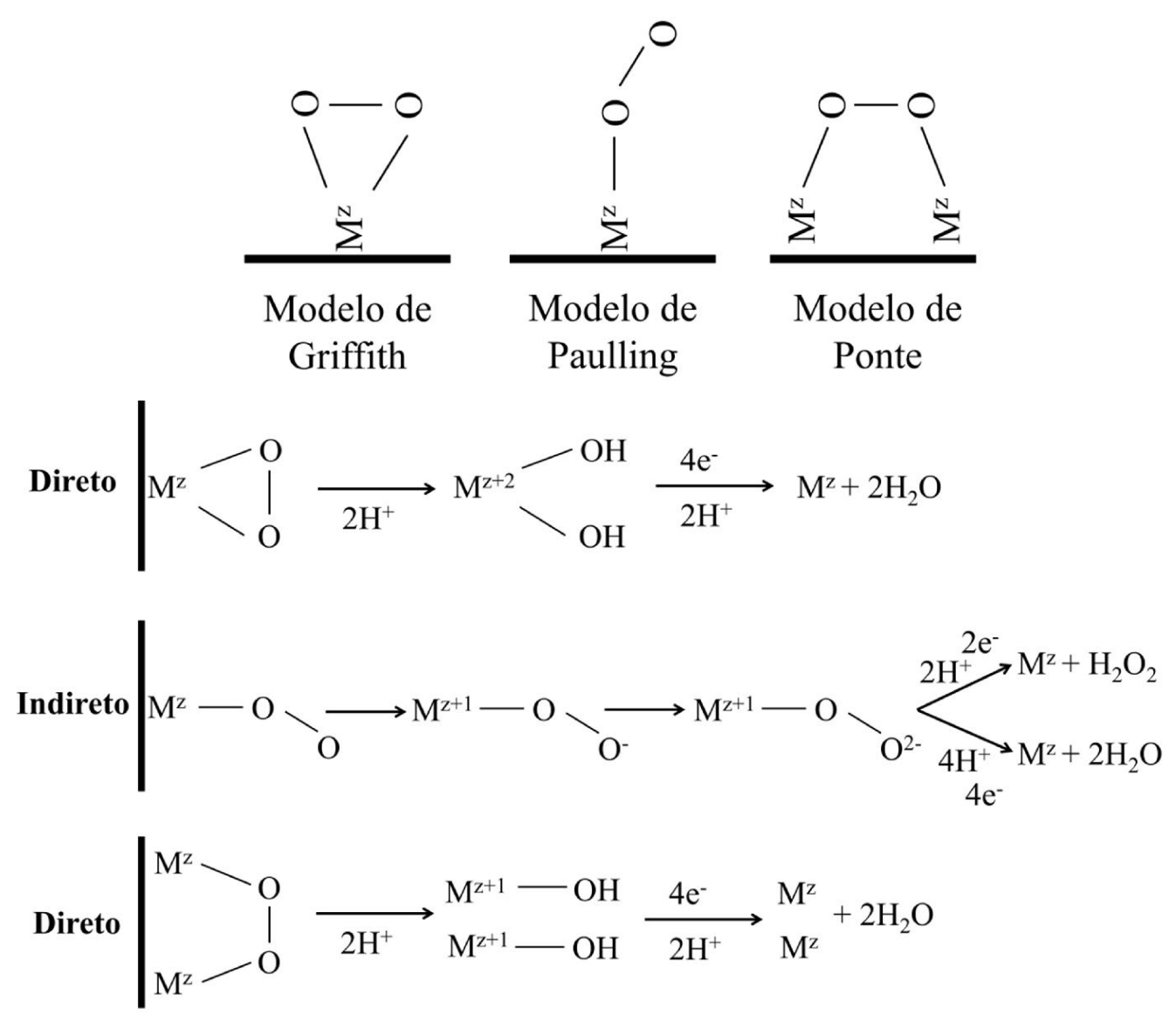

Fonte: Figura adaptada de TICIANELLI, E. A.; GONZALEZ, E. R. Eletroquímica: Princípios e Aplicações. - 2a ed. - São Paulo: Editora da Universidade de São Paulo, 2005 [34].

Se a adsorção seguir os modelos de adsorção de Griffith e de Ponte, que facilitam a ruptura da ligação $\mathrm{O}-\mathrm{O}$, o mecanismo de redução envolverá $4 \mathrm{e}^{-}$. Por outro lado, se a adsorção seguir o modelo de Paulling, eventualmente a redução dar-se-á segundo um mecanismo envolvendo 2 elétrons, resultando como produto o $\mathrm{H}_{2} \mathrm{O}_{2}$. Porém, um sistema eletrocatalítico pode envolver mais de uma forma de adsorção, e a preponderância de um mecanismo sobre outro dependerá dos impedimentos estéricos e do espaçamento entre os sítios ativos, ou seja, do material eletródico e/ou das condições experimentais empregadas.

Apesar das dificuldades em elucidar completamente o tipo de mecanismo para RRO nas superfícies metálicas em geral, diversos trabalhos têm demonstrado que em superfícies de platina o mecanismo para RRO é o 'direto', ou seja, não há formação de $\mathrm{H}_{2} \mathrm{O}_{2}$ em condições típicas de operação $(\sim 0,7 \mathrm{~V} v s$. ERH) de uma célula a combustível de eletrólito polimérico 
(PEMFC) [2,13]. Em potenciais onde ocorre a adsorção/dessorção de hidrogênio (região de $\left.\mathrm{H}_{\text {upd }}\right)$ em superfícies de platina $(0-0,4 \mathrm{~V} v s$. ERH), o mecanismo da RRO é modificado. Esse fato é confirmado por experimentos em eletrodos de disco-rotatório, onde se pode medir a quantidade de $\mathrm{H}_{2} \mathrm{O}_{2}$ formado durante a redução de $\mathrm{O}_{2}$. Em trabalhos envolvendo o estudo da RRO em monocristais de Pt pode ser constatado que a estrutura da superfície do eletrodo possui influência direta no tipo de mecanismo da reação de redução de oxigênio [20,28,33]. $\mathrm{Na}$ região de $\mathrm{H}_{\text {upd, }}$, há a formação de $\mathrm{H}_{2} \mathrm{O}_{2}$ nos três planos de baixo índice da $\mathrm{Pt}$, com maior extensão no plano (111), menor extensão no plano (100) e extensão praticamente nula no plano (110). As diferenças na quantidade de $\mathrm{H}_{2} \mathrm{O}_{2}$ são atribuídas a impedimentos estéricos gerados pela adsorção de hidrogênio nos átomos de Pt nos diferentes planos, dificultando a adsorção de $\mathrm{O}_{2}$ nas formas que proporcionam a quebra da ligação O-O. Estes estudos comprovam a então mencionada dependência da estrutura dos átomos de Pt na superfície eletródica no tipo de mecanismo da RRO. Outros trabalhos também abordam a influência dos tamanhos dos cristalitos de Pt bem como as distâncias entre eles no mecanismo e velocidade da RRO [24,26,30,38-40].

\subsection{Estabilidade e durabilidade de células a combustível de membrana de troca protônica (PEMFCs)}

Como mencionado na sessão 1.1 deste trabalho, o desenvolvimento das células a combustível data de meados do séc. XX, quando a preocupação em relação à disponibilidade de combustíveis fósseis levou à busca por fontes alternativas de conversão de energia além das máquinas de combustão convencionais. Atrelada a esta necessidade houve também o incremento na preocupação quanto a preservação do meio ambiente devido à poluição gerada pelas máquinas de combustão [41]. A célula a combustível foi uma alternativa encontrada para a conversão de energia de forma mais limpa, pois ao contrário do processo de combustão, não há a transformação de energia química em mecânica, mas sim em elétrica, sem a geração de gases poluentes e com a possibilidade de maior aproveitamento energético do combustível utilizado.

Um dos grandes problemas enfrentados até então para aplicação efetiva de células a combustível no mercado é a necessidade de catalisadores que acelerem a reação de redução de oxigênio (RRO, principal reação catódica), uma reação extremamente lenta comparada à reação anódica de uma PEMFC típica (reação de oxidação de hidrogênio, ROH). A partir dos muitos esforços pesquisas sobre este problema, tem sido concluído que o melhor material catalisador para a RRO é baseado em platina metálica, nanopartículas de platina e ligas dessa 
com metais não-nobres suportadas em carbono de alta área superficial. Trata-se de materiais de elevado custo e que ainda são considerados instáveis para a aplicação em larga escala. Por exemplo, de acordo com o Departamento de Energia dos EUA (DOE, U.S. Department of Energy) um sistema de célula a combustível automotivo que custe cerca de 30 dólares americanos $/ \mathrm{kW}$ tornaria esta tecnologia mais favorável comparada às plantas de energia por máquinas de combustão-interna [42,43]. Entretanto, o valor atual alcançado é de aproximadamente 51 dólares americanos $/ \mathrm{kW}$, fato que indica a contínua necessidade de aprimoramento para atingir a meta proposta pelo DOE.

As camadas catalíticas anódica e catódica representam, sozinhas, cerca de $50 \%$ do custo total de um stack de célula a combustível. Logo, a redução do custo de uma PEMFC poderia ser atingida por meio da diminuição da carga de platina utilizada nos eletrodos. Outra maneira de se otimizar as PEMFCs seria aumentar a durabilidade desses eletrocatalisadores. Sabe-se que a durabilidade de uma PEMFC depende estritamente do conjunto membranaeletrodo (MEA) [44]. Por meio de diversos trabalhos foi descoberto que grande parcela da baixa durabilidade de uma PEMFC deve-se a processos de corrosão do suporte das nanopartículas de platina na camada catalítica catódica [13,44-53]. Estudos mostram que em condições de liga/desliga das PEMFCs, um potencial de cerca de 1,5 V pode ser atingido, região em que o carbono tende a corroer. A oscilação de potencial quando uma PEMFC é ligada e desligada também confere grande influência na estabilidade das nanopartículas de Pt (NPs de Pt): variando-se o potencial da célula abruptamente de forma a atingir potenciais onde a superfície de platina está completamente oxidada $(\sim 1,0 \mathrm{~V})$ e completamente reduzida $(\sim 0,6 \mathrm{~V})$ acarreta em processos bastante conhecidos de degradação de NPs de Pt suportadas em carbono (ex.: dissolução e redeposição (Ostwald Ripening eletroquímico) e migração e coalescência de cristalitos). Os principais efeitos são a diminuição da área eletroquimicamente ativa e consequente diminuição da atividade mássica $\left(\mathrm{A}_{\mathrm{Pt}}{ }^{-1}\right)$ das NPs de $\mathrm{Pt}[44,53-55]$.

\subsubsection{Modelos de degradação do grupamento catalisador/suporte presente nos eletrodos de PEMFCs}

Em geral, dentre os processos de degradação dos eletrocatalisadores baseados em nanopartículas de platina suportadas em carbono nas células a combustível, quatro deles tem sido considerados relevantes [14,54-61]:

i) Ostwald Ripening eletroquímico, o qual envolve a dissolução de Pt de partículas pequenas, seguida de difusão das espécies solúveis de Pt para partículas grandes na fase 
ionômera e redeposição/redução das espécies solúveis de Pt em cima das partículas maiores (Figura 7(a)). Este efeito confere maior estabilidade às partículas, pois há uma diminuição da energia superficial das mesmas [62]. Deste modo, este mecanismo é, em parte, responsável pela perda de área superficial no cátodo das PEMFCs quando este é exposto a elevados potenciais e também por variações bruscas de potenciais da célula;

ii) Migração e coalescência de cristalitos de Pt (Figura 7(b)), as quais compreendem o movimento de partículas de Pt seguido pela coalescência dessas no suporte catalítico (ex.: carbono). A principal consequência deste processo é a diminuição da área superficial cátodo das PEMFCs. Acredita-se que este processo ocorra em baixas voltagens da célula, uma vez que a solubilidade das nanopartículas de Pt é insignificante em potenciais abaixo de $0,7 \mathrm{~V} v s$. ERH [63];

iii) Afastamento das NPs de Pt do suporte de carbono geralmente induzido pela corrosão do carbono (Figura 7(c)). A extensão deste processo de degradação dependerá principalmente do potencial da célula e da natureza das interações das NPs de Pt com o suporte catalítico. Este processo também acarreta diminuição da área superficial do catalisador. Sabe-se que potencias menores que 0,8 V em PEMFCs operando a baixas temperaturas não levam a corrosão do suporte de carbono Vulcan ${ }^{\circledR}$. Porém, foi constatado que quando a célula é ligada há a ocorrência de um salto de potencial na mesma, que pode chegar próximo a $1,5 \mathrm{~V}$, acarretando em possíveis perdas de massa do suporte por corrosão [53];

iv) Dissolução e reprecipitação de cristalitos de $\mathrm{Pt}$ na membrana ionomérica ocasionado pela redução química de espécies solúveis de Pt com moléculas de hidrogênio (Figura 7(d)). Durante o funcionamento de uma PEMFC típica, a permeação de moléculas de $\mathrm{H}_{2}$ através da membrana trocadora de prótons pode ocorrer, levando ao processo acima. A localização da deposição de Pt dependerá da pressão parcial de oxigênio na célula [64]. Por exemplo, quanto maior a pressão parcial de oxigênio, maior será a distância da deposição de Pt relativa ao cátodo no MEA. Este mecanismo ocorre em escala micrométrica, provocando perda considerável de Pt no cátodo das PEMFCs. 
Figura 7 - Mecanismos propostos para processos de degradação dos eletrocatalisadores baseados em nanopartículas de platina suportadas em carbono nas células a combustível, (a) Ostwald Ripening eletroquímico, (b) Migração e coalescência de cristalitos de Pt, (c) Afastamento das NPs de Pt do suporte de carbono, e (d) Dissolução e reprecipitação de cristalitos de Pt na membrana ionomérica.

(a) Crescimento via Ostwald Ripening Modificado

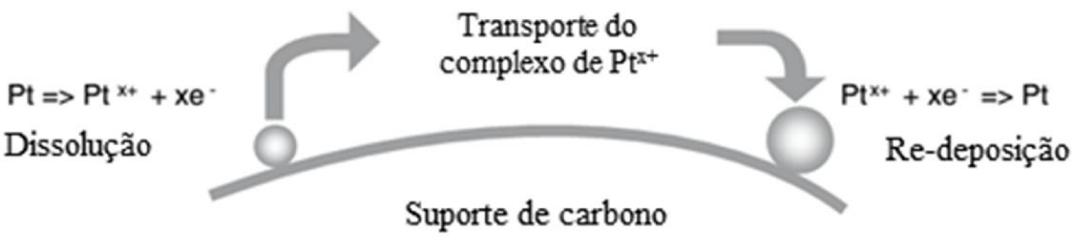

(b) Coalescência via Migração de Cristalitos

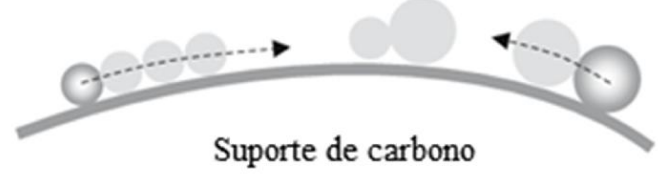

(c) Desprendimento do suporte de carbono

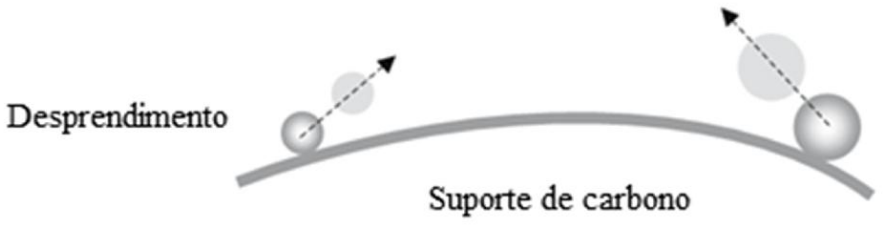

(d) Dissolução e Precipitação no Condutor de Íons

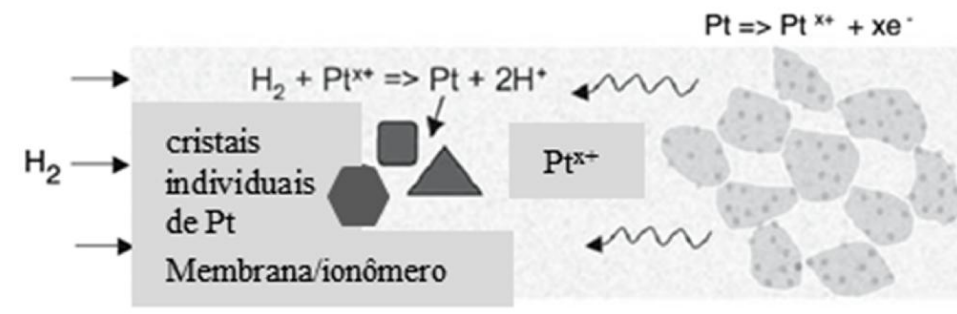

Fonte: Figura adaptada de SHAO-HORN et al. Top. Catal., v. 46, 2007 [57].

Visto os variados problemas que ocorre durante as condições típicas de uso de uma PEMFC, uma grande parte dos trabalhos nesta área tem focado na busca por soluções que possam contornar a instabilidade dos catalisadores eletródicos [44]. Uma delas está em aprimorar e aumentar a interação entre as partículas catalíticas e seu respectivo suporte. O 
modo como ocorre a interação catalisador-suporte está diretamente relacionado com o desempenho do eletrodo [65]. Por exemplo, Zhou et al. [66] constataram, por meio de experimentos de espectroscopia de absorção de raios $\mathrm{X}$ (XAS, X ray absorption spectroscopy), que o modo como os nanotubos de carbono e NPs de Pt interagem entre si favorece a formação de pequenas partículas de Pt com uma dispersão elevada nos nanotubos de carbono e também um elevado grau de imobilização das NPs de Pt nos mesmos, de forma que evita problemas de difusão das NPs de Pt durante as condições de operação de uma PEMFC. Outra alternativa para solucionar o problema da instabilidade de eletrodos em células a combustível está em desenvolver suportes catalíticos mais adequados, ou seja, que estabilizem as nanopartículas e diminuam ou eliminem o problema de corrosão dos suportes típicos de carbono encontrados no mercado.

\subsubsection{Utilização de óxidos de molibdênio/carbono como suporte catalítico para cátodos de PEMFCs}

Como observado anteriormente, a corrosão do suporte possui um papel de elevada importância quando a estabilidade dos eletrocatalisadores é discutida. Sabe-se que atrelados com a corrosão do suporte estão os problemas de agregação, dissolução e isolamento das NPs de Pt $[14,44,53-55,58,59]$. Portanto, a busca por materiais que previnam estes problemas é de fundamental importância para o aumento da faixa de aplicação de células a combustível ao redor do mundo $[13,14,44,51,52,57,60,66-69]$.

Dentre os inúmeros materiais alternativos para aplicação como suportes catalíticos, os baseados em óxidos de molibdênio vêm se apresentando como possíveis agentes estabilizadores. Haber et al. [70] constataram que uma das características mais marcantes dos óxidos de molibdênio é a versatilidade de suas propriedades catalíticas, que são determinadas pelo estado de valência dos íons de molibdênio e pelo ambiente químico em que eles se encontram. Catalisadores baseados em óxidos de molibdênio são ativos e seletivos em vários tipos de reações, tais como as que ocorrem com a participação de oxigênio e hidrogênio (processos redox). Os autores também observaram que a superfície do $\mathrm{MoO}_{3}$ contém vários sítios ativos diferentes, sendo que cada um é ativo para diferentes etapas elementares de reação. O papel desses diferentes tipos de planos cristalinos do $\mathrm{MoO}_{3}$ na oxidação de hidrocarbonetos foi largamente estudado [71-73], tendo sido encontrado que a concentração relativa desses planos cristalinos na superfície dos óxidos de molibdênio deve ser fortemente dependente do grau de redução dos óxidos [70]. 
Levando em consideração o $\mathrm{pH}$ do ambiente em que os óxidos de molibdênio encontram-se, fator decisivo para a estabilidade dos mesmos, observou-se que a estabilidade dos óxidos em meio ácido é superior, decrescendo significativamente em condições neutras e alcalinas, devido à formação de espécies superficiais solúveis [74,75]. A energia de ativação para a dissolução de um filme de óxido em meio alcalino é $\sim 28,3 \mathrm{~kJ} \mathrm{~mol}^{-1}$, aproximadamente metade daquela para o meio neutro $\left(\sim 52,5 \mathrm{~kJ} \mathrm{~mol}^{-1}\right)$ e ácido $\left(\sim 62,4 \mathrm{~kJ} \mathrm{~mol}^{-1}\right)$ [74]. Na região de potencial de operação típica de uma $\operatorname{PEMFC~(~0,7~V~vs.~ERH),~o~eletrodo~contendo~óxido~}$ de molibdênio estará na região chamada de 'transpassiva' independente do $\mathrm{pH}$ da célula [7477]. Nesta região, a dissolução de espécies de Mo é passível de ocorrer através da oxidação de compostos de Mo com estados de valência menores que o $\mathrm{Mo}(\mathrm{VI})$, que são encontrados em óxidos de Mo mistos. Por meio do método de canal de fluxo em eletrodo duplo [78], aplicado para determinação dos íons de Mo dissolvidos em solução de ácido sulfúrico, tanto os íons $\mathrm{Mo}(\mathrm{V})$ e $\mathrm{Mo}(\mathrm{VI})$ foram detectados na região transpassiva [79].

Uma das características marcantes dos óxidos de molibdênio é a elevada capacitância da interface óxido/solução. Wikstrom e Nobe [80] sugerem que a elevada capacitância pode ser devida aos intermediários eletroativos adsorvidos produzidos durante a modificação dos estados de oxidação das espécies de Mo. Em um trabalho de Sugimoto et al. [81], eles produziram um material composto por carbono ativo e trióxido de molibdênio que possuia comportamento supercapacitivo. Por meio da adição de uma pequena quantidade de trióxido de molibdênio em carbono, a capacitância específica do material foi aumentada de 29\% (136 $\left.\rightarrow 176 \mathrm{~F} \mathrm{~g}^{-1}\right)$ tanto em eletrólito alcalino $\left(\mathrm{NaOH} 1 \mathrm{~mol} \mathrm{~L}^{-1}\right)$ quanto em eletrólito ácido $\left(\mathrm{H}_{2} \mathrm{SO}_{4}\right.$ $0,5 \mathrm{~mol} \mathrm{~L}^{-1}$ ). A partir deste trabalho é visto que a adição de uma pequena quantidade de um óxido de baixo custo e de baixa condutividade elétrica pode resultar em um aprimoramento da capacidade de armazenamento de carga de carbonos porosos. Ambos os eletrodos das PEMFCs são compostos por eletrocatalisadores baseados em suportes de carbono Vulcan ${ }^{\circledR}$, o qual possui uma capacitância específica de $\sim 30 \mathrm{~F} \mathrm{~g}^{-1}$ [82]. Os resultados de Sugimoto et al. propiciam, portanto, fortes indicativos para que tal estratégia seja também empregada em materiais destinados a aplicações em células a combustível.

Um trabalho que demonstra o aumento da estabilidade de Pt/C após a incorporação de espécies de Mo é o de Justin et al. [83]. A incorporação de $\mathrm{MoO}_{3}$ em carbono Vulcan ${ }^{\circledR}$ XC$72 \mathrm{R}$ foi realizada por reação em estado-sólido usando o método de aquecimento por microondas. Após a preparação desse material, NPs de Pt foram dispersas pelo processo de poliol assistido por micro-ondas $[83,84]$. Os autores constataram que a característica não-condutora de $\mathrm{MoO}_{3}$ é superada por meio da formação de $\mathrm{H}_{\mathrm{x}} \mathrm{MoO}_{3}$ ('hydrogen molybdenum bronze') 
após a redução eletroquímica do $\mathrm{MoO}_{3}$ em meio ácido. Eles observaram que o pico da corrente de oxidação de metanol neste composto é cerca de $128 \%$ maior do que a obtida por $\mathrm{Pt}-\mathrm{Ru} / \mathrm{C}$. Em relação a elevada estabilidade do $\mathrm{Pt}-\mathrm{MoO}_{3} / \mathrm{C}$ comparada à do $\mathrm{Pt}-\mathrm{Ru} / \mathrm{C}$ em potencial de polarização de $0,6 \mathrm{~V}$, Justin et al. atribuem este efeito a um aumento na tolerância ao envenenamento por CO. As razões que justificam este aumento de estabilidade são: (i) mudança nas propriedades eletrônicas da Pt devido a interação forte entre Pt e $\mathrm{MoO}_{3}$, e assim enfraquecendo a força de adsorção de intermediários da reação; (ii) a conversão de intermediários de reação adsorvidos em $\mathrm{CO}_{2}$ através da formação in situ de espécies $\mathrm{H}_{\mathrm{x}} \mathrm{MoO}_{3}$; (iii) o transporte de carga entre Pt e o suporte também devido à formação de espécies $\mathrm{H}_{\mathrm{x}} \mathrm{MoO}_{3}$; e (iv) um possível efeito bifuncional entre NPs de Pt e $\mathrm{MoO}_{3}$, onde este último contribui para a liberação de $\mathrm{CO}_{2}$ recém-formado na superfície eletródica liberando sítios ativos para que ocorram as reações de interesse.

Em relação à redução de oxigênio Ho et al. [85] apresentaram a utilização de um novo suporte catalítico, $\mathrm{Ti}_{0,7} \mathrm{Mo}_{0,3} \mathrm{O}_{2}$, para platina em lugar do carbono, então largamente utilizado. Um dos benefícios encontrados em se usar o $\mathrm{Ti}_{0,7} \mathrm{Mo}_{0,3} \mathrm{O}_{2}$ como suporte para Pt é que o mesmo proporcionou um aumento na estabilidade do eletrocatalisador durante o processo de ciclagem de potencial. Outro benefício demonstrado foi o aumento da densidade de corrente da RRO em 2,6 vezes comparada àquela obtida por eletrocatalisadores comerciais como $\mathrm{Pt} / \mathrm{C}$ e $\mathrm{PtCo} / \mathrm{C}$ contendo a mesma carga de Pt. Também em relação à reação de redução de oxigênio Alonso-Vante et al. [86] mostraram uma melhor performance e estabilidade quando se utiliza o eletrodo com uma matriz de polianilina (PANI) e uma fase dispersa de seleneto de rutênio dopado com molibdênio (MRS, Molybdenum-doped Ruthenium Selenide) como cátodo em comparação a $\mathrm{Pt}$ em $0,5 \mathrm{~mol} \mathrm{~L}^{-1}$ de $\mathrm{H}_{2} \mathrm{SO}_{4}$ com a presença de metanol. O eletrodo PANI + MRS apresentou um bom desempenho na faixa de $\mathrm{pH}$ de 0 a 3; em $\mathrm{pH}$ maior que 3 a matriz PANI apresenta baixa condutividade.

Recentemente, Luque et al. [87] analisaram o comportamento de eletrocatalisadores baseados em filmes de fosfato de molibdênio eletrodepositados frente a reação de redução de oxigênio em meio ácido. O filme é um sólido não-cristalino composto por óxido do metal e grupos fosfatos que, de acordo com as análises de espectroscopia fotoeletrônica de raios $\mathrm{X}$ (XPS, X ray photoelectron spectroscopy), contém majoritariamente Mo(VI) e uma pequena fração de $\mathrm{Mo}(\mathrm{V})$. O filme apresenta uma atividade na RRO estável em meio ácido em sobrepotenciais muito baixos (aproximadamente $-0,3 \mathrm{~V}$ ). A densidade de corrente observada alcança um valor limite muito baixo $\left.(\sim 2,0 \mu \mathrm{A} \mathrm{cm})^{-2}\right)$, que é independente do efeito de transporte de massa e pode estar associado à pequena fração de centros de $\mathrm{Mo}(\mathrm{V})$ que atuam 
como sítios ativos para RRO. Outro fator importante ressaltado por Luque et al. é que apesar dos filmes serem termicamente estáveis (suportam temperaturas de $400{ }^{\circ} \mathrm{C}$ ), quando aquece-se o material a temperaturas acima de $100{ }^{\circ} \mathrm{C}$, o mesmo torna-se inativo para RRO o que foi atribuído à completa oxidação dos íons $\mathrm{Mo}(\mathrm{V})$ para $\mathrm{Mo}(\mathrm{VI})$. Este filme pode, portanto, ser utilizado em uma PEMFC de baixa temperatura, que atinge cerca de $90^{\circ} \mathrm{C}$.

Çakar et al. [88] observaram que eletrodo de carbono vítreo modificado por óxido de molibdênio (VI) e platina possuem melhor atividade eletrocatalítica para RRO comparada a eletrodo de carbono vítreo modificado por platina somente. Sabe-se que a atividade de catalisadores baseados em metais nobres pode ser aumentada pela adição de óxidos inorgânicos (por exemplo, o $\mathrm{MoO}_{3}$ ), já que eles separam fisicamente as partículas catalíticas prevenindo a aglomeração das mesmas [89]. Acredita-se também que o óxido modifica a natureza eletrônica das NPs de Pt afetando suas propriedades quimissortivas e catalíticas. Desse modo, Çakar et al. mostraram que a elevada dispersão das NPs de Pt em $\mathrm{MoO}_{\mathrm{x}}$ resulta em maior área superficial e melhor atividade catalítica para a RRO. Em dois trabalhos de Elezović et al. [90,91], foi constatado também que o aumento da atividade catalítica para a RRO de catalisadores compostos por $\mathrm{Pt} / \mathrm{C}$ dopados com $\mathrm{MoO}_{\mathrm{x}}$ pode ser explicado através do aumento do número de sítios ativos para a RRO ou por efeitos sinérgicos devido a formação da interface entre Pt e MoOx. Yan et al. [92] estudaram a performance de catalisadores $\mathrm{Pt} / \mathrm{C}$ $\mathrm{MoO}_{2}$ e Pt/C frente a RRO em meio ácido. Por meio de resultados obtidos por XPS, eles constataram que a interação das espécies de $\mathrm{Pt}$ com $\mathrm{MoO}_{2}$ é mais forte que a interação entre espécies de Pt e carbono. Eles atribuíram este efeito como promotor do aumento da estabilidade desses catalisadores frente às condições típicas da RRO comparado aos catalisadores de $\mathrm{Pt} / \mathrm{C}$. O aumento da atividade catalítica de $\mathrm{Pt} / \mathrm{C}-\mathrm{MoO}_{2}$ foi atribuído ao efeito doador de espécies oxigenadas pelo $\mathrm{MoO}_{2}$, o qual aumenta a concentração de oxigênio e reduz a energia de ativação para RRO. 


\section{OBJETIVOS}

Visto que a instabilidade das nanopartículas de platina (NPs de Pt) suportadas em carbono continua a ser um dos grandes entraves que tem impedido a ampla aplicação de PEMFCs como conversores de energia, a busca por maneiras que aperfeiçoem a sua estabilidade tem sido muito intensa. Dentre elas, a substituição do suporte das NPs de Pt por compostos mais estáveis e que também promovam aumento de sua estabilidade tem levado a resultados promissores, como descritos acima. Os suportes catalíticos baseados em óxidos de molibdênio parecem ser uma opção relevante para promoção da estabilidade da platina em meio ácido, porém os estudos envolvendo estes materiais ainda são escassos. Neste contexto, os objetivos deste trabalho são:

I) Sintetizar suportes catalíticos baseados em $\mathrm{MoO}_{3}$ e $\mathrm{MoO}_{2}$ suportados em carbono Vulcan ${ }^{\circledR}$ XC72-R através de método de impregnação seguido por tratamento térmico;

II) Formar os eletrocatalisadores por impregnação de NPs de Pt nos suportes recémpreparados pelo método do ácido fórmico;

III) Caracterizar física e estruturalmente os suportes e catalisadores recém-preparados com o auxílio das técnicas de Espectroscopia por dispersão de energia de raios $\mathrm{X}$ (EDX), Difratometria de raios X (DRX), Microscopia eletrônica de transmissão (TEM), Espectroscopia fotoeletrônica de raios X (XPS) e Espectroscopia de absorção de raios X (XAS);

IV) Caracterizar eletroquimicamente os materiais por meio de voltametria cíclica e avaliar a atividade frente à reação de redução de oxigênio (RRO) através de curvas de polarização potenciodinâmicas; avaliar a estabilidade dos catalisadores recém-preparados frente à RRO em condições similares às dos cátodos em PEMFCs. Realizar testes de degradação eletroquímicos, que consistirão em aplicar diversos ciclos de potenciais de onda quadrada com curto período de tempo para cada potencial (0,6 e 1,0 V vs. ERH), em uma solução 0,5 M de $\mathrm{H}_{2} \mathrm{SO}_{4}$, a temperatura ambiente e atmosfera de ar;

V) Investigar as alterações na área eletroquimicamente ativa e nas atividades catalíticas frente à RRO causadas pelos testes de degradação em intervalos de ciclagem definidos. Ao final do teste de degradação, avaliar possíveis alterações morfológicas na superfície dos catalisadores com o auxílio da técnica de TEM. 


\section{PROCEDIMENTO EXPERIMENTAL}

\subsection{Síntese dos suportes baseados em óxidos de molibdênio suportados em carbono Vulcan ${ }^{\circledR}$ XC72-R}

O método utilizado para preparação dos suportes foi o de impregnação seguido por tratamento térmico para formação das estruturas cristalinas dos óxidos de molibdênio. Todos os produtos químicos usados foram de grau analítico e as soluções foram preparadas com água ultrapura (Milli-Q, Millipore ${ }^{\circledR}$ ).

\subsubsection{Dióxido de molibdênio suportado em carbono}

Primeiramente foi pesada a quantidade apropriada de heptamolibdato de amônio em sua forma tetra-hidratada $\left(\left(\mathrm{NH}_{4}\right)_{6} \mathrm{Mo}_{7} \mathrm{O}_{24} \cdot 4 \mathrm{H}_{2} \mathrm{O}\right)$ e de carbono Vulcan ${ }^{\circledR} \mathrm{XC} 72-\mathrm{R}$ de forma que a proporção final entre C e Mo fosse próxima a 3:1 $(\mathrm{m} / \mathrm{m})$. A porção de carbono pesada foi colocada em $50 \mathrm{~mL}$ de $\mathrm{H}_{2} \mathrm{O}$ e posteriormente em ultrassom para formação de uma suspensão. Ao obter-se uma suspensão homogênea, a porção do precursor de Mo previamente pesada foi adicionada na mesma sob agitação. Esta mistura foi seca em banho Maria mantendo-se sempre agitação constante. Após todo o solvente ter sido evaporado, o material foi colocado para secar em estufa em $\sim 70{ }^{\circ} \mathrm{C}$ por um período de 12 horas. Em seguida, o material foi vigorosamente macerado e pré-tratado termicamente a $100{ }^{\circ} \mathrm{C}$ sob atmosfera de Ar por 1 hora seguido de tratamento térmico a $550{ }^{\circ} \mathrm{C}$ em também sob atmosfera de Ar por 5 horas. $\mathrm{O}$ produto foi deixado resfriar lentamente até a temperatura ambiente.

\subsubsection{Trióxido de molibdênio suportado em carbono}

Primeiramente foi pesada a quantidade apropriada de heptamolibdato de amônio em sua forma tetra-hidratada $\left(\left(\mathrm{NH}_{4}\right)_{6} \mathrm{Mo}_{7} \mathrm{O}_{24} .4 \mathrm{H}_{2} \mathrm{O}\right)$ e de carbono Vulcan ${ }^{\circledR} \mathrm{XC} 72-\mathrm{R}$ de forma que a proporção final entre $\mathrm{C}$ e Mo fosse próxima de 4:1 $(\mathrm{m} / \mathrm{m})$. A porção de precursor de Mo pesada foi dissolvida em $70 \mathrm{~mL}$ de $\mathrm{H}_{2} \mathrm{O}$ utilizando-se ultrassom. Em seguida, a porção de carbono previamente pesada foi misturada a esta solução sob ultrassom. Algumas gotas de isopropanol foram utilizadas para melhor dispersão do carbono, buscando-se a formação de 
uma suspensão homogênea. A suspensão foi colocada em banho Maria para que todo o solvente fosse evaporado. Em seguida, o material foi colocado para secar em estufa a $\sim 60{ }^{\circ} \mathrm{C}$ por um período de 16 horas para sua completa secagem. Após seco, o material foi vigorosamente macerado e tratado termicamente a $400{ }^{\circ} \mathrm{C}$ sob atmosfera de ar por 3 horas. $\mathrm{O}$ produto foi então deixado resfriar lentamente até a temperatura ambiente.

\subsection{Impregnação de nanopartículas de platina nos suportes recém-preparados.}

A formação e a impregnação das nanopartículas de platina (NPs de Pt) foram realizadas pelo método do ácido fórmico (MAF) [93]. Primeiramente preparou-se $50 \mathrm{~mL}$ de uma solução $0,5 \mathrm{M}$ de ácido fórmico. Uma porção dos suportes recém-preparados $\left(\mathrm{MoO}_{2}-\mathrm{C}\right.$ para formação de $\mathrm{Pt} / \mathrm{MoO}_{2}-\mathrm{C}$ e $\mathrm{MoO}_{3}-\mathrm{C}$ para formação de $\mathrm{Pt} / \mathrm{MoO}_{3}-\mathrm{C}$ ) foi pesada objetivando-se obter porcentagens de $80 \%$ de suporte e $20 \%$ em massa de Pt. A porção de suporte foi adicionada à solução $0,5 \mathrm{M}$ de ácido fórmico e colocada em ultrassom para formação de uma suspensão homogênea (cerca de 20 minutos). Em seguida, a suspensão foi aquecida até $80{ }^{\circ} \mathrm{C}$ e mantida em constante agitação. Após atingir e manter a temperatura constante, o precursor de platina $\left(\mathrm{H}_{2} \mathrm{PtCl}_{6} \cdot\left(\mathrm{H}_{2} \mathrm{O}\right)_{6}\right)$ foi adicionado em quatro porções em intervalos de 15 minutos. Após 20 minutos da última adição, uma alíquota da suspensão foi coletada e depositada em papel de filtro comum. Em seguida, algumas gotas de iodeto de potássio $(\mathrm{KI})$ foram adicionadas sobre a alíquota depositada para verificação da total redução das espécies de Pt presentes em solução. Nos casos em que o KI indicou a presença de espécies oxidadas de Pt remanescentes, as suspensões foram mantidas em agitação a $80{ }^{\circ} \mathrm{C}$ até que o teste mostrasse total redução de Pt. O produto obtido foi deixado esfriar vagarosamente até a temperatura ambiente e, em seguida, filtrado e lavado diversas vezes com $\mathrm{H}_{2} \mathrm{O}$ para completa remoção do ácido fórmico. O produto foi seco em estufa a $\sim 70{ }^{\circ} \mathrm{C}$ por um período de 4 horas. $\mathrm{O}$ catalisador seco foi colocado num frasco limpo e macerado para desaglomerar as partículas.

\subsection{Caracterização física e estrutural dos suportes e eletrocatalisadores recém- preparados}

\subsubsection{Espectroscopia por dispersão de energia de raios $\mathrm{X}$}

A composição dos suportes recém-preparados e também dos catalisadores recémpreparados e comercial foi determinada por EDX em um equipamento EDX LINK 
ANALYTICAL, (Isis System Series 200), com detetor de SiLi Pentafet, janela ultrafina ATW II (Atmosphere Thin Window), de resolução de $133 \mathrm{eV}$ à 5,9 keV, acoplado a um Microscópio Eletrônico (ZEISS LEO 440 (Cambridge,England)). Utilizou-se padrão de Co para calibração, feixe de elétrons de $20 \mathrm{kV}$, distância focal de $25 \mathrm{~mm}$, dead time de $30 \%$, corrente de 2,82 A e I probe de $950 \mathrm{pA}$.

\subsubsection{Difratometria de raios $X$}

A difratometria de raios $\mathrm{X}(\mathrm{DRX})$ foi utilizada para caracterização física de todos os suportes sintetizados e catalisadores sintetizados e comercial, utilizando o equipamento da marca Rigaku ${ }^{\circledR}$, modelo ULTIMA IV. As medidas foram conduzidas em um intervalo de $2 \theta$ de $10^{\circ}$ a $90^{\circ}$ usando radiação $\mathrm{Cu} \mathrm{K \alpha}$, com velocidade de varredura de $1^{\circ} \mathrm{min}^{-1}$. Os tamanhos médios dos cristalitos das NPs de Pt, NPs de $\mathrm{MoO}_{2}$ e NPs de $\mathrm{MoO}_{3}$ foram estimados usando os pico referente os planos (111) da Pt, (-111) do $\mathrm{MoO}_{2}$ e (020) do $\mathrm{MoO}_{3}$, respectivamente, por meio da equação de Scherrer (Equação 3.1) [94] e o parâmetro de rede das respectivas estruturas com o auxílio do programa computacional Checkcell [95]:

$d=\frac{k \lambda}{\beta \cos \theta} \quad$ (Equação 3.1$)$

onde d é a média dos tamanhos dos cristalitos em $\AA$, $\mathrm{k}$ é um coeficiente igual a 0,9 (dependente da geometria dos cristalitos), assumindo-se que os cristalitos possuem a forma esférica, $\lambda$ é o comprimento de onda do raio X usado $(\mathrm{Cu} \mathrm{K} \alpha 1,5406 \AA), \beta$ é a largura do pico de difração à meia altura em radianos e $\theta$ é o ângulo da posição de seu máximo.

\subsubsection{Microscopia eletrônica de transmissão}

A microscopia eletrônica de transmissão (TEM, Transmission electron microscopy) foi utilizada para os estudos de composição, morfologia e distribuição de tamanhos das NPs de Pt nos eletrocatalisadores $\mathrm{Pt} / \mathrm{MoO}_{2}-\mathrm{C}, \mathrm{Pt} / \mathrm{MoO}_{3}-\mathrm{C}$ e Pt/C ETEK ${ }^{\circledR}$ (20\% em massa de Pt). Para tanto, foi utilizado um microscópio JEOL 2100 operando a $200 \mathrm{kV}$. Os porta-espécimes utilizados são compostos por grades de cobre recobertas com filme de carbono lacey. O depósito dos materiais novos foi realizado do mesmo modo como descrito na seção 2.4 (formação da camada ultrafina), porém a suspensão foi previamente diluída. Após os testes de estabilidade aplicados (seção 2.5), o catalisador foi retirado da superfície do eletrodo de disco 
rotatório em isopropanol com o auxilio de ultrassom. A suspensão formada foi então depositada no porta-espécime.

\subsubsection{Espectroscopia fotoeletrônica de raios $\mathrm{X}$}

A espectroscopia fotoeletrônica de raios X (XPS, X-ray photoelectron spectroscopy) foi utilizada objetivando-se determinar a proporção entre o número de átomos presentes na superfície de $\mathrm{Pt} / \mathrm{MoO}_{2}-\mathrm{C}$ e $\mathrm{Pt} / \mathrm{MoO}_{3}-\mathrm{C}$, bem como distinguir os estados de oxidação de cada espécie presente na mesma.

A análise de XPS foi realizada na linha de luz SXS do Laboratório Nacional de Luz Síncrotron (LNLS). O espectro de XPS foi coletado utilizando uma energia de fóton $\left(\mathrm{E}_{\mathrm{ph}}\right)$ incidente de $1840 \mathrm{eV}$, fornecida pelo monocromador de cristal duplo de InSb (111). O analisador hemisférico de elétrons (Specs - Phoibos 150) foi programando para passagem de $20 \mathrm{eV}$, com passo de energia de $0,2 \mathrm{eV}$ e tempo de aquisição de $200 \mathrm{~ms}$.

A resolução energética global alcançada foi cerca de $0,3 \mathrm{eV}$ a $\mathrm{E}_{\mathrm{ph}}=1840 \mathrm{eV}$. A pressão de base da câmara de análise foi de $1,3.10^{-9} \mathrm{mBar}$. A calibração da energia dos fótons do monocromador foi realizada na borda $\mathrm{K}$ do $\mathrm{Si}(1839 \mathrm{eV})$. Uma calibração adicional do analisador de energia foi realizada utilizando uma folha de Au padrão (Au 4f). Todas as medidas de XPS foram realizadas à temperatura ambiente.

A contribuição inelástica dos espectros de nível eletrônico Mo $3 d$ e Pt $4 f$ foi subtraída utilizando o método de Shirley. Os espectros de Mo e Pt foram construídos a partir de perfis mistos de curvas Gaussiana-Lorentziana e a largura total à meia-altura (FWHM) variou entre 1,5 e $2,0 \mathrm{eV}$.

\subsubsection{Espectroscopia de absorção de raios $X$}

A espectroscopia de absorção de raios X (XAS, X-ray absorption spectroscopy) in situ, no modo de transmissão e na região de XANES (X-ray absorption near edge structure) da borda $\mathrm{L}_{3}$ da platina foi utilizada para avaliar a estrutura eletrônica dos átomos de Pt nos eletrocatalisadores recém-preparados e comercial. A célula eletroquímica consistiu de um arranjo que se assemelha a uma meia-célula típica composta por três eletrodos (Figura 8). O eletrodo de referência utilizado foi eletrodo reversível de hidrogênio (ERH), o contra-eletrodo consistiu de uma rede de platina de alta área superficial e o eletrodo de trabalho consistiu de pastilhas formadas por prensagem de uma mistura de tecido de carbono, PTFE e uma pasta do 
material catalítico a ser analisado aglutinada com Nafion ${ }^{\circledR}$ para evitar desprendimento do material. Os eletrodos foram dispostos de modo que o feixe de raios $\mathrm{X}$ passasse somente através do eletrodo de trabalho. $\mathrm{O}$ eletrólito utilizado foi uma solução $0,5 \mathrm{M}$ de $\mathrm{H}_{2} \mathrm{SO}_{4}$, a temperatura ambiente e com atmosfera de ar. Os experimentos foram realizados no Laboratório Nacional de Luz Síncroton (LNLS) na linha XAFS-2 cujo sistema de aquisição de dados consiste em três câmaras ionizáveis ( $I_{0}$ incidente, $I_{t}$ transmitido e $I_{r}$ referência) que agem como sensores. A câmara de referência é usada para calibrações utilizando-se uma folha de Pt.

Figura 8 - Fotografia do arranjo montado para realização das medidas de XAS in situ nos catalisadores recém-preparados e comercial.

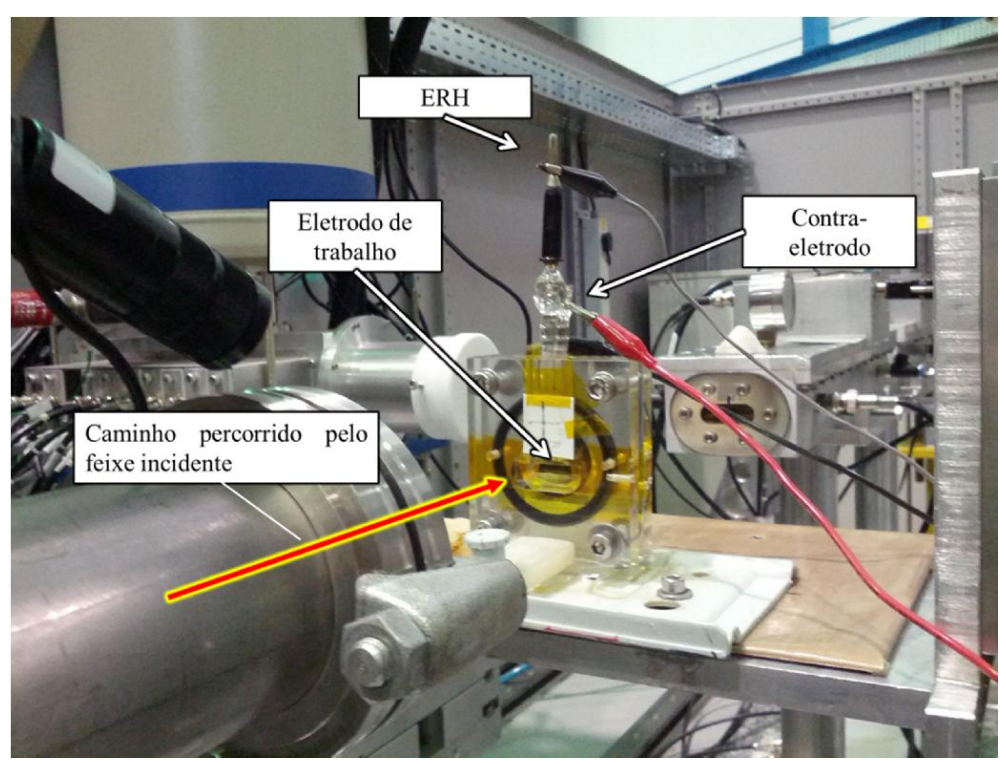

\subsection{Caracterização eletroquímica dos suportes e eletrocatalisadores recém-preparados}

A célula eletroquímica utilizada é composta por três eletrodos: (i) o eletrodo reversível de hidrogênio (ERH) como o eletrodo de referência; (ii) o contra-eletrodo composto por uma rede de platina platinizada de elevada área superficial; e (iii) o eletrodo de trabalho. Para preparação do eletrodo de trabalho, primeiramente uma suspensão alcoólica de concentração $1,5 \mathrm{mg} \mathrm{mL}^{-1}$ de cada material, contendo isopropanol (Aldrich ${ }^{\circledR}$ ) e $0,09 \%(\mathrm{v} / \mathrm{v}$ ) de Nafion (DuPont ${ }^{\circledR}$ ), foi preparada. A suspensão foi colocada em ultrassom por 30 minutos para homogeneização da mesma. Uma alíquota de $20 \mu \mathrm{L}$ da suspensão foi depositada na superfície de um disco de carbono vítreo de diâmetro de 5,0 $\mathrm{mm}$ (área geométrica $=0,196$ 
$\mathrm{cm}^{2}$ ) embutido em PTFE (Politetrafluoretileno) e seca em atmosfera de ar, a temperatura ambiente. Em seguida, foi depositada uma alíquota de água sobre a camada ultrafina recémpreparada e o eletrodo foi colocado num dessecador e feito vácuo, a fim de retirar possíveis bolhas de ar que possam ter sido formadas durante a deposição do catalisador sobre a superfície do carbono vítreo. O eletrodo foi imerso no eletrólito composto por $0,5 \mathrm{M}$ de $\mathrm{H}_{2} \mathrm{SO}_{4}$ no interior da célula eletroquímica.

Com o intuito de conduzir medidas quantitativas, a quantidade de material disperso no eletrodo de disco de carbono vítreo deve ser precisamente conhecida, ao mesmo tempo em que cargas muito baixas (da ordem de $<100 \mu \mathrm{g}_{\text {material }} \mathrm{cm}^{-2}$ ) são necessárias para evitar perdas excessivas por transporte de massa que ocorrem em camadas espessas $(>1 \mu \mathrm{m})$. Esse cuidado na preparação da camada catalítica sobre o eletrodo de disco evita o uso de modelos matemáticos que apresentam vários parâmetros desconhecidos (por exemplo, a estrutura do aglomerado, difusores no filme ionomérico, etc.) [96]. Portanto, considerando este problema, foram de fato preparadas camadas ultrafinas contendo uma concentração final do catalisador de aproximadamente $30 \mu \mathrm{g}_{\text {material }} \mathrm{cm}^{-2}$.

A técnica de voltametria cíclica foi utilizada com o objetivo de analisar as propriedades superficiais do eletrodo, como por exemplo, estimar sua área eletroquimicamente ativa. Os experimentos voltamétricos foram realizados no intervalo de $0,05-1,2 \mathrm{~V}$ (vs. ERH), utilizando um bipotenciostato AUTOLAB (PGSTAT 30). Para obter um perfil voltamétrico estável durante as medidas, o eletrodo foi ciclado diversas vezes para a limpeza de sua superfície no mesmo intervalo de potencial mencionado acima. Com o intuito de determinar-se a linha de base utilizada para o cálculo da área ativa por voltametria cíclica, foi também realizada primeiramente uma voltametria cíclica para oxidação de uma monocamada de CO previamente adsorvida na superfície eletródica, chamado de método de “stripping de CO" [97]. Para esses experimentos, o eletrodo em estudo foi polarizado em potencial baixo $(0,05 \mathrm{~V} v s$. ERH) durante 15 minutos enquanto borbulhava-se o monóxido de carbono na solução eletrolítica. Em seguida, a solução foi purgada com $\mathrm{N}_{2}$ durante 30 minutos para completa remoção de monóxido de carbono da atmosfera da célula, restando apenas o monóxido de carbono adsorvido na superfície da platina. Dessa forma, após a primeira ciclagem, todo o $\mathrm{CO}_{\text {ads }}$ foi oxidado para $\mathrm{CO}_{2}$ e o segundo ciclo possui o perfil típico da platina obtido após a limpeza do eletrodo. A velocidade de varredura usada foi de $50 \mathrm{mV} \mathrm{s}^{-1}$. Utilizando a área superior da região de $\mathrm{H}_{\text {upd }}$ do segundo ciclo e a linha de base obtida pelo primeiro ciclo, determinou-se a área eletroativa de Pt em cada material [97]. A área do pico de oxidação da monocamada de $\mathrm{CO}_{\mathrm{ads}}$ também foi utilizada para estimar a área eletroativa de Pt. 
Para tanto, foi considerado que a carga necessária para oxidar uma monocamada completa é de $420 \mu \mathrm{C} \mathrm{cm}^{-2}$. Utilizou-se o segundo ciclo após a oxidação de $\mathrm{CO}$ para determinar a linha de base deste pico [58].

As curvas de polarização foram obtidas potenciodinamicamente, em várias velocidades de rotação para avaliar os parâmetros cinéticos da RRO. O intervalo de potencial utilizado para essas curvas de polarização foi de $0,05-1,0 \mathrm{~V}$ (vs. ERH) e a velocidade de varredura foi de $5 \mathrm{mV} \mathrm{s}^{-1}$. Todos os experimentos foram realizados à temperatura ambiente $\left(25^{\circ} \mathrm{C}\right)$. Em todos os experimentos foi utilizada uma solução eletrolítica $0,5 \mathrm{M} \mathrm{de} \mathrm{H}_{2} \mathrm{SO}_{4}$. O eletrólito foi saturado com $\mathrm{N}_{2}$ durante a limpeza do eletrodo e determinação de sua área eletroquimicamente ativa, e com $\mathrm{O}_{2}$ para o estudo da reação de redução de oxigênio.

\subsection{Teste de degradação eletroquímico acelerado}

Sabe-se que a dissolução de platina ocorre durante as variações de potencial na célula [98-101]. De acordo com a Conferência de comercialização de células a combustível do Japão (FCCJ, Fuel Cell Commercialization Conference of Japan), a faixa de potencial de cada célula em um conjunto de células ('stack') pode estar entre 0,6 e 1,0 V vs. ERH em veículos operando com PEMFCs (FCVs, Fuel cell vehicles) [53]. O primeiro potencial corresponde à carga máxima de operação e o segundo ao potencial de circuito aberto durante a interrupção da célula. Sendo assim, objetivando imitar as variações de potencial abordadas acima, foi aplicado um teste de degradação como apresentado na Figura 9. De maneira resumida, após a caracterização eletroquímica, o eletrodo de trabalho foi polarizado por 30 segundos em $0,6 \mathrm{~V}$, seguido de ciclagem de potencial pelo método de ondas quadradas. Os potenciais aplicados foram 0,6 e 1,0 V com período de polarização de 3 segundos cada. O eletrólito utilizado foi uma solução 0,5 $\mathrm{M} \mathrm{H}_{2} \mathrm{SO}_{4}$ em atmosfera de ar e temperatura ambiente. Após 4500, $10000 \mathrm{e}$ 12000 ciclos, o eletrodo foi caracterizado eletroquimicamente, visando obter-se sua área eletroativa e atividade frente à RRO. Em cada um dos intervalos de ciclagem, o eletrólito foi renovado para evitar possíveis contaminações por espécies químicas. 
Figura 9 - Protocolo do teste de degradação por ciclo de potencial acelerado.

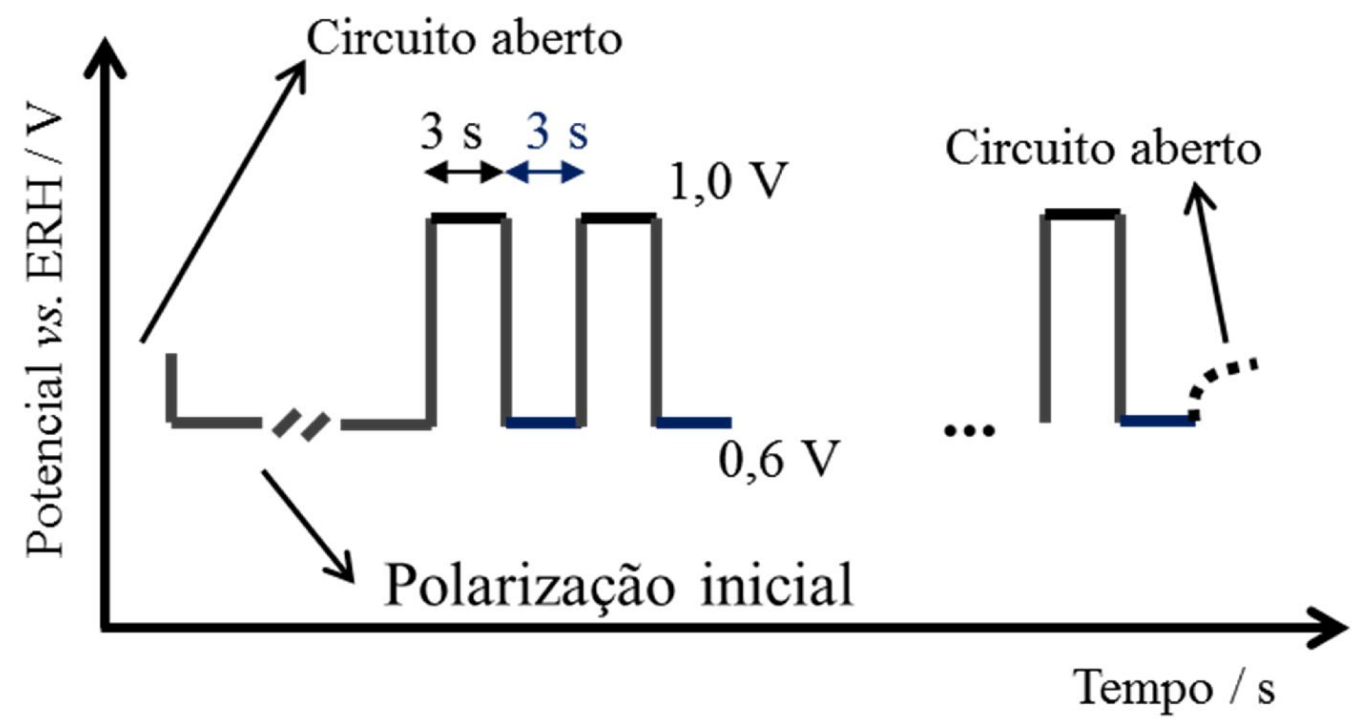

Fonte: Figura adaptada de OHMA, A. et al. ECS Trans., v. 41, 2011 [53]. 


\section{RESULTADOS E DISCUSSÃO}

\subsection{Caracterização física e estrutural dos suportes catalíticos}

Os suportes $\mathrm{MoO}_{3}-\mathrm{C}$ e $\mathrm{MoO}_{2}-\mathrm{C}$ preparados foram analisados por energia dispersiva de raios X (EDX) para verificação da composição das amostras. Na Tabela 1 encontram-se as porcentagens em massa e suas respectivas proporções entre os elementos Mo e C. A presença do elemento molibdênio indica que o método de síntese utilizado foi satisfatório para a impregnação de espécies de Mo na superfície de carbono Vulcan. Para o composto $\mathrm{MoO}_{3}-\mathrm{C}$ obteve-se a proporção de 1:5,2 (Mo:C, $\mathrm{m} / \mathrm{m})$, aproximadamente $23 \%$ menor da esperada (1:4; Mo:C). O composto $\mathrm{MoO}_{2}-\mathrm{C}$ apresentou um decréscimo de $35 \%$ em relação ao teor de Mo esperado (1:3; Mo:C). Possíveis fatores que podem ser usados para explicar as consideráveis diferenças são perdas de espécies de Mo durante o tratamento térmico [102] dos suportes e também dispersão não homogênea das partículas de óxidos de molibdênio na superfície de carbono. No entanto, as proporções obtidas entre Mo:C são razoáveis para o propósito desse trabalho.

Tabela 1 - Proporção em massa dos elementos Mo e C presentes no suporte catalítico recémpreparado obtidas por EDX

\begin{tabular}{c|c|c|c|c}
\hline \multirow{2}{*}{ Materiais } & \multicolumn{2}{|c|}{$\%$ mássica } & \multicolumn{2}{c}{$\begin{array}{c}\text { Proporção } \\
\text { mássica }\end{array}$} \\
\cline { 2 - 5 } & $\mathbf{C}$ & Mo & $\mathbf{C}$ & Mo \\
\hline $\mathrm{MoO}_{\mathbf{3}}-\mathbf{C}$ & 84 & 16 & 5,2 & 1 \\
\hline $\mathrm{MoO}_{\mathbf{2}}-\mathbf{C}$ & 82 & 18 & 4,6 & 1 \\
\hline
\end{tabular}

A fim de verificar a estrutura física dos compostos de Mo formados após o tratamento térmico, utilizado para sinterização dos materiais, bem como o grau de cristalinidade dos mesmos, utilizou-se a técnica de difração de raios $\mathrm{X}$ (DRX) e os resultados obtidos encontram-se na Figura 10. A reflexão observada em $2 \theta=25^{\circ}$ para o $\mathrm{MoO}_{3}-\mathrm{C}$ (Figura 10(a)) é associada ao carbono utilizado como suporte. A mesma não é observada para o material $\mathrm{MoO}_{2}-\mathrm{C}$ (Figura 10(b)), mas esse fato não significa perda do carbono durante a síntese, como observado pelos dados obtidos por EDX (Tabela 1). Como a temperatura e o tempo do tratamento térmico foram elevados $\left(500^{\circ} \mathrm{C}\right.$ durante 5 horas $)$, obteve-se o dióxido de molibdênio com alta cristalinidade, que por consequência resulta em picos bastante discretos e com alta intensidade. Esse efeito pode ter levado a uma supressão da reflexão do alomorfo de 
carbono de baixa intensidade devido a efeitos de escala. As comparações destes perfis com os dos padrões cristalográficos dos óxidos de molibdênio encontrados na literatura $[103,104]$ mostram elevada concordância, onde tanto os picos de alta quanto os de baixa intensidade estão sobrepostos e com intensidade bastante similares, indicando a formação de estruturas de $\mathrm{MoO}_{3}$ e $\mathrm{MoO}_{2}$ com excelente cristalinidade (cristais ortorrômbicos e monoclínicos, respectivamente).

Figura 10 - Difratogramas obtidos para os suportes catalíticos recém-preparados $\mathrm{MoO}_{3}$-C (a) e $\mathrm{MoO}_{2}$ C (b).
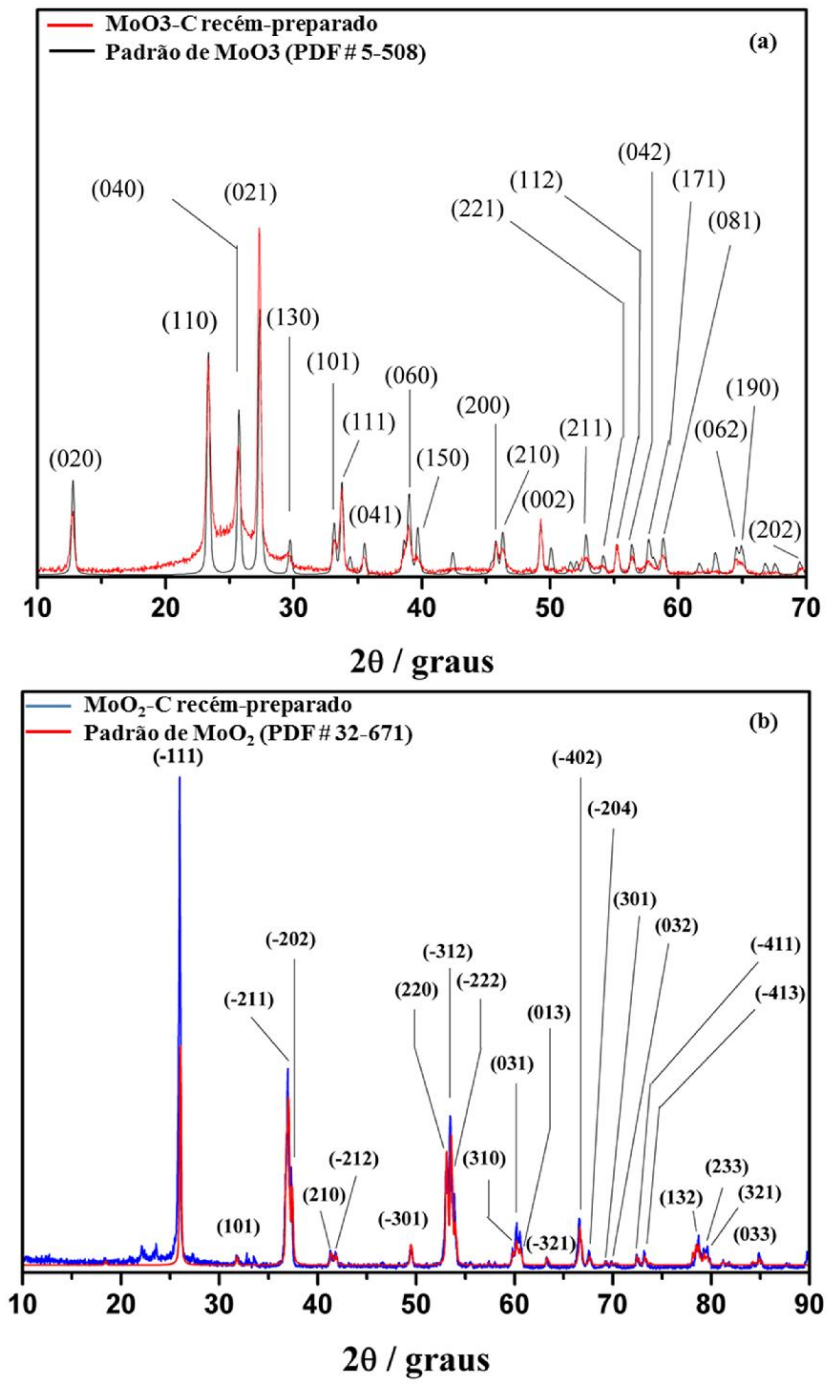

A partir dos difratogramas (Figura 10) foi possível determinar os parâmetros de rede [95], o ângulo $\beta$ e estimar o tamanho médio dos cristalitos $d$ por meio da equação de Scherrer [94]. Os resultados encontram-se sumarizados na Tabela 2. Os picos utilizados para o cálculo 
do tamanho médio foi os $(-111)$ e $(020)$ para $\mathrm{MoO}_{2}-\mathrm{C}$ e $\mathrm{MoO}_{3}-\mathrm{C}$, respectivamente. Como previsto pela observação da localização dos picos nos difratogramas, ambos os óxidos sintetizados possuem os parâmetros de rede iguais aos dos óxidos puros encontrados na literatura $[103,104]$, indicando que o carbono não influenciou na estrutura cristalina final dos mesmos. O tamanho dos cristalitos dos óxidos é relativamente elevado, sendo a diferença na magnitude dos tamanhos entre os óxidos possivelmente ocasionada pelas diferenças na temperatura e tempo nos tratamentos térmicos. Vale ressaltar que outras proporções mássicas, bem como diferentes tempos e temperaturas de tratamento térmico, foram aplicados para preparação dos suportes de $\mathrm{MoO}_{\mathrm{x}}-\mathrm{C}$, de modo a otimizar as condições de preparação dos materiais usados neste trabalho, conforme acima descritas.

Tabela 2 - Tamanho médio dos cristalitos e parâmetros de rede dos suportes catalíticos $\mathrm{MoO}_{2}-\mathrm{C}$ e $\mathrm{MoO}_{3}-\mathrm{C}$ calculados por dados obtidos por DRX

\begin{tabular}{|c|c|c|c|c|c|c|c|c|c|}
\hline \multirow{2}{*}{$\begin{array}{l}\text { Suportes } \\
\text { catalíticos }\end{array}$} & \multicolumn{4}{|c|}{$\begin{array}{c}\text { Parâmetros de rede } \\
\text { padrões / } \AA\end{array}$} & \multicolumn{4}{|c|}{$\begin{array}{c}\text { Parâmetros de rede } \\
\text { calculados / } \AA\end{array}$} & \multirow{2}{*}{$\begin{array}{c}\text { Diâmetro } \\
\text { médio dos } \\
\text { cristalitos } / \\
\text { nm }\end{array}$} \\
\hline & $\mathbf{a}$ & b & c & $\boldsymbol{\beta}$ & $\mathbf{a}$ & b & c & $\beta$ & \\
\hline $\mathrm{MoO}_{2}-\mathrm{C}$ & 5,61 & 4,86 & 5,54 & $119,37^{\circ}$ & 5,60 & 4,86 & 5,55 & $119,28^{\circ}$ & 40,8 \\
\hline $\mathrm{MoO}_{3}-\mathrm{C}$ & 3,96 & 13,86 & 3,63 & - & 3,97 & 13,87 & 3,68 & - & 23,5 \\
\hline
\end{tabular}

A Figura 11 ilustra o voltamograma obtido para o suporte $\mathrm{MoO}_{2}-\mathrm{C}$ recém-preparado. Observa-se um perfil voltamétrico bem definido, com picos claros e em concordância com perfis de $\mathrm{MoO}_{2}$ bem estabelecidos na literatura [83,90-92,105-109]. Particularmente, os picos presentes na região destacada na curva voltamétrica (Figura 11) são atribuídos ao comportamento redox dos estados de oxidação $\mathrm{Mo}^{+4}$ e $\mathrm{Mo}^{+6}[107,109]$. De acordo com Machida et al. [110], os picos redox que aparecem na região em torno de 0,25 V (vs. ERH) podem ser atribuídos a pares redox superficiais tais como $\mathrm{Mo}^{3+} / \mathrm{MoO}_{2}, \mathrm{Mo}^{3+} / \mathrm{MoO}_{3}$ e $\mathrm{MoO}_{2} / \mathrm{MoO}_{3}$. Tais picos também se encontram presentes na curva de voltametria cíclica para o $\mathrm{MoO}_{3}-\mathrm{C}$ que, por possuir perfil próximo ao da curva de $\mathrm{MoO}_{2}-\mathrm{C}$, foi omitida. Foram realizados diversos ciclos voltamétricos e constatou-se que o perfil não sofre qualquer variação, indicando que os óxidos de molibdênio possuem estabilidade em meio $0,5 \mathrm{M} \mathrm{H}_{2} \mathrm{SO}_{4}$ e na faixa de potencial aplicada $[74,75]$. 
Figura 11 - Voltametria cíclica do suporte $\mathrm{MoO}_{2}-\mathrm{C}$ recém-preparado, realizada em solução $0,50 \mathrm{M}$ de $\mathrm{H}_{2} \mathrm{SO}_{4}$ saturada com gás $\mathrm{N}_{2}$, com velocidade de varredura de $20 \mathrm{mV} \mathrm{s}^{-1}$, à temperatura ambiente $\left(25^{\circ} \mathrm{C}\right)$. As flechas indicam a direção de varredura no intervalo $0,05-1,0 \mathrm{~V}$.

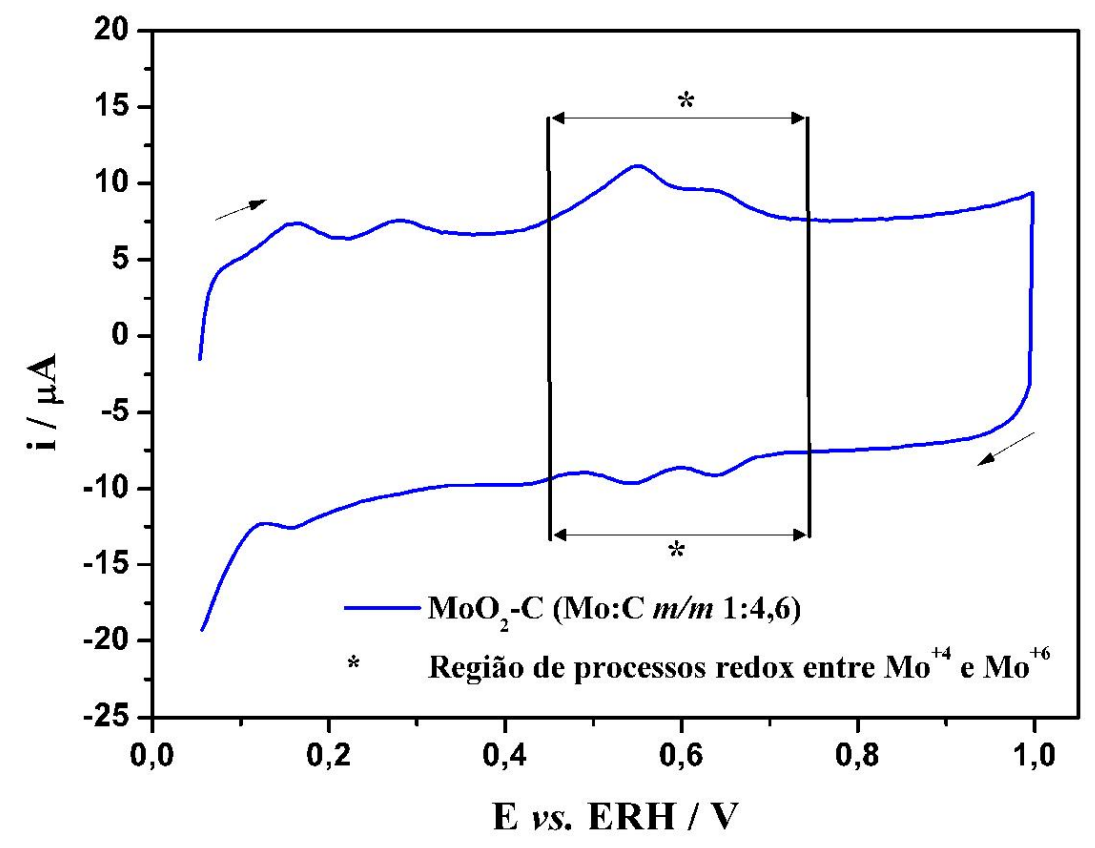

\subsection{Caracterização dos eletrocatalisadores recém-preparados e comercial}

\subsubsection{Caracterização física e estrutural}

$\mathrm{O}$ suportes de $\mathrm{MoO}_{3}$ e $\mathrm{MoO}_{2}$ em carbono foram impregnados com nanopartículas de platina (NPs de Pt) para formação dos eletrocatalisadores $\mathrm{Pt} / \mathrm{MoO}_{3}-\mathrm{C}$ e $\mathrm{Pt} / \mathrm{MoO}_{2}-\mathrm{C}$, respectivamente. A Tabela 3 ilustra os resultados obtidos por EDX para composição das amostras após a incorporação de NPs de Pt nos suportes catalíticos e do eletrocatalisador comercial Pt/C ETEK (20\% em massa de Pt). Analisando as porcentagens mássicas obtidas conclui-se que o método do ácido fórmico (MAF) utilizado para impregnação de NPs de Pt apresentou um rendimento excelente, tendo sido calculados $19 \%$ e $18 \%$ em massa de Pt para $\mathrm{Pt} / \mathrm{MoO}_{3}-\mathrm{C}$ e $\mathrm{Pt} / \mathrm{MoO}_{2}-\mathrm{C}$, respectivamente, valores muito próximos dos $20 \%$ previsto pelos cálculos da quantidade de precursor de Pt durante a síntese. 
Tabela 3 - Porcentagens mássicas entre Pt, Mo e C presente nos eletrocatalisadores recém-preparados e comercial

\begin{tabular}{c|c|c|c}
\hline \multirow{2}{*}{ Materiais } & \multicolumn{3}{|c}{ \% mássica } \\
\cline { 2 - 4 } & $\mathbf{C}$ & Mo & Pt \\
\hline $\mathbf{P t} / \mathbf{M o O}_{\mathbf{3}}-\mathbf{C}$ & 72 & 9 & 19 \\
\hline $\mathbf{P t}_{\mathbf{M}}$ & 67 & 15 & 18 \\
\hline Pt/C ETEK $^{\circledR}$ & 79 & - & 21 \\
\hline
\end{tabular}

A Tabela 4 apresenta as proporções mássicas dos elementos Mo e $\mathrm{C}$ presentes no suporte catalítico antes e após a incorporação de $\mathrm{Pt}$. $\mathrm{O}$ suporte $\mathrm{MoO}_{2}-\mathrm{C}$ manteve sua proporção entre Mo e $\mathrm{C}$, mostrando que o procedimento de impregnação de NPs de Pt não ocasiona perdas de espécies de Mo pela formação de possíveis complexos de Mo solúveis em meio ácido. Já o suporte $\mathrm{MoO}_{3}-\mathrm{C}$ teve sua proporção de Mo diminuída. Um fator que pode ser atribuído a esse resultado é a formação de compostos de Mo solúveis nas condições empregadas durante o MAF. Conforme discutido na seção 4.1 deste trabalho, o suporte $\mathrm{MoO}_{3}-\mathrm{C}$ apresenta estabilidade em meio ácido $0,5 \mathrm{M} \mathrm{H}_{2} \mathrm{SO}_{4}$, confirmada pela técnica de voltametria cíclica $[74,75]$. Porém o tempo de tratamento térmico empregado, 4 horas, pode não ter sido o suficiente para completa transformação das espécies de $\mathrm{Mo}$ em $\mathrm{MoO}_{3}$ cristalino. As espécies remanescentes podem ter sido então atacadas pelo ácido fórmico a $80{ }^{\circ} \mathrm{C}$ e sofrido processos de oxirredução formando compostos solúveis, que foram perdidos durante a filtração e lavagem do material. Analisando o diagrama de potencial-pH (Diagrama de Pourbaix) para um sistema $\mathrm{Mo}-\mathrm{H}_{2} \mathrm{O}$ [75], em valores próximos de $\mathrm{pH} 2$ (condição típica apresentada pelo MAF, onde utiliza-se uma solução 0,5 M de ácido fórmico), verifica-se que há a possibilidade de formação de espécies solúveis de $\mathrm{Mo}^{3+}$ e $\mathrm{HMoO}_{4}^{-}$(Figura 12), o que reforça a suposição de perda por dissolução realizada acima. 
Tabela 4 - Proporções mássicas dos elementos Mo e C presentes nos suportes catalíticos antes e após o MAF

\begin{tabular}{c|c|c}
\hline \multirow{2}{*}{ Materiais } & \multicolumn{2}{|c}{ Proporção mássica } \\
\cline { 2 - 3 } & $\mathbf{C}$ & Mo \\
\hline $\mathrm{MoO}_{\mathbf{3}}-\mathbf{C}$ & 5,2 & 1 \\
\hline $\mathbf{P t}_{\mathbf{M o O}} \mathbf{- C}$ & 8 & 1 \\
\hline $\mathrm{MoO}_{\mathbf{2}}-\mathbf{C}$ & 4,6 & 1 \\
\hline $\mathbf{P t} / \mathbf{M o O}_{\mathbf{2}}-\mathbf{C}$ & 4,6 & 1 \\
\hline
\end{tabular}

Figura 12 - Diagrama de Pourbaix (potencial-pH) para um sistema Mo- $\mathrm{H}_{2} \mathrm{O}$.

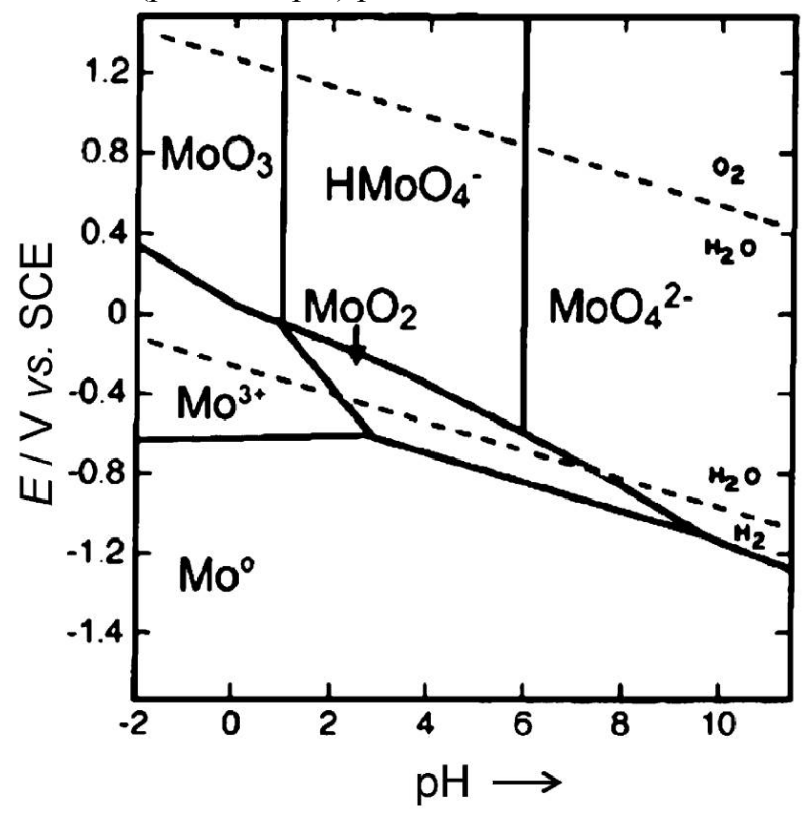

Fonte: Figura adaptada de SAJI, V. S.; LEE, C.-W. ChemSusChem., v. 5, 2012 [75].

A Figura 13 apresenta os difratogramas obtidos para os três eletrocatalisadores e o referente ao padrão de platina metálica presente na literatura [111]. A reflexão observada em $2 \theta=25^{\circ}$ para todos os catalisadores é associada ao carbono utilizado como suporte. As posições $2 \theta$ dos picos (111), (200), (220), (311) e (222) das linhas de difração para os eletrocatalisadores recém-preparados e comercial (exceto pico (222), não claramente evidenciado para $\mathrm{Pt} / \mathrm{C}$ ETEK) se comparam com a posição padrão dos picos do padrão de $\mathrm{Pt}$ fornecido, indicando que todos os materiais possuem rede cristalina $f c c$ similar à Pt maciça. $\mathrm{O}$ formato relativamente largo dos picos de difração refletem o pequeno tamanho das partículas 
de Pt nos catalisadores, como pode ser observado pela Tabela 5. Portanto, o MAF pode ser considerado um método de impregnação de NPs de Pt em suportes contendo espécies de Mo bastante eficaz, com a formação de pequenas partículas garantindo um melhor aproveitamento das espécies de Pt na catálise. Ademais, como não houve qualquer alteração dos parâmetros de rede da platina nos materiais, pode-se concluir que não houve a formação de liga entre Pt e Mo nas condições empregadas no MAF [112].

Figura 13 - Difratogramas obtidos para os eletrocatalisadores recém-preparados, comercial e também o padrão cristalográfico de platina metálica. Os asteriscos (*) representam picos remanescentes referentes ao trióxido de molibdênio.

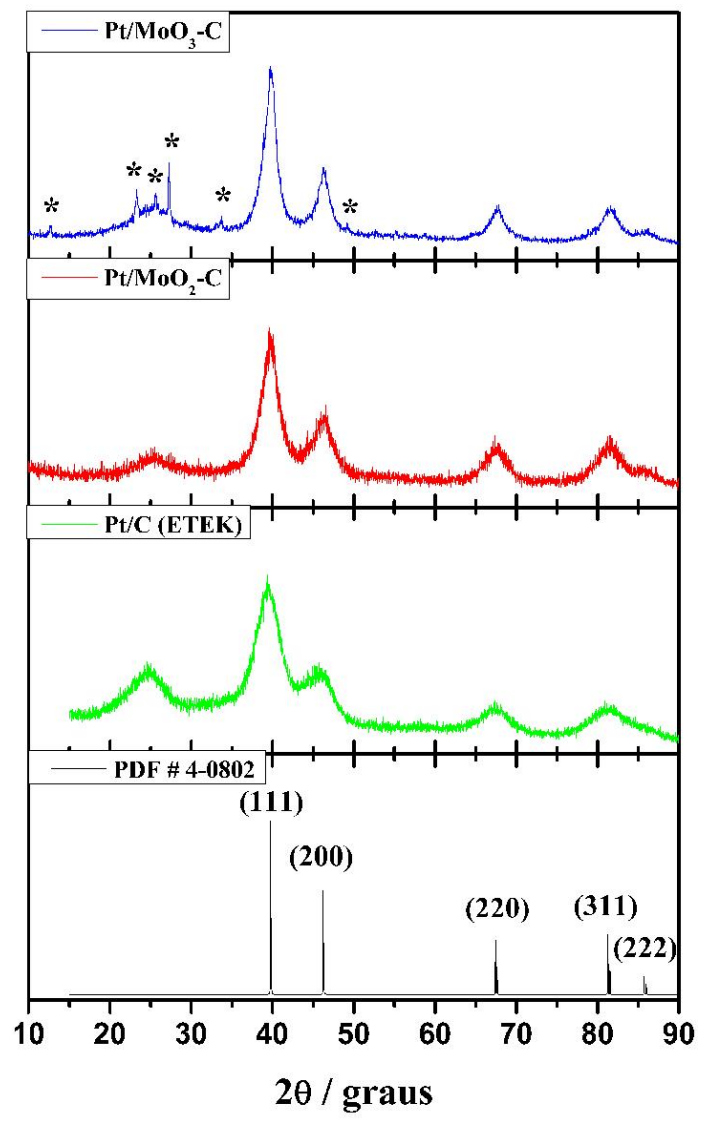


Tabela 5 - Diâmetro médio dos cristalitos e parâmetros de rede padrões e dos eletrocatalisadores $\mathrm{Pt} / \mathrm{MoO}_{2}-\mathrm{C}, \mathrm{Pt} / \mathrm{MoO}_{3}-\mathrm{C}$ e Pt/C ETEK calculados por dados obtidos por DRX. Também estão inseridos os diâmetros médios dos cristalitos obtidos por TEM

\begin{tabular}{c|c|c|c|c}
\hline Eletrocatalisadores & $\begin{array}{c}\text { Parâmetros } \\
\text { de rede } \\
\text { padrões / } \AA\end{array}$ & $\begin{array}{c}\text { Parâmetros } \\
\text { de rede } \\
\text { calculados / } \\
\AA\end{array}$ & $\begin{array}{c}\text { Diâmetro } \\
\text { médio dos } \\
\text { cristalitos / nm } \\
\text { (DRX) }\end{array}$ & $\begin{array}{c}\text { Diâmetro } \\
\text { médio dos } \\
\text { cristalitos / } \mathbf{~ m ~} \\
\text { (TEM) }\end{array}$ \\
\hline $\mathbf{P t} / \mathbf{M o O}_{\mathbf{2}}-\mathrm{C}$ & 3,923 & 3,922 & 3,1 & 3,0 \\
\hline $\mathbf{P t} / \mathbf{M o O}_{3}-\mathbf{C}$ & 3,923 & 3,918 & 4,5 & 2,8 \\
\hline $\mathbf{P t} / \mathbf{C} \mathbf{E T E K}^{\circledR}$ & 3,923 & 3,933 & 2,7 & 2,9 \\
\hline
\end{tabular}

A Figura 14 apresenta as imagens obtidas por microscopia eletrônica de transmissão (TEM), e seus respectivos histogramas, para os catalisadores recém-preparados e o comercial. Os diâmetros médios das partículas nos catalisadores obtidos nesta análise estão descritos na Tabela 5. Analisando as micrografias de TEM, constata-se o elevado grau de distribuição homogênea das NPs de Pt nos suportes. A diferença encontrada nos valores dos tamanhos dos cristalitos obtidos por DRX e das partículas obtidas por TEM (Tabela 5) deve-se ao fato da aproximação de que todos os cristalitos em questão são esféricos para aplicarmos a equação de Scherrer em DRX ou de que as partículas são na realidade aglomerados e nanocristalitos.

A técnica TEM mostra-se mais eficaz para determinações de tamanhos de partículas em materiais nanoparticulados, pois se pode analisar partícula por partícula. Quando uma partícula não é esférica, medem-se dois diâmetros e calcula-se uma média entre eles, que será o tamanho daquela partícula específica. Portanto, os histogramas apresentados na Figura 14 foram obtidos globalmente, ou seja, considerando todos os formatos de partículas encontradas nas micrografias de TEM, sejam elas esféricas, achatadas ou aglomerados mais complexos. Vale ressaltar que para a construção dos histogramas foram utilizadas diversas micrografias dos materiais, resultando em um total de aproximadamente 700 partículas contadas para cada catalisador. Os insertos presentes nos histogramas globais dos catalisadores (Figura 14) são a frequência da esfericidade das NPs de Pt nos materiais, determinadas pela razão entre os dois diâmetros medidos para cada partícula $\left(r_{1} / r_{2}\right.$, onde $r_{1}$ e $r_{2}$ são o menor e maior diâmetros, respectivamente). Analisando esses insertos observa-se que tanto as partículas em $\mathrm{Pt} / \mathrm{C}$ quanto em $\mathrm{Pt} / \mathrm{MoO}_{3}-\mathrm{C}$ apresentam elevado grau de esfericidade. Em contrapartida, $\mathrm{Pt} / \mathrm{MoO}_{2}-\mathrm{C}$ apresenta um menor grau, indicando a presença de partículas com formatos variados. Será visto nas próximas seções que esses insertos proporcionam ferramentas bastante úteis para se 
entender os processos de envelhecimento que estão ocorrendo nos catalisadores quando submetidos às condições do teste de degradação acelerada descritas na seção 3.5.

Figura 14 - Micrografias dos eletrocatalisadores recém-preparado e comercial obtidas por TEM. Os histogramas de distribuição de tamanho de partículas correspondentes estão inseridos abaixo das micrografias. Os insertos presentes são histogramas referentes à esfericidade das NPs de Pt.
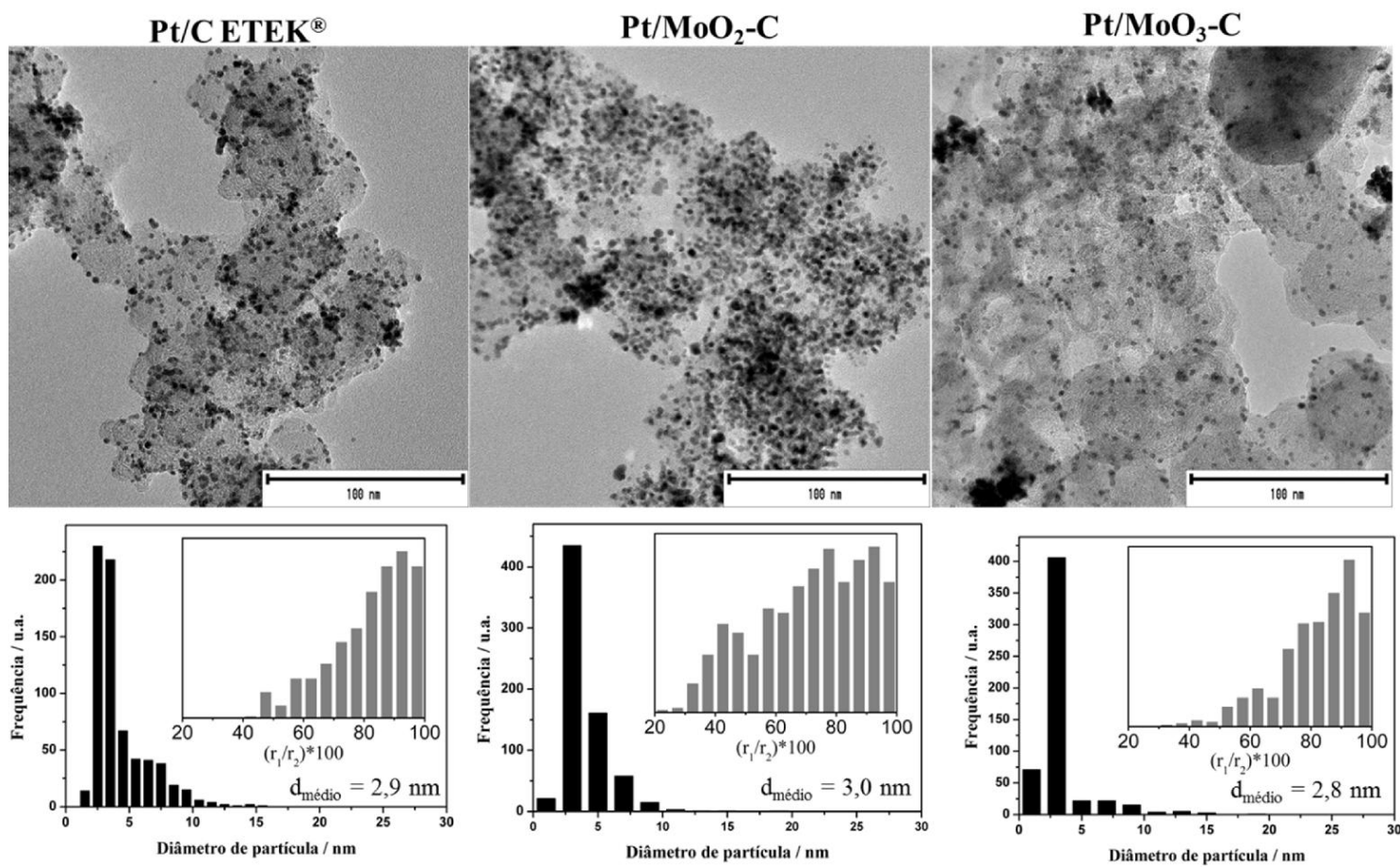

Os catalisadores recém-preparados foram analisados por espectroscopia fotoeletrônica de raios X (XPS), sendo na Figura 15 mostrados os espectros em uma longa faixa de energia. Analisando estes espectros, observam-se picos bem definidos relacionados apenas às espécies de oxigênio, carbono, platina e molibdênio. Portanto, pode-se inferir que a superfície do catalisador está livre de contaminantes. Pelos espectros também se pode afirmar que os métodos de síntese utilizados tanto para preparação dos suportes baseados em Mo quanto para posterior impregnação de NPs de Pt resultaram satisfatórios. 
Figura 15 - Espectros dos catalisadores recém-preparados obtidos por XPS.

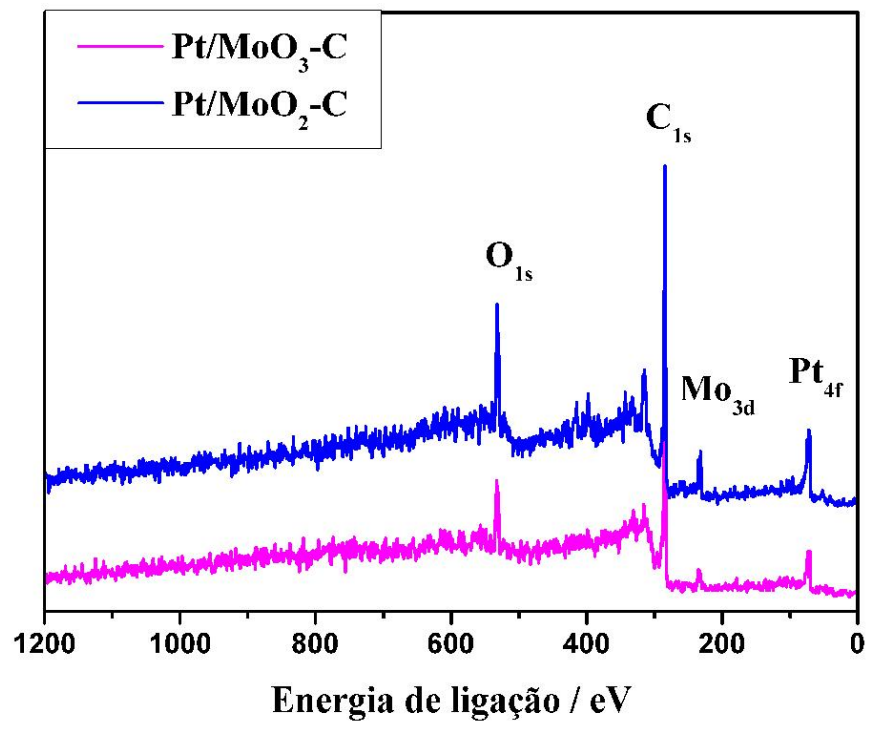

Os espectros de XPS dos níveis $3 \mathrm{~d}_{5 / 2}$ e $3 \mathrm{~d}_{3 / 2}$ do Mo dos catalisadores recémpreparados estão apresentados na Figura 16. Eles foram tratados considerando-se apenas os

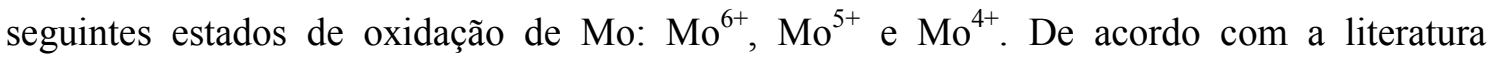
$[102,113]$, caso alguma espécie de Mo estivesse na forma metálica $\left(\mathrm{Mo}^{0}\right)$, o pico referente ao nível $3 \mathrm{~d}_{5 / 2}$ estaria localizado em aproximadamente $227,7 \mathrm{eV}$, o que claramente não é o caso nos catalisadores estudados.

Figura 16 - Espectros de XPS para Mo 3d para os catalisadores $\mathrm{Pt} / \mathrm{MoO}_{3}-\mathrm{C}$ (a) e $\mathrm{Pt} / \mathrm{MoO}_{2}-\mathrm{C}$ (b) recém-preparados.
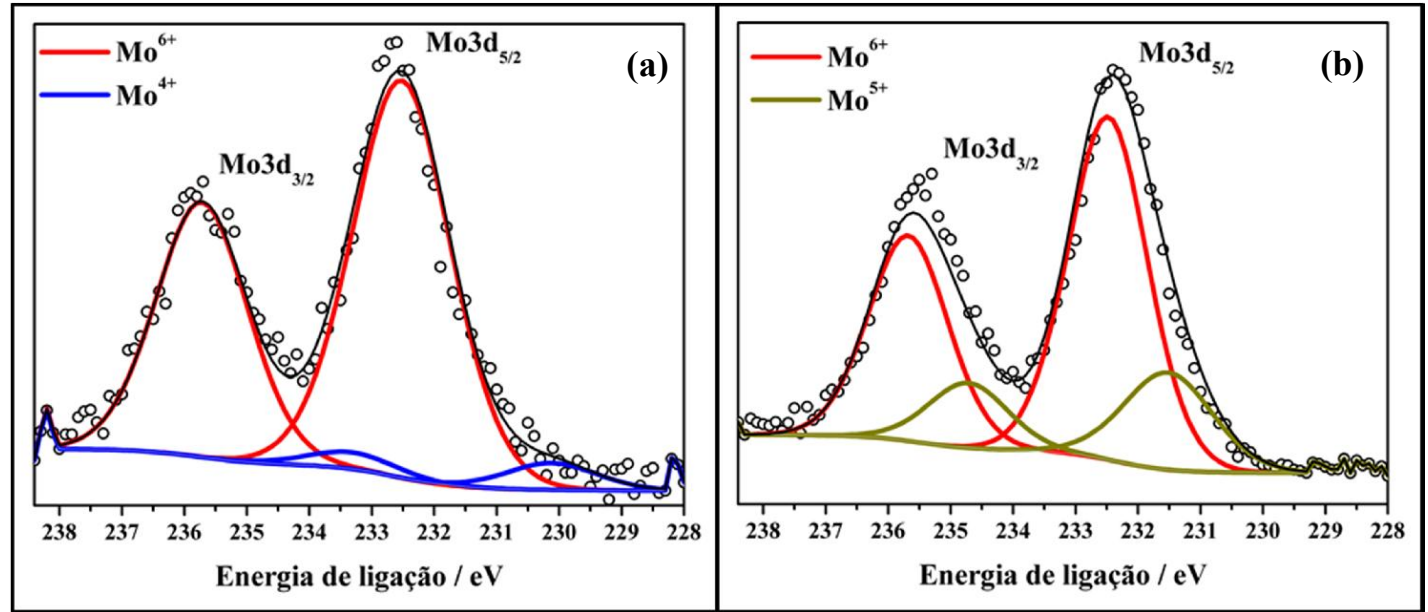
$\mathrm{Na}$ Tabela 6 estão compiladas as porcentagens atômicas para cada espécie $\mathrm{Mo}^{+\mathrm{x}}$, as energias de ligação para cada nível em cada estado de oxidação obtidas experimentalmente e também os padrões de energias de ligação para os respectivos níveis [114]. Analisando os resultados constata-se que as energias de ligação obtidas para os materiais sintetizados são idênticas às encontradas na literatura [102,113-115]. No caso do $\mathrm{Pt} / \mathrm{MoO}_{3}-\mathrm{C}$ (Figura 16(a)), os valores de energia de ligação juntos com os padrão de DRX obtido desse material, fortalecem as evidências de que o óxido desejado foi de fato formado. Isto demonstra que o MAF utilizado para impregnação de platina no suporte não alterou significativamente a estrutura e a superfície do $\mathrm{MoO}_{3}$. Deve-se notar também a presença de algumas espécies de $\mathrm{Mo}^{4+}$ nesse catalisador, mesmo que pequena (6\%). Alguns trabalhos apontam que a ocorrência de espécies diferentes daquelas esperadas em quantidades pequenas pode ser atribuída a formação de óxidos não-estequiométricos em algumas regiões do material (ex.: superfície em contato com ar da atmosfera), resultando em espécies de Mo deficientes de oxigênio [70,75,116].

Tabela 6 - Energias de ligação dos componentes Mo $3 \mathrm{~d}_{5 / 2}$ e Mo $3 \mathrm{~d}_{3 / 2}$ nos catalisadores recémpreparados e porcentagem atômica calculada para cada sinal. Dados obtidos por XPS

\begin{tabular}{|c|c|c|c|c|c|c|}
\hline \multirow{2}{*}{ Materiais } & \multirow{2}{*}{$\begin{array}{l}\text { Estado de } \\
\text { oxidação }\end{array}$} & \multicolumn{2}{|c|}{$\begin{array}{c}\text { Energia de Ligação } \\
\text { experimental / eV }\end{array}$} & \multicolumn{2}{|c|}{$\begin{array}{c}\text { Energia de Ligação } \\
\text { padrão/ eV }\end{array}$} & \multirow{2}{*}{$\begin{array}{c}\% \\
\text { atômica }\end{array}$} \\
\hline & & $\operatorname{Mo~3d~}$ & Mo 3d & $\operatorname{Mo~3d} d_{5 / 2}$ & $\operatorname{Mo~3d} d_{3 / 2}$ & \\
\hline \multirow{3}{*}{$\mathrm{Pt} / \mathrm{MoO}_{3}-\mathrm{C}$} & $\mathrm{Mo}^{6+}$ & 232,5 & 235,7 & 232,5 & 235,7 & 94 \\
\hline & $\mathrm{Mo}^{5+}$ & - & - & 231,5 & 234,7 & - \\
\hline & $\mathrm{Mo}^{4+}$ & 230,1 & 233,3 & 230,1 & 233,3 & 6 \\
\hline \multirow{3}{*}{$\mathrm{Pt} / \mathrm{MoO}_{2}-\mathrm{C}$} & $\mathrm{Mo}^{6+}$ & 232,5 & 235,7 & 232,5 & 235,7 & 76 \\
\hline & $\mathrm{Mo}^{5+}$ & 231,5 & 234,7 & 231,5 & 234,7 & 24 \\
\hline & $\mathrm{Mo}^{4+}$ & - & - & 230,1 & 233,3 & - \\
\hline
\end{tabular}


Ao se analisar os resultados obtidos para o $\mathrm{Pt} / \mathrm{MoO}_{2}-\mathrm{C}$ (Tabela 6) constata-se que não há presença de espécies $\mathrm{Mo}^{4+}$ na superfície do material. As espécies de Mo estão divididas em $\mathrm{Mo}^{5+}{\mathrm{e} \mathrm{Mo}^{6+}}^{6+}$ com esta última em maior quantidade (76\%). Apesar dos resultados de EDX terem mostrado que não houve qualquer perda de espécies de Mo após a impregnação de NPs de $\mathrm{Pt}, \mathrm{o} \mathrm{MoO}_{2}$ teve sua estrutura superficial física e química alterada, como mostrado na Figura 16(b). Analisando o difratograma de $\mathrm{Pt} / \mathrm{MoO}_{2}-\mathrm{C}$ (Figura 13), ao contrário do obtido para $\mathrm{Pt} / \mathrm{MoO}_{3}-\mathrm{C}$, não foi possível distinguir picos referentes ao óxido em questão. Portanto, correlacionando esses resultados, pode-se sugerir que o MAF de alguma forma alterou a estrutura do suporte, provavelmente por processos de oxirredução, deixando-o amorfo ou com baixa cristalinidade, porém sem a ocorrência de compostos de Mo solúveis. Vale ressaltar que os dados obtidos por XPS fornece um conhecimento sobre a estrutura na superfície ou regiões internas muito próximas a ela. Apesar de os picos de DRX para o $\mathrm{MoO}_{2}$ (Figura 13) terem sido suprimidos, não se pode descartar a possibilidade de que o MAF tenha modificado somente as regiões superficiais dos óxidos e que as regiões internas podem estar intactas, ou seja, na forma de $\mathrm{MoO}_{2}$ e que devido a elevada intensidade dos picos da Pt, não foi possível distinguir os picos de $\mathrm{MoO}_{2}$ no difratograma de $\mathrm{Pt} / \mathrm{MoO}_{2}-\mathrm{C}$ (Figura 13).

Os espectros de XPS dos níveis $4 \mathrm{f}_{7 / 2}$ e $4 \mathrm{f}_{5 / 2}$ da Pt dos catalisadores recém-preparados estão apresentados na Figura 17. Os espectros foram deconvoluídos em três dubletos correspondentes aos estados de oxidação $\mathrm{Pt}^{0}, \mathrm{Pt}^{2+}$ e $\mathrm{Pt}^{4+}$ da $\mathrm{Pt} 4 \mathrm{f}_{7 / 2}$ e $4 \mathrm{f}_{5 / 2}$. A linha de maior intensidade é referente ao estado metálico da Pt (centralizada em $71,4 \mathrm{eV}$ para $\mathrm{Pt} 4 \mathrm{f}_{7 / 2}$ ), de acordo com os valores estabelecidos na literatura $\left(\mathrm{Pt} 4 \mathrm{f}_{7 / 2}=71,2 \mathrm{eV}\right)$ [114]. As demais linhas,

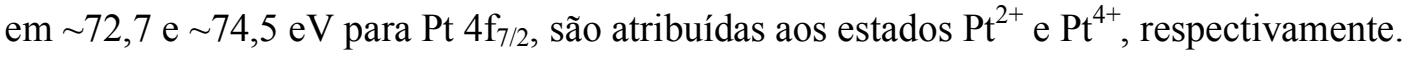

Na Tabela 7 encontram-se as energias de ligação e proporção atômicas das espécies de Pt consideradas nos catalisadores recém-preparados e comercial. O perfil do espectro de XPS para o Pt/C ETEK está bem estabelecido na literatura, de modo que os resultados apresentados na Tabela 7 para esse catalisador foram retirados de Corradini et al. [117]. 
Figura 17 - Espectros de XPS para Pt 4f para os catalisadores $\mathrm{Pt} / \mathrm{MoO}_{3}-\mathrm{C}$ (a) e $\mathrm{Pt} / \mathrm{MoO}_{2}-\mathrm{C}$ (b) recémpreparados.
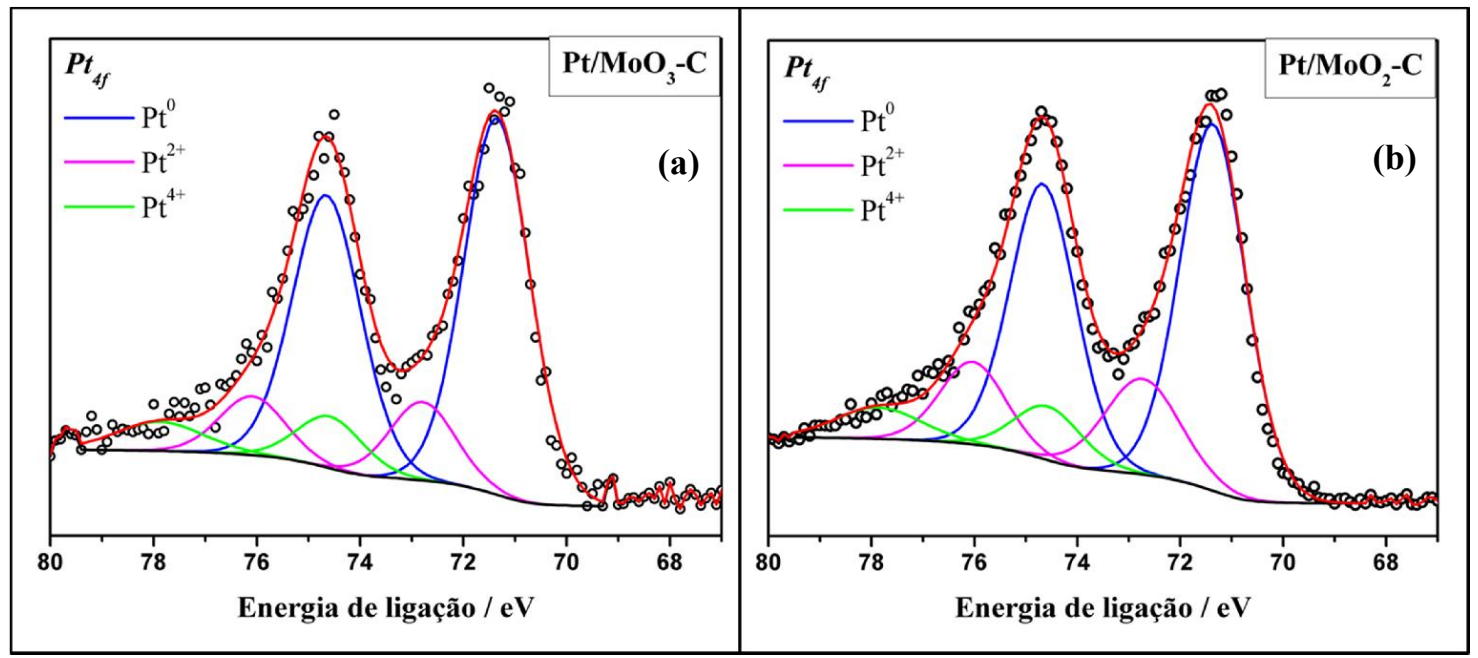

Tabela 7 - Energias de ligação dos componentes Pt 4f nos catalisadores recém-preparados e comercial, e porcentagem atômica calculada para cada sinal. (*) Dados retirados de Corradini et al. [117].

\begin{tabular}{|c|c|c|c|c|c|c|}
\hline \multirow{2}{*}{ Materiais } & \multirow{2}{*}{$\begin{array}{l}\text { Estado de } \\
\text { oxidação }\end{array}$} & \multicolumn{2}{|c|}{$\begin{array}{c}\text { Energia de Ligação } \\
\text { experimental / eV }\end{array}$} & \multicolumn{2}{|c|}{$\begin{array}{c}\text { Energia de Ligação } \\
\text { padrão/ eV }\end{array}$} & \multirow{2}{*}{$\begin{array}{c}\% \\
\text { atômica }\end{array}$} \\
\hline & & $\operatorname{Pt} 4 f_{7 / 2}$ & $\operatorname{Pt} 4 f_{5 / 2}$ & $\operatorname{Pt} 4 \mathbf{f}_{7 / 2}$ & $\operatorname{Pt} 4 f_{5 / 2}$ & \\
\hline \multirow{3}{*}{$\mathrm{Pt} / \mathrm{MoO}_{3}-\mathrm{C}$} & $\mathbf{P t}^{0}$ & 71,4 & 74,6 & 71,2 & 74,5 & 77,0 \\
\hline & $\mathbf{P t}^{2+}$ & 72,8 & 76,1 & 72,5 & 75,8 & 15,3 \\
\hline & $\mathbf{P t}^{4+}$ & 74,5 & 77,8 & 74,4 & 77,7 & 7,7 \\
\hline \multirow{3}{*}{$\mathrm{Pt} / \mathrm{MoO}_{2}-\mathrm{C}$} & $\mathbf{P t}^{0}$ & 71,4 & 74,7 & 71,2 & 74,5 & 69,1 \\
\hline & $\mathbf{P t}^{2+}$ & 72,7 & 76,0 & 72,5 & 75,8 & 20,7 \\
\hline & $\mathbf{P t}^{4+}$ & 74,6 & 77,9 & 74,4 & 77,7 & 10,2 \\
\hline \multirow{3}{*}{$\begin{array}{c}\mathbf{P t} / \mathrm{C}_{\circledast} \\
\operatorname{ETEK}^{{ }^{(*}}\left({ }^{*}\right)\end{array}$} & $\mathbf{P t}^{0}$ & 71,3 & 74,6 & 71,2 & 74,5 & 60 \\
\hline & $\mathbf{P t}^{2+}$ & 72,5 & 75,8 & 72,5 & 75,8 & 26 \\
\hline & $\mathrm{Pt}^{4+}$ & 74,5 & 77,8 & 74,4 & 77,7 & 14 \\
\hline
\end{tabular}


Os valores das energias de ligação para todas as espécies de Pt estão em concordância com os valores obtidos na literatura, evidenciando a presença de Pt metálica, $\mathrm{PtOH}_{2}, \mathrm{PtO}_{2} \mathrm{e}$ $\mathrm{PtO}_{2} \cdot n \mathrm{H}_{2} \mathrm{O}$ (referentes a $\mathrm{Pt}^{0}, \mathrm{Pt}^{2+} \mathrm{e} \mathrm{Pt}^{4+}$, respectivamente). Todos os catalisadores apresentam Pt metálica em maior proporção atômica, porém os recém-preparados apresentam maior porcentagem de $\mathrm{Pt}^{0}$ do que o comercial. A presença de espécies de Mo na superfície dos materiais pode ter influenciado no grau de oxidação dos átomos de Pt, servindo como sítios de reação para as espécies de oxigênio encontradas no ar diminuindo, portanto, as quantidades de

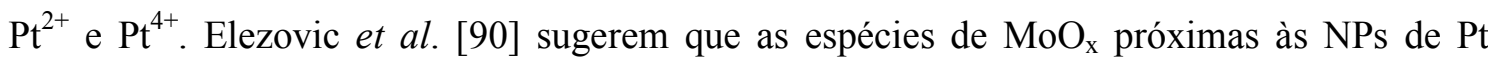
afetam sua natureza eletrônica devido a efeitos sinérgicos gerados pela formação da interface metal/óxido. Pode-se inferir que por consequência, $\mathrm{MoO}_{\mathrm{x}}$ modifica as propriedades catalíticas e quimissortivas da $\mathrm{Pt}$, alterando as forças de adsorção de espécies oxigenadas, o que dificulta a sua oxidação.

A Figura 18 apresenta os espectros XANES dos materiais recém-preparados e comercial obtidos in situ utilizando uma célula eletroquímica apropriada, já descrita na seção 3.3.5, polarizada em 0,5 V (Figura 18(a)) e 0,9 V (Figura 18(b)) vs. ERH na borda $\mathrm{L}_{3}$ da Pt, que corresponde a transição do estado eletrônico $2 p_{3 / 2}-5 d$. A magnitude da "linha branca" localizada em 11564 eV (inserto da Figura 18) determina o grau de ocupação do nível eletrônico $5 d$, conforme o princípio de Pauli [118]. O perfil apresentado para os catalisadores polarizados em $0,5 \mathrm{~V}$ mostra que houve um leve aumento nas magnitudes da "linha branca" para $\mathrm{Pt} / \mathrm{MoO}_{3}-\mathrm{C}$ e $\mathrm{Pt} / \mathrm{MoO}_{2}-\mathrm{C}$ em relação à $\mathrm{Pt} / \mathrm{C}$. De acordo com Lopes [119], a ocorrência dessa mudança na magnitude comparada à $\mathrm{Pt} / \mathrm{C}$ pode ser associada às interações entre NPs de $\mathrm{Pt}$ e $\mathrm{MoO}_{\mathrm{x}}$. O aumento da magnitude da "linha branca" é atribuído ao aumento da vacância do nível eletrônico $5 d$ da Pt [120,121]. Isto se deve ao estado de oxidação dos átomos de Pt na superfície do catalisador, ou seja, quanto mais espécies oxigenadas (inclusive de Mo) estão presentes na superfície da $\mathrm{Pt}$, maior será a vacância do nível $5 d$, pois os átomos eletronegativos de oxigênio deslocam a densidade eletrônica desta banda da $\mathrm{Pt}$, permitindo que mais elétrons possam 'saltar' do nível $2 p_{3 / 2}$ para o $5 d$. Portanto, esse resultado indica que de fato as espécies de óxido de molibdênio depositadas no carbono em $\mathrm{Pt} / \mathrm{MoO}_{3}-\mathrm{C}$ e $\mathrm{Pt} / \mathrm{MoO}_{2}-\mathrm{C}$ estão muito próximas às NPs de Pt.

Nota-se que a magnitude das "linhas brancas" para todos os catalisadores são idênticas em $0,9 \mathrm{~V}$, evidenciando que os óxidos de Mo presentes nos catalisadores recém-preparados não exercem influência direta no grau de ocupação do nível $5 d$ da Pt. Ou seja, em $0,9 \mathrm{~V}$, região onde a superfície de $\mathrm{Pt}$ encontra-se totalmente oxidada, $\mathrm{MoO}_{2}$ e $\mathrm{MoO}_{3}$ não influenciaram a formação de óxidos na Pt, não exercendo, portanto, influência no estado 
eletrônico da Pt. Como será abordado na seção 4.2.3, a atividade catalítica para cada material frente à RRO é determinada no potencial de $0,9 \mathrm{~V}$. Portanto, a princípio, as possíveis variações de atividade para cada material não possuem relação com a magnitude da vacância da banda $5 d$ da Pt.

Figura 18 - Espectros de XANES in situ dos catalisadores $\mathrm{Pt} / \mathrm{MoO}_{3}-\mathrm{C}$ e $\mathrm{Pt} / \mathrm{MoO}_{2}-\mathrm{C}$ recém-preparados e Pt/C ETEK comercial polarizados em (a) 0,5 V, e (b) 0,9 V vs. ERH, em eletrólito de $0,5 \mathrm{M} \mathrm{de}_{2} \mathrm{SO}_{4}$, a temperatura ambiente e atmosfera de ar.
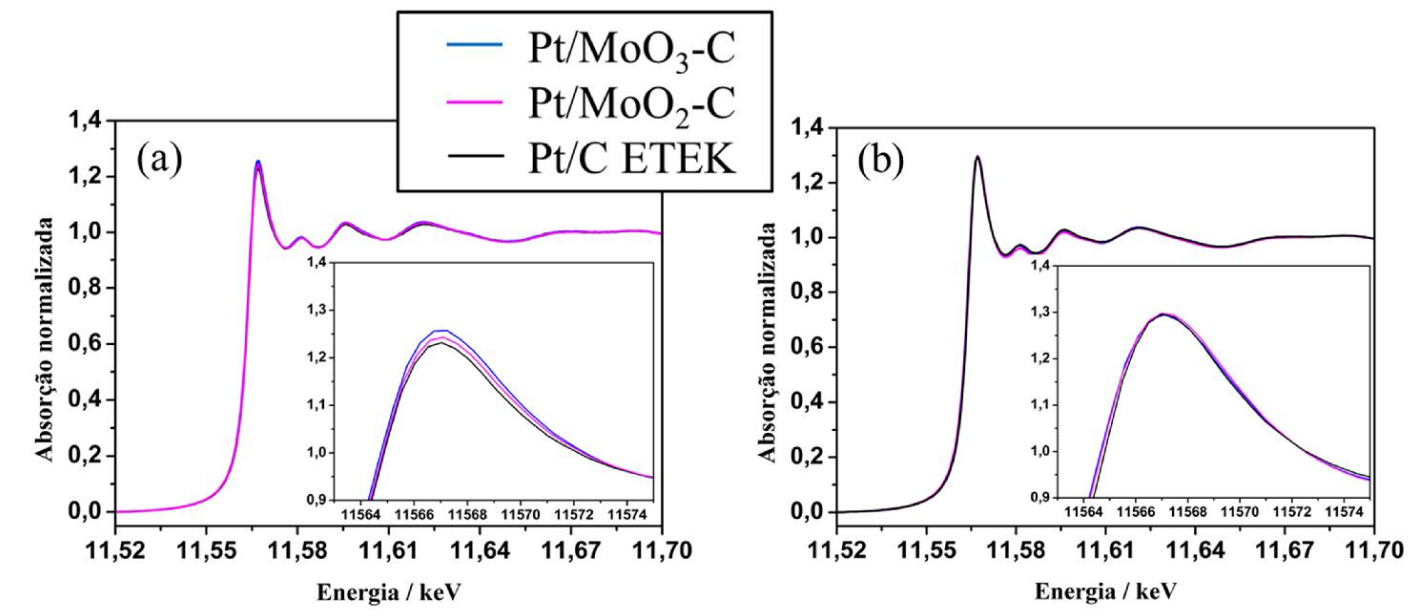

\subsubsection{Caracterização eletroquímica: determinação da área superficial ativa}

A Figura 19 ilustra os voltamogramas obtidos para os eletrocatalisadores $\mathrm{Pt} / \mathrm{MoO}_{3}-\mathrm{C}$, $\mathrm{Pt} / \mathrm{MoO}_{2}-\mathrm{C}$ recém-preparados e para Pt/C ETEK. Para todos os catalisadores é possível notar claramente os picos referentes aos processos de adsorção-dessorção de hidrogênio na superfície da Pt, que encontram-se na região entre $0,05-0,40 \mathrm{~V}$ chamada de região de $\mathrm{H}_{\text {upd }}$ (região I), seguidos pela região da dupla-camada elétrica entre $0,40-\sim 0,80 \mathrm{~V}$ (região II), e por fim os picos referentes aos processos de formação e redução de óxidos $\left(\mathrm{Pt}-\mathrm{OH}_{\mathrm{ads}}\right)$ que encontram-se entre $\sim 0,80-1,2 \mathrm{~V}$ (região III). A simetria das correntes anódica e catódica na região da dupla-camada (melhor visualizada no início da região II), observada traçando-se uma reta passando pelo zero de corrente, indica a ausência de moléculas de $\mathrm{O}_{2}$ no eletrólito, fator essencial para obter o perfil típico de platina. A área ativa de cada eletrodo foi calculada integrando a área superior da região de $\mathrm{H}_{\text {upd }}$ (processo de dessorção do $\mathrm{Pt}-\mathrm{H}_{\mathrm{ads}}$ ), considerando 
que a relação entre a quantidades de hidrogênio adsorvido e de átomos de Pt é sempre 1:1, e que o valor da carga de hidrogênio adsorvido é $210 \mu \mathrm{C} \mathrm{cm}^{-2}$, que corresponde a uma medida da carga de uma monocamada de hidrogênio adsorvida sobre a superfície de platina policristalina [96].

Figura 19 - Voltametrias cíclicas dos catalisadores $\mathrm{Pt} / \mathrm{MoO}_{3}-\mathrm{C}, \mathrm{Pt} / \mathrm{MoO}_{2}-\mathrm{C}$ recém-preparados e $\mathrm{Pt} / \mathrm{C}$

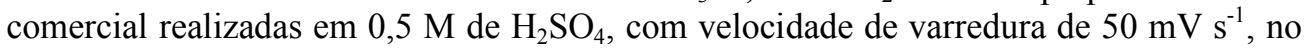
intervalo de $0,05-1,2 \mathrm{~V}$ vs. ERH, em atmosfera inerte de Ar e a temperatura ambiente de $\sim 25^{\circ} \mathrm{C}$.

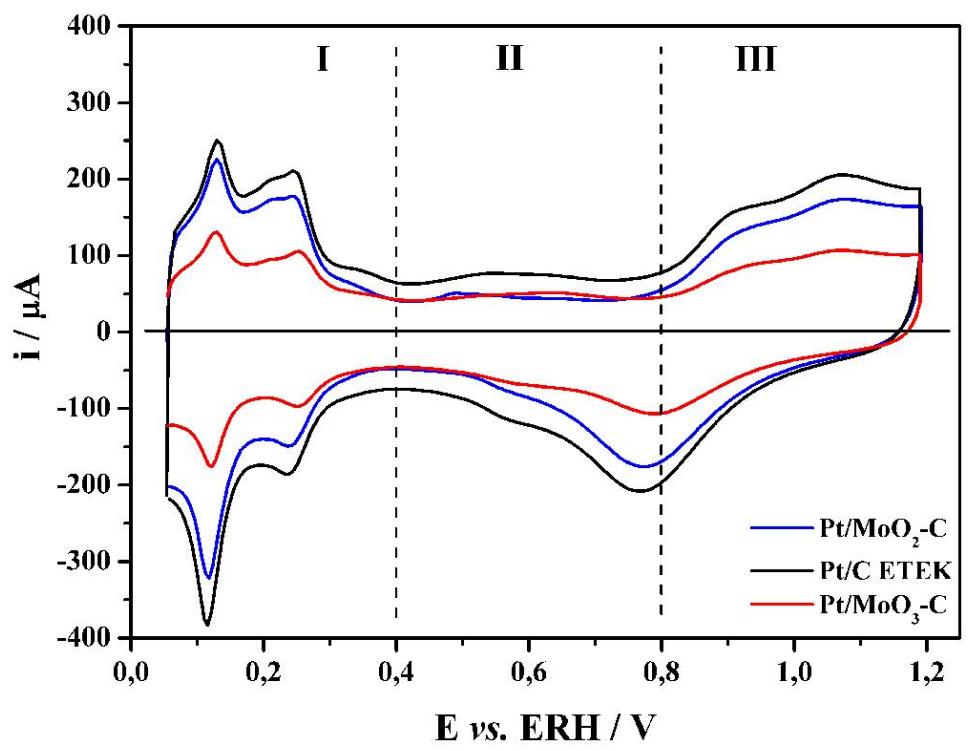

A determinação da linha de base para o cálculo da área ativa por $\mathrm{H}_{\text {upd }}$ foi feita por um método de adsorção de $\mathrm{CO}$, com o intuito de bloquear o processo de formação destas espécies. Para isto, os eletrodos foram polarizados a $50 \mathrm{mV}$ por um certo período de tempo para a formação de uma monocamada de $\mathrm{CO}$ adsorvido $\left(\mathrm{CO}_{\mathrm{ads}}\right)$ na superfície de platina, seguida de uma varredura linear para a oxidação do $\mathrm{CO}_{\mathrm{ads}}$, $\mathrm{CO}$-stripping (este procedimento encontra-se descrito na seção 3.4). Desse modo, garante-se que todos os sítios ativos de platina estejam inicialmente com $\mathrm{CO}_{\mathrm{ads}}$. Analisando as curvas da Figura 20 observa-se que no primeiro ciclo (CO-stripping) não há a presença dos picos típicos de $\mathrm{H}_{\text {upd }}$, sendo as pequenas correntes observadas nessa região atribuídas à carga/descarga da dupla-camada do carbono. Em seguida, após a oxidação de todas as espécies de $\mathrm{CO}_{\mathrm{ads}}$, o segundo ciclo é idêntico ao perfil típico de NPs de Pt suportadas em carbono (Figura 19). Portanto, utilizando a região superior de $\mathrm{H}_{\text {upd }}$ nesses dois ciclos, sendo o primeiro correspondente à linha de base, 
determina-se a área ativa do eletrodo [97]. Este método foi utilizado para determinação da área ativa em todos os catalisadores, sendo a Figura 20 inserida para fins de ilustração do método. Outra maneira também bastante utilizada para a determinação da área eletroativa de Pt é baseada no cálculo da área correspondente ao pico do processo de oxidação da monocamada de CO (CO-stripping) utilizando o segundo ciclo como linha de base [97], também apresentado na Figura 20. Neste método deve-se considerar que a carga necessária para oxidar uma monocamada completa de $\mathrm{CO}$ é de $420 \mu \mathrm{C} \mathrm{cm}{ }^{-2}$. Os resultados obtidos são apresentados na Tabela 8. A diferença na magnitude das áreas ativas obtidas por $\mathrm{H}_{\text {upd }}$ e COstripping pode estar atribuídas a possíveis defeitos nas nanoestruturas de $\mathrm{Pt}$, de modo que a adsorção do CO ocorra por dois sítios, levando a uma diminuição do valor de área calculado. Portanto, visto que o método de cálculo de área por $\mathrm{H}_{\text {upd }}$ leva a valores mais certos da quantidade de sítios ativos de Pt, o mesmo foi considerado para a determinação da atividade específica de Pt neste trabalho.

Figura 20 - Voltametria cíclica de oxidação de CO adsorvido na superfície da platina no catalisador $\mathrm{Pt} / \mathrm{MoO}_{2}-\mathrm{C}$ seguida pelo segundo ciclo onde nota-se o perfil voltamétrico típico de NPs

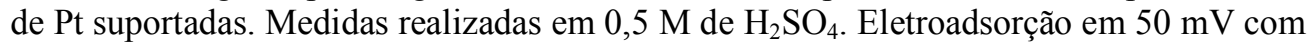
$\mathrm{CO}$ (em atmosfera de $\mathrm{CO}$ ) por $10 \mathrm{~min}$ seguido pela saturação da atmosfera por Ar por $30 \mathrm{~min}$, e por fim a varredura de potencial com velocidade de varredura de $50 \mathrm{mV} \mathrm{s}^{-1}$, no intervalo de $0,05-1,2 \mathrm{~V} v s$. ERH e a temperatura ambiente de $\sim 25^{\circ} \mathrm{C}$.

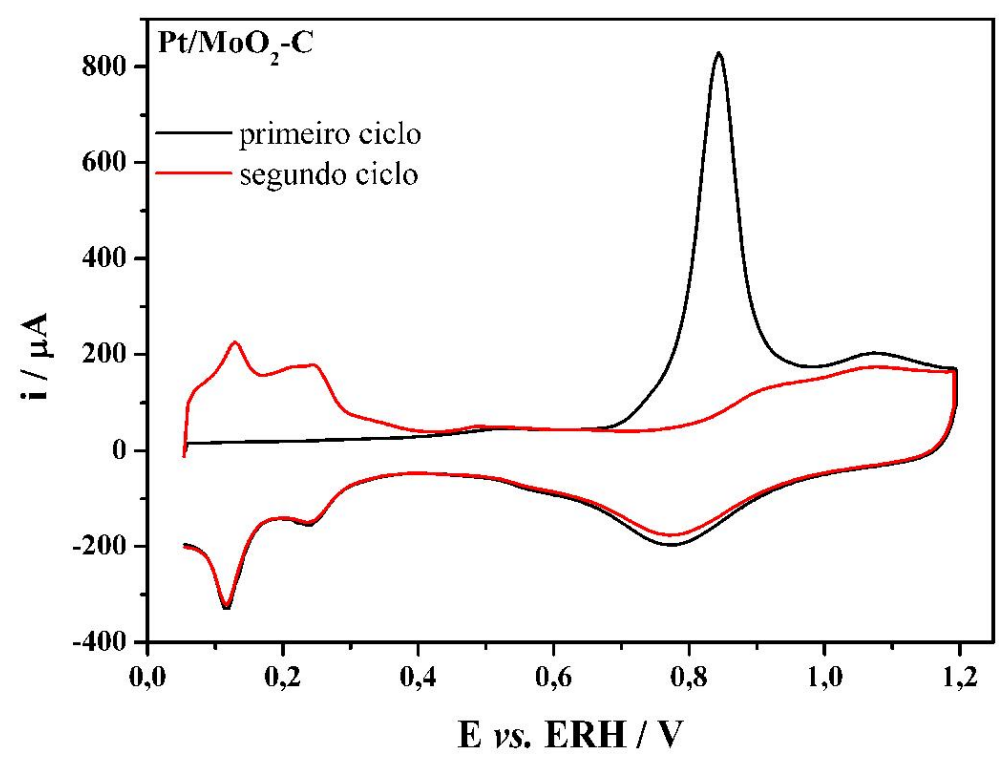


Tabela 8 - Carga mássica de Pt e área eletroquimicamente ativa para os eletrodos $\mathrm{Pt} / \mathrm{MoO}_{3}-\mathrm{C}$, $\mathrm{Pt} / \mathrm{MoO}_{2}-\mathrm{C}$ recém-preparados e $\mathrm{Pt} / \mathrm{C}$ comercial determinadas pelos métodos $\mathrm{H}_{\text {upd }}$ e COstripping

\begin{tabular}{|c|c|c|c|}
\hline Eletrocatalisadores & $\begin{array}{c}\text { Carga mássica de Pt / } \\
{\mu g_{P t}} \mathrm{~cm}^{-2}\end{array}$ & $\begin{array}{c}\text { Área ativa do } \\
\text { eletrodo por } \mathbf{H}_{\mathrm{upd}} / \\
\mathrm{cm}_{\mathrm{Pt}}^{2}\end{array}$ & $\begin{array}{c}\text { Área ativa do } \\
\text { eletrodo por } \mathrm{CO}_{\mathrm{ads}} \\
/ / \mathrm{cm}_{\mathrm{Pt}}{ }^{2}\end{array}$ \\
\hline $\mathrm{Pt} / \mathrm{MoO}_{3}-\mathrm{C}$ & 29 & 1,72 & 1,45 \\
\hline $\mathrm{Pt} / \mathrm{MoO}_{2}-\mathrm{C}$ & 27 & 3,49 & 3,11 \\
\hline Pt/C ETEK ${ }^{\circledR}$ & 32 & 3,77 & 3,49 \\
\hline
\end{tabular}

De acordo com os dados apresentados na Tabela 8 , observa-se que $\mathrm{Pt} / \mathrm{MoO}_{2}-\mathrm{C}$ e $\mathrm{Pt} / \mathrm{C}$ ETEK possuem área ativas de Pt bastante próximas, e a pequena diferença pode ser atribuída a também ligeira diferença nas cargas mássicas aplicadas em cada eletrodo (Tabela 8). O catalisador $\mathrm{Pt} / \mathrm{MoO}_{3}-\mathrm{C}$ apresentou uma área ativa de $\mathrm{Pt}$ muito mais baixa comparada às demais, cerca de 51\% menor. Essa pronunciada diferença pode ser atribuída às características semicondutoras do $\mathrm{MoO}_{3}$ utilizado como suporte [122,123]. As NPs de Pt que foram impregnadas na região onde somente há espécies de $\mathrm{MoO}_{3}$ podem ter sido isoladas eletricamente do circuito externo da célula. No caso do $\mathrm{Pt} / \mathrm{MoO}_{2}-\mathrm{C}$, as espécies $\mathrm{MoO}_{2}$ são óxidos condutores e, portanto, tal efeito não é observado [123-125].

\subsubsection{Caracterização eletroquímica: atividade frente à reação de redução de oxigênio (RRO)}

A Figura 21(a) ilustra o fenômeno de histerese que ocorre entre as curvas de polarização do eletrodo de $\mathrm{Pt} / \mathrm{MoO}_{2}-\mathrm{C}$ frente à $\mathrm{RRO}$, nos sentidos de varredura catódico e anódico $[30,96,126]$. Este efeito de histerese pode ser explicado considerando-se que a superfície da Pt está inicialmente recoberta por $\mathrm{OH}_{\mathrm{ads}}$ nos estágios iniciais da polarização no sentido catódico, porém encontra-se na forma reduzida $\left(\mathrm{Pt}^{0}\right)$ após a reversão do sentido de polarização (sentido anódico), sendo a forma reduzida mais ativa frente à RRO, conforme já é amplamente conhecido [30]. 
Figura 21 - Curvas de polarização para a RRO obtida potenciodinamicamente sobre o catalisador $\mathrm{Pt} / \mathrm{MoO}_{2}-\mathrm{C}$ em solução $0,5 \mathrm{M} \mathrm{H}_{2} \mathrm{SO}_{4}$, com atmosfera saturada com gás $\mathrm{O}_{2}$, a uma velocidade de varredura de $5 \mathrm{mV} \mathrm{s}^{-1}$ e à temperatura ambiente de $\sim 25^{\circ} \mathrm{C}$. (a) efeito de histerese na RRO, e (b) curvas em diferentes velocidades de rotação. As correntes foram normalizadas pela área geométrica do eletrodo, $0,196 \mathrm{~cm}^{2}$.

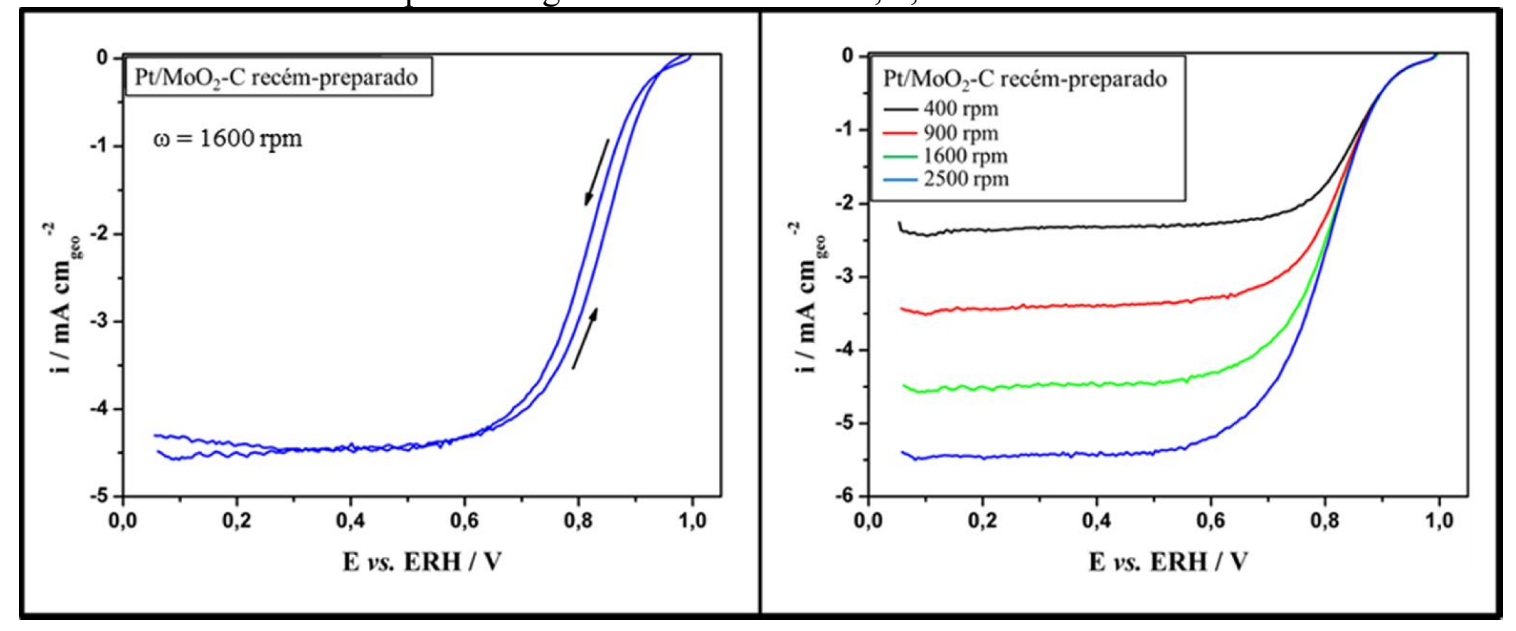

Observa-se (Figura 21 (a)) que as curvas de polarização registradas apresentam um patamar de densidade de corrente limite difusional bem definido e independente do sentido de varredura; devido a este fato, somado ao fato de que quando a célula eletrolítica está saturada de $\mathrm{O}_{2}$, o potencial do circuito aberto $(\sim 1 \mathrm{~V})$ é suficiente para promover a formação de espécies $\mathrm{Pt}-\mathrm{OH}_{\mathrm{ads}}$ na superfície do eletrodo, somente os resultados obtidos durante a varredura catódica foram utilizados para análises ao longo deste trabalho.

A Figura 21(b) mostra as curvas de polarização para a RRO obtidas para o eletrodo de $\mathrm{Pt} / \mathrm{MoO}_{2}-\mathrm{C}$ recém-preparado em diversas velocidades de rotação, onde pode ser visto que, como esperado, há um aumento da corrente limite difusional com o aumento da velocidade de rotação do eletrodo [27]. Todos os catalisadores apresentaram o mesmo perfil, portanto, os dados foram omitidos. As respostas das curvas de polarização para a RRO conforme ilustradas na Figura 21(b) podem ser divididas em três regiões. Na região entre 0,05-0,6 V a RRO é governada pelo transporte de massa, de forma que a chegada de $\mathrm{O}_{2}$ se torna o fator limitante de velocidade. Na região entre $0,9-1,0 \mathrm{~V}$, a RRO atua sob controle de transferência de carga, onde o fator limitante é a transferência dos elétrons do eletrodo para as espécies oxigenadas geradas pela adsorção do oxigênio. Por fim, na região entre $0,6-0,9 \mathrm{~V}$, a RRO ocorre sob controle cinético misto, onde tanto a transferência de carga quanto o transporte de massa influenciam diretamente na velocidade da reação. Analisando a Figura 21, nota-se que 
a RRO têm início em $\sim 0,95 \mathrm{~V}$, ou seja, em um elevado sobrepotencial (cerca de $280 \mathrm{mV}$ em relação ao potencial padrão termodinâmico para a RRO em meio ácido, $E^{0}=1,23 \mathrm{~V}$ ), corroborando com a sua complicada e lenta cinética de reação [34,127-129]. É importante ressaltar que os suportes $\mathrm{MoO}_{3}-\mathrm{C}$ e $\mathrm{MoO}_{2}-\mathrm{C}$ recém preparados foram testados frente à $\mathrm{RRO}$ e não apresentaram atividade catalítica no domínio de potencial abrangido na Figura 21.

As curvas de polarização para a RRO obtidas em várias velocidades de rotação, como exemplificadas na Figura 21(b), foram utilizadas para construção do gráfico de Levich, o qual permite determinar o número de elétrons envolvidos na reação de redução de oxigênio em cada catalisador $[27,130,131]$. Os gráficos de Levich para os catalisadores recém-preparados e o comercial estão apresentados na Figura 22.

Figura 22 - Curvas de Levich para a RRO nos catalisadores $\mathrm{Pt} / \mathrm{MoO}_{2}-\mathrm{C}, \mathrm{Pt} / \mathrm{MoO} 3-\mathrm{C}$ recémpreparados e $\mathrm{Pt} / \mathrm{C}$ comercial. As curvas de RRO foram obtidas em solução $0,5 \mathrm{M} \mathrm{H}_{2} \mathrm{SO}_{4}$, com atmosfera saturada com gás $\mathrm{O}_{2}$, a uma velocidade de varredura de $5 \mathrm{mV} \mathrm{s}^{-1}$, em diversas velocidades de rotação e à temperatura ambiente de $\sim 25^{\circ} \mathrm{C}$.

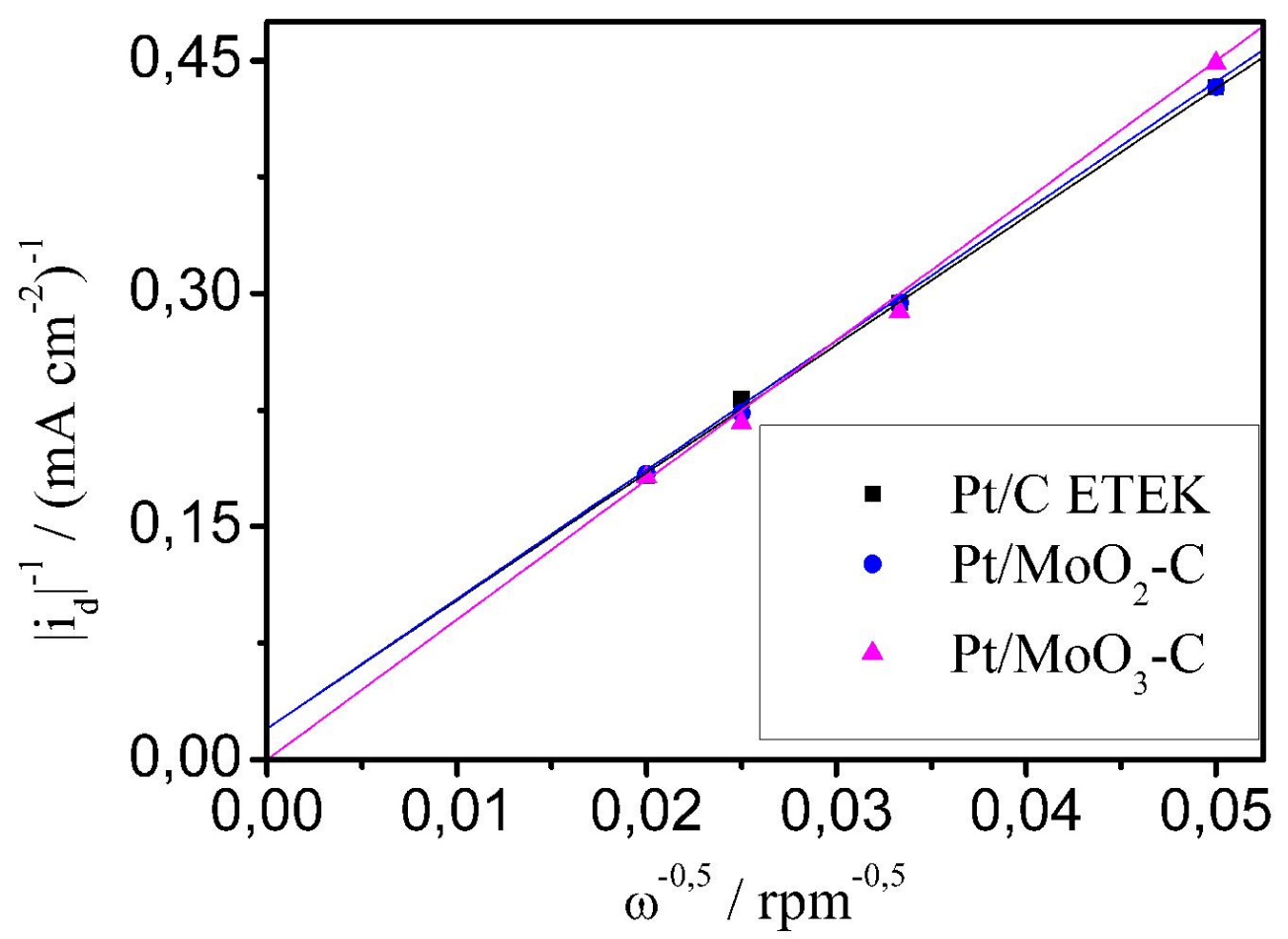

Analisando a Figura 22 nota-se que as curvas de Levich apresentam alta linearidade, o que confirma que a difusão de oxigênio é a etapa determinante da velocidade da RRO em elevados sobrepotenciais. Para uma reação de primeira ordem com relação à concentração das 
espécies reagentes, a densidade de corrente limite difusional observada em um eletrodo de disco rotatório pode ser expressa pela equação de Levich [132]:

$\mathrm{i}_{\mathrm{d}}=\mathrm{B} \omega^{0,5} \quad$ (Equação 4.1)

$\mathrm{B}=0,20 \mathrm{nFD}{ }^{(2 / 3)} v^{(-1 / 6)} \mathrm{C}^{0} \quad$ (Equação 4.2)

onde $i_{d}$ é a densidade de corrente limite difusional $\left(\mathrm{mA} \mathrm{cm}^{-2}\right)$, B é o coeficiente de Levich $\left(\mathrm{mA} \mathrm{cm} \mathrm{rpm}^{-1 / 2}\right), \omega$ é a velocidade angular (rpm), n é o número de elétrons envolvidos por molécula de espécie reagente $\left(\mathrm{mol}^{-1}\right)$, F é a constante de Faraday $\left(\mathrm{C} \mathrm{mol}^{-1}\right)$, D é o coeficiente de difusão da espécie reagente $\left(\mathrm{cm}^{2} \mathrm{~s}^{-1}\right), v$ é a viscosidade cinemática do meio $\left(\mathrm{cm}^{2} \mathrm{~s}^{-1}\right)$ e $\mathrm{C}^{0}$ é a concentração da espécie reagente no seio da solução $\left(\mathrm{mol} \mathrm{cm}^{-3}\right)$.

A partir dos valores dos coeficientes angulares (B) obtidos das curvas de Levich (Figura 22), e conhecendo-se os valores de $\mathrm{F}=96485 \mathrm{C} \mathrm{mol}^{-1}, \mathrm{D}=1,410^{-5} \mathrm{~cm}^{2} \mathrm{~s}^{-1}, v=110^{-2}$ $\mathrm{cm}^{2} \mathrm{~s}^{-1}$ e $\mathrm{C}^{0}=1,110^{-6} \mathrm{~mol} \mathrm{~cm}^{-3}$, foi calculado o número de elétrons envolvidos na RRO para cada eletrocatalisador [133]. Os resultados obtidos são incluídos na Tabela 9. Estes resultados indicam valores de $\mathrm{n}$ próximos de 4 , dentro dos erros experimentais, mostrando que a RRO segue o mecanismo de 4 elétrons em todos os eletrocatalisadores.

Tabela 9 - Número de elétrons envolvidos, densidades de correntes cinéticas obtidas em potencial de $0,9 \mathrm{~V}$ e coeficientes de Tafel $\mathrm{b}_{1}$ e $\mathrm{b}_{2}$ obtidos para a RRO nos eletrodos $\mathrm{Pt} / \mathrm{MoO}_{3}-\mathrm{C}$, $\mathrm{Pt} / \mathrm{MoO}_{2}-\mathrm{C}$ recém-preparados e $\mathrm{Pt} / \mathrm{C}$ comercial.

\begin{tabular}{c|c|c|c|c}
\hline Eletrocatalisadores & $\mathbf{n}_{\text {elétrons }}$ & $\begin{array}{c}\mathbf{i}_{\mathbf{0}, \mathbf{9} \mathbf{v}} / \mathbf{m A} \\
\mathbf{c m}_{\mathbf{P t}}^{-\mathbf{2}}\end{array}$ & $\mathbf{b}_{\mathbf{1}} / \mathbf{m V} \mathbf{d e c}^{-\mathbf{1}}$ & $\mathbf{b}_{\mathbf{2}} / \mathbf{m V} \mathbf{d e c}^{-\mathbf{1}}$ \\
\hline $\mathbf{P t} / \mathbf{M o O}_{\mathbf{3}}-\mathbf{C}$ & 4,10 & 49,0 & 87 & 120 \\
\hline $\mathbf{P t} / \mathbf{M o O}_{\mathbf{2}}-\mathbf{C}$ & 3,93 & 29,5 & 87 & 120 \\
\hline $\mathbf{P t} / \mathbf{C} \mathbf{E T E K}^{\circledR}$ & 3,98 & 33,1 & 87 & 120 \\
\hline
\end{tabular}


Figura 23 - Diagrama de Tafel dos eletrocatalisadores $\mathrm{Pt} / \mathrm{MoO}_{2}-\mathrm{C}$, Pt/MoO3-C recém-preparados e $\mathrm{Pt} / \mathrm{C}$ comercial corrigidos por transporte de massa e as correntes normalizadas pela área

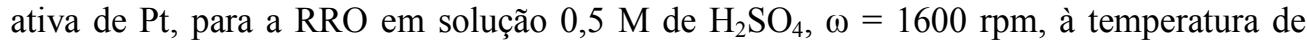
$25^{\circ} \mathrm{C}$.

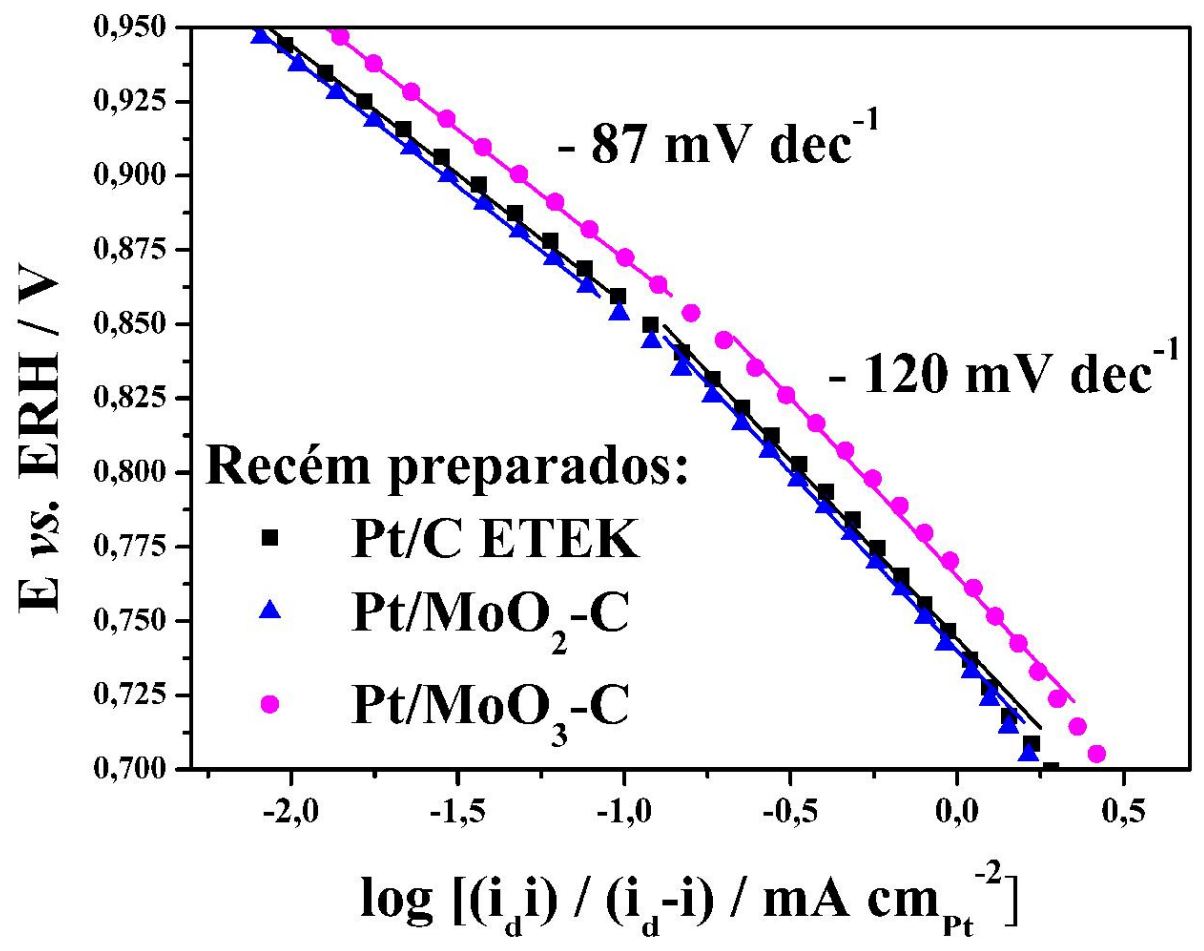

A análise cinética e mecanística da RRO foi realizada por meio de diagramas de Tafel obtidos após a correção por transporte de massa [97] das correntes medidas experimentalmente. Para realizar esta correção foram considerados os conceitos descritos a seguir. A equação de Butler-Volmer [132,134] apresenta a relação entre a corrente e o potencial para uma reação de transferência de carga mono-eletrônica em um eletrodo (Equação 4.3).

$i=i_{0}\left[e^{-\alpha f \eta}-e^{(1-\alpha) f \eta}\right] \quad$ (Equação 4.3)

onde $i_{0}$ é a densidade de corrente de troca, $\eta$ é o sobrepotencial, $f$ é a constante F/RT e $\alpha$ é o coeficiente de simetria. Considerando que para elevados sobrepotenciais $(\eta)$ negativos, onde de fato ocorre a RRO, o termo $e^{-\alpha f \eta}>>e^{(1-\alpha) f \eta}$, e a Equação 4.3 pode ser simplificada, resultando na Equação 4.4.

$i=i_{0} e^{-\alpha f \eta} \quad$ (Equação 4.4) 
que aplicando-se o logaritmo, torna-se:

$\eta=\frac{2,3 R T}{\alpha F} \log i_{0}-\frac{2,3 R T}{\alpha F} \log i \quad$ (Equação 4.5)

A Equação 4.5 é conhecida como equação de Tafel, e o termo $(2,3 R T / \alpha F)$ como coeficiente de Tafel (b).

A aproximação realizada acima é válida somente para as regiões que apresentam densidades de correntes pouco elevadas, onde a corrente do sistema reacional é controlada pela cinética da reação eletródica (chamada de corrente cinética). Entretanto, como já foi dito mais acima, a RRO apresenta três regiões que são governadas por controle de transferência de carga (controle cinético), por transporte de massa ou por controle cinético misto, onde tanto a transferência de carga quanto o transporte de massa influenciam na velocidade de reação. Assim, para que a Equação 4.5 seja passível de aplicação para a RRO na região de controle cinético misto, foi necessária a correção da corrente para se compensar o efeito difusional (transporte de massa). Segundo a literatura [97,132], tal correção pode ser expressa como apresentada na Equação 4.6.

$i_{k}=\left(\frac{i_{d} \times i}{i_{d}-i}\right) \quad$ (Equação 4.6)

onde $i_{d}$ é a corrente limite difusional, $i$ a corrente obtida diretamente das curvas de polarização e $i_{k}$ a corrente cinética. Portanto, a equação de Tafel corrigida por transporte de massa assume a forma apresentada pela Equação 4.7, da qual foram obtidos os diagramas de Tafel de E vs. $\log i_{k}$ (Figura 23).

$\eta=\frac{2,3 R T}{\alpha F} \log i_{0}-\frac{2,3 R T}{\alpha F} \log \left(\frac{i_{d} \times i}{i_{d}-i}\right) \quad$ (Equação 4.7)

A Figura 23 apresenta os diagramas de Tafel referentes à RRO sobre os diversos catalisadores. Pode-se notar a presença de duas regiões lineares nas curvas de Tafel (Figura 23), com coeficientes angulares $b_{1}$ e $b_{2}$ (coeficientes de Tafel) que tangenciam os valores de 87 e $120 \mathrm{mV} \mathrm{dec}^{-1}$ para as regiões de baixos e altos sobrepotenciais, respectivamente. Os resultados para todos os catalisadores são reunidos na Tabela 9. Nota-se que os valores de $b_{1} e$ 


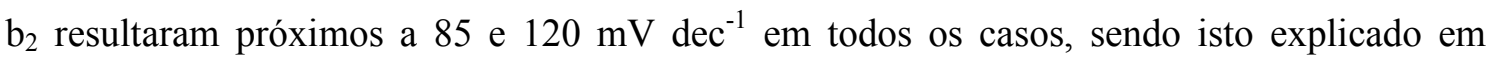
função do grau de recobrimento superficial da Pt por espécies oxigenadas. Sabe-se que na região de baixos sobrepotenciais, uma a inclinação de $\sim 60 \mathrm{mV} \mathrm{dec}{ }^{-1}$ ocorre na região de potenciais onde a superfície eletródica encontra-se recoberta por espécies de oxigênio, e a

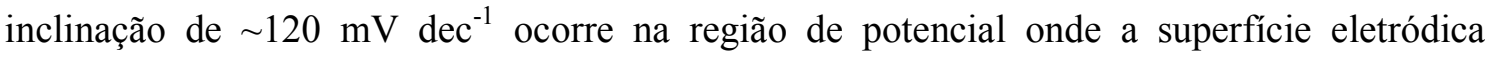
encontra-se livre de oxigênio (região de altos sobrepotenciais). A adsorção de oxigênio em baixos sobrepotenciais segue a isoterma de Temkin (altos recobrimentos) e em altos sobrepotenciais segue a isoterma de Langmuir (baixos recobrimentos) [34,130,135]. O desvio de $\sim 60 \mathrm{mV} \mathrm{dec}^{-1}$ para $85 \mathrm{mV} \mathrm{dec}{ }^{-1}$ observado para todos os catalisadores pode ser atribuído à adsorção de espécies sulfato e bissulfato provenientes do eletrólito utilizado, que compete com as moléculas de oxigênio, dificultando sua adsorção na superfície das NPs de Pt. Como o valor de $\mathrm{b}_{1}$ para a curva de Tafel da $\mathrm{Pt} / \mathrm{C}$ foi também perto de $85 \mathrm{mV} \mathrm{dec}^{-1}$, não se pode atribuir o desvio de $b_{1}$ em termos da influência direta dos óxidos presentes no suporte catalítico. Como mencionado anteriormente, os suportes baseados em óxidos de Mo sintetizados não possuem atividade catalítica alguma frente à RRO. Isto é mais um fator que indica que os óxidos não exercem influência direta no mecanismo e, portanto, na variação na inclinação de $b_{1}$.

A comparação entre as atividades eletrocatalíticas dos diversos materiais foi feita por meio dos valores de atividades específicos obtidos dividindo as correntes experimentais de redução de oxigênio registradas a $0,9 \mathrm{~V}$ pela área ativa de Pt obtida pelo método $\mathrm{H}_{\text {upd }}$ (Tabela 8). Estes resultados são apresentados na Tabela 9, sendo notado que $\mathrm{Pt} / \mathrm{MoO}_{3}-\mathrm{C}$ apresenta-se como o catalisador mais eficiente para redução de oxigênio. Apesar da baixa área eletroativa, atribuída ao isolamento de espécies de Pt por $\mathrm{MoO}_{3}$ (óxido semicondutor), as NPs de Pt que estão próximas a esses óxidos mas não diretamente (particularmente) ligadas neles pode ter tido suas propriedades eletrônicas modificadas, de modo a favorecer a cinética da RRO. Elezović et al. [90,91] atribuem esta melhora nas propriedades catalíticas a efeitos sinérgicos que ocorrem na interface formada por $\mathrm{Pt} / \mathrm{MoO}_{3}$, que facilita a remoção de espécies intermediárias oxigenadas da superfície da Pt. Desse modo a superfície torna-se livre para que outra molécula de oxigênio possa ser adsorvida, aumentando, portanto, a velocidade da reação.

Analisando os resultados obtidos por XPS (Tabela 7), observa-se, como já mencionado, que a incorporação de $\mathrm{MoO}_{\mathrm{x}}$ no suporte catalítico favorece a permanência das espécies de $\mathrm{Pt}$ em seu estado metálico. Esses resultados podem explicar as atividades específicas apresentadas na Tabela 9. Sabe-se que a forma mais ativa de Pt para RRO é sua 
forma metálica $\left(\mathrm{Pt}^{0}\right)$, pois quando as NPs de Pt estão passivadas (superfície recoberta por espécies oxigenadas) elas impedem a aproximação de $\mathrm{O}_{2}$ nos sítios ativos para $\mathrm{RRO}$, diminuindo a velocidade da reação $[128,136]$. Os resultados obtidos por voltametria cíclica (Figura 19) também apontam para a melhora da catálise da RRO pelas NPs de Pt quando impregnadas em suportes baseados em $\mathrm{MoO}_{\mathrm{x}}$. De acordo com a literatura, a posição do pico de redução da Pt é intrinsicamente relacionado com a atividade catalítica frente a RRO $[50,96]$. Um deslocamento do pico de redução da Pt em direção a potenciais mais elevados reflete a diminuição da força de adsorção de espécies $\mathrm{OH}_{\mathrm{ads}}$, as quais inibem a RRO [137]. Desse modo, observa-se pela Figura 19 que o $\mathrm{Pt} / \mathrm{MoO}_{3}-\mathrm{C}$ apresenta o pico de redução de $\mathrm{Pt}$ deslocado positivamente em relação aos demais materiais, explicando o aumento da atividade específica frente a RRO (Tabela 9).

\subsection{Investigação da estabilidade dos eletrocatalisadores $\mathrm{Pt} / \mathrm{MoO}_{3}-\mathrm{C}, \mathrm{Pt} / \mathrm{MoO}_{2}-\mathrm{C}$ e $\mathrm{Pt} / \mathrm{C}$ ETEK $^{\circledR}$}

Os voltamogramas referentes aos materiais antes e após os envelhecimentos eletroquímicos estão apresentados na Figura 24. As respectivas áreas eletroativas estão registradas na Tabela 10. Os materiais foram caracterizados eletroquimicamente em intervalos definidos de ciclagem para melhor entender a velocidade de degradação em função das condições impostas pelo teste de envelhecimento acelerado. Pela Figura 24, observa-se que os primeiros 4500 ciclos são responsáveis por grande parte da perda de área ativa $\left(\mathrm{A}_{\mathrm{Pt}}\right)$ dos materiais (cerca de 30\%), o que pode ser resultado do crescimento das NPs de Pt. Acredita-se que partículas maiores de platina são menos suscetíveis à corrosão, como mencionado na literatura [39]. Isso explica a diminuição da velocidade de degradação das NPs de Pt conforme os eletrodos são ciclados. Após mais 2000 ciclos de um total de 10000 ciclos já realizados, não foi possível observar mais perdas significativas de $A_{P t}$, sugerindo que as partículas podem ter atingido um tamanho que garante maior estabilidade [39]. Apesar da elevada diminuição de $A_{P t}$ observada em todos os materiais, não ocorreram variações significativas na região da dupla camada elétrica, indicando que tal método de degradação é específico para o teste de estabilidade das NPs de Pt. 
Figura 24 - Voltametrias cíclicas a velocidade de $50 \mathrm{mV} \mathrm{s}^{-2}$, em $0,5 \mathrm{M} \mathrm{H}_{2} \mathrm{SO}_{4}$, dos catalisadores $\mathrm{Pt} / \mathrm{MoO}_{3}-\mathrm{C}, \mathrm{Pt} / \mathrm{MoO}_{2}-\mathrm{C}$ e Pt/C ETEK novos e em definidos números de ciclagens do teste de envelhecimento acelerado aplicado.
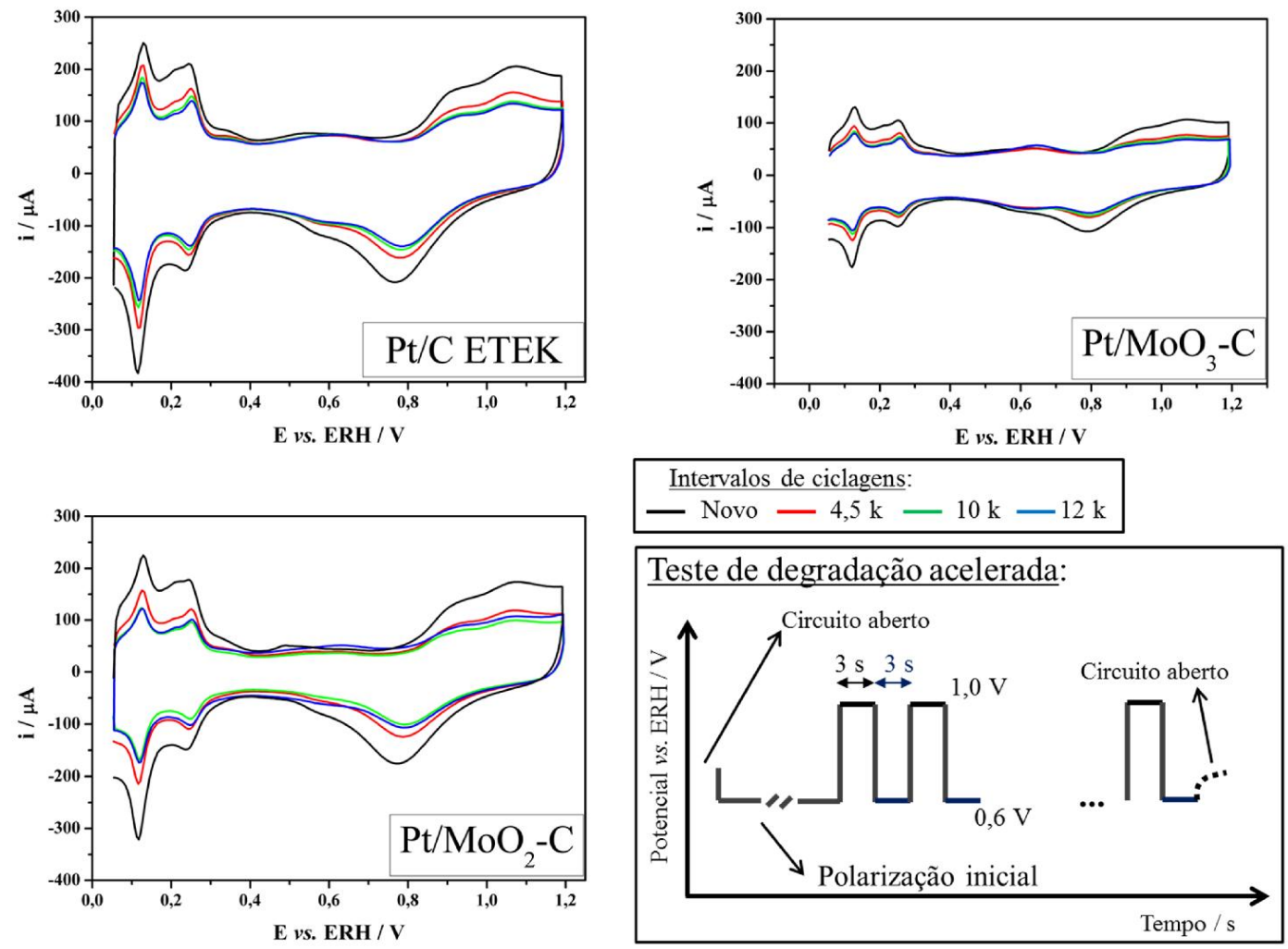

Tabela 10 - Área eletroquimicamente ativa dos eletrodos $\mathrm{Pt} / \mathrm{MoO}_{3}-\mathrm{C}, \mathrm{Pt} / \mathrm{MoO}_{2}-\mathrm{C}$ recém-preparados e $\mathrm{Pt} / \mathrm{C}$ comercial novos e após diversos ciclos de teste de degradação

\begin{tabular}{|c|c|c|c|}
\hline Materiais & Número de ciclos & $\begin{array}{l}\text { Área ativa do } \\
\text { eletrodo / } \mathrm{cm}_{\mathrm{Pt}}{ }^{2}\end{array}$ & $\begin{array}{l}\text { Porcentagem de } \\
\text { perda de área }\end{array}$ \\
\hline \multirow{4}{*}{$\mathrm{Pt} / \mathrm{MoO}_{3}-\mathrm{C}$} & Novo & 1,72 & - \\
\hline & 4500 & 1,06 & 38,4 \\
\hline & 10000 & 0,89 & 48,3 \\
\hline & 12000 & 0,85 & 50,6 \\
\hline \multirow{4}{*}{$\mathrm{Pt} / \mathrm{MoO}_{2}-\mathrm{C}$} & Novo & 3,49 & - \\
\hline & 4500 & 2,17 & 37,8 \\
\hline & 10000 & 1,64 & 53,0 \\
\hline & 12000 & 1,62 & 53,6 \\
\hline \multirow{4}{*}{ Pt/C ETEK ${ }^{\circledR}$} & Novo & 3,77 & - \\
\hline & 4500 & 2,71 & 28,1 \\
\hline & 10000 & 2,34 & 37,9 \\
\hline & 12000 & 2,22 & 41,1 \\
\hline
\end{tabular}


Em eletrodos de $\mathrm{Pt} / \mathrm{C}$ já é conhecido que ocorre dissolução de platina durante variações de potencial [98-100]. De acordo com Ohma et al. [53] a faixa de potencial na qual opera cada célula a combustível no conjunto de células ('stack') que forma o sistema operacional é de aproximadamente 0,6 a 1,0 vs. ERH, nos protótipos de veículos elétricos, sendo que o primeiro potencial se refere ao máximo desempenho da célula (carga máxima de operação) e o último ao potencial de circuito aberto que se verifica durante a interrupção da operação. Sabe-se que em potencial de $0,6 \mathrm{~V}$ a superfície de platina está completamente livre de óxidos $\left(\mathrm{Pt}^{0}\right)$ e que em $1,0 \mathrm{~V}$ a mesma se encontra na forma de $\mathrm{Pt}-\mathrm{OH}_{\mathrm{ads}}$, por exemplo. Quando as espécies oxigenadas recobrem a superfície de platina, sua dissolução é suprimida devido a essa camada protetora de óxidos. De acordo com a literatura, a dissolução de platina ocorre majoritariamente em $\mathrm{Pt}^{0}[138,139]$. Portanto, o teste de degradação utilizado, onde se varia rapidamente o potencial entre 0,6 e 1,0 V (salto potenciostático), faz com que as NPs de Pt levem um pouco de tempo para se oxidarem em 1,0 V, deixando-as expostas e, assim, aumentando a taxa de dissolução. Desta forma, quando $\mathrm{Pt}^{0}$ é exposta subitamente a um elevado potencial, ela pode ser mais facilmente dissolvida até que a camada de óxido seja novamente formada $[138,139]$. Desse modo, o teste de degradação empregado acelera o processo de dissolução das NPs de Pt, permitindo correlaciona-lo com os efeitos de longo prazo nos eletrodos das células a combustível operando em condições normais.

As micrografias obtidas por TEM para cada material novo e após 12000 ciclos no regime do teste de degradação mencionado encontram-se na Figura 25, enquanto os seus respectivos histogramas globais estão na Figura 26. As micrografias dos catalisadores novos já foram abordadas na seção 4.2.1 e foram aqui repetidas para facilitar as comparações. As micrografias dos catalisadores $\mathrm{Pt} / \mathrm{C}$ e $\mathrm{Pt} / \mathrm{MoO}_{3}-\mathrm{C}$ após o extenso ciclo de degradação (12000 ciclos) mostram a formação de partículas de platina com maior grau de cristalinidade, refletindo a esperada aglomeração das NPs, inicialmente com formato arredondado. $\mathrm{O}$ catalisador $\mathrm{Pt} / \mathrm{MoO}_{2}-\mathrm{C}$ também teve suas partículas de platina aumentadas, porém em menor extensão que os demais. Todos os catalisadores apresentaram perdas de carga de Pt após o envelhecimento. Apesar de não ter sido possível realizar medidas de EDX após as ciclagens, as micrografias mostram qualitativamente a diminuição da quantidade de NPs de Pt por área do material. Isto reflete prováveis decréscimos na proporção mássica de Pt no eletrodo e, consequentemente, na diminuição do valor de área eletroativa (Tabela 10). Portanto, nenhum dos óxidos de molibdênio, a princípio, diminui a extensão da degradação da platina. 
Figura 25 - Micrografias de cada eletrocatalisador novo e após 12000 ciclos de 0,6 - 1,0 V em $0,5 \mathrm{M} \mathrm{H}_{2} \mathrm{SO}_{4}$, atmosfera de ar e temperatura de $25^{\circ} \mathrm{C}$. Micrografias obtidas por TEM.

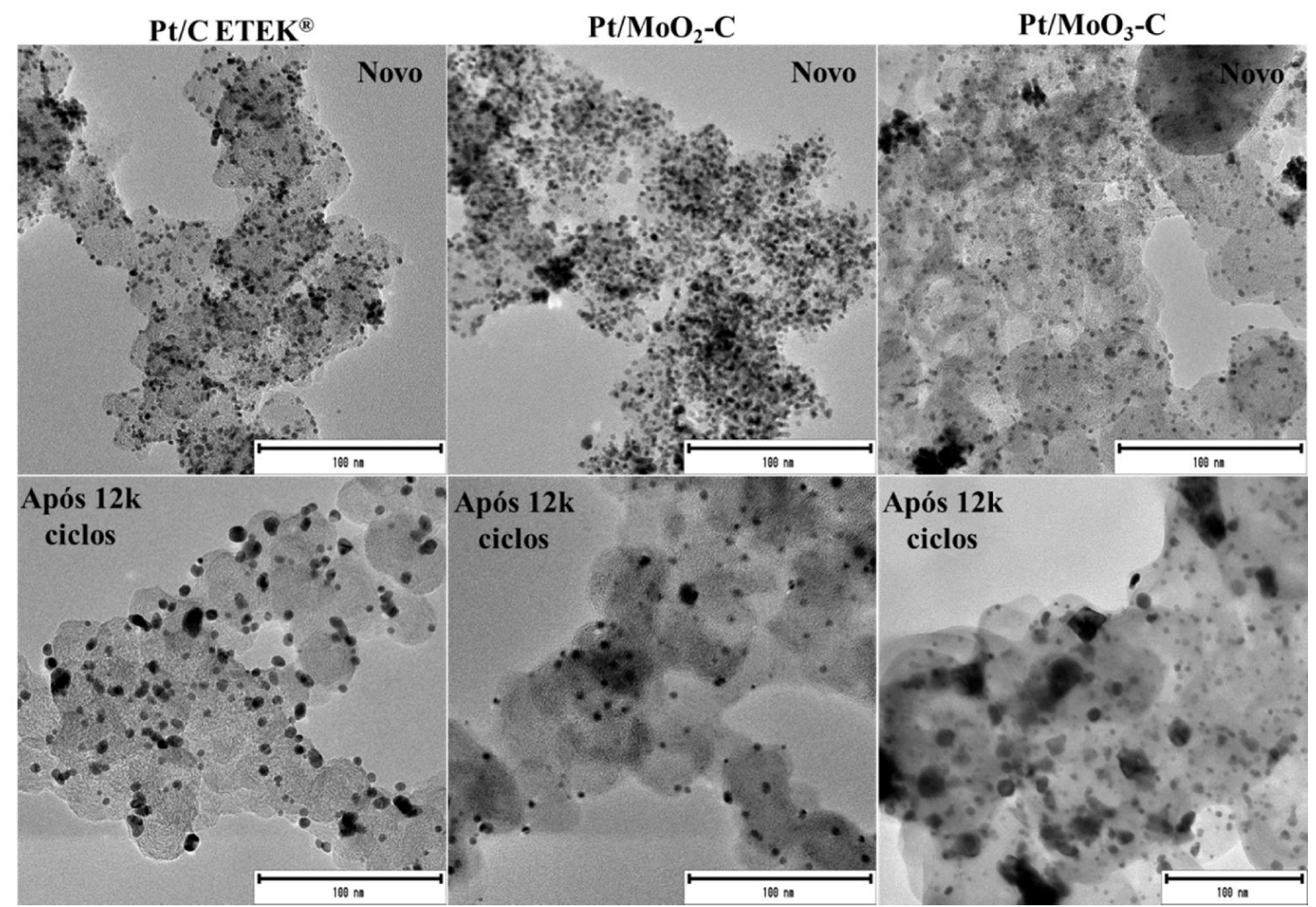

Figura 26 - Histogramas globais para cada eletrocatalisador novo e após 12000 ciclos. Os insertos presentes são histogramas referentes à esfericidade das NPs de Pt presentes em cada catalisador.

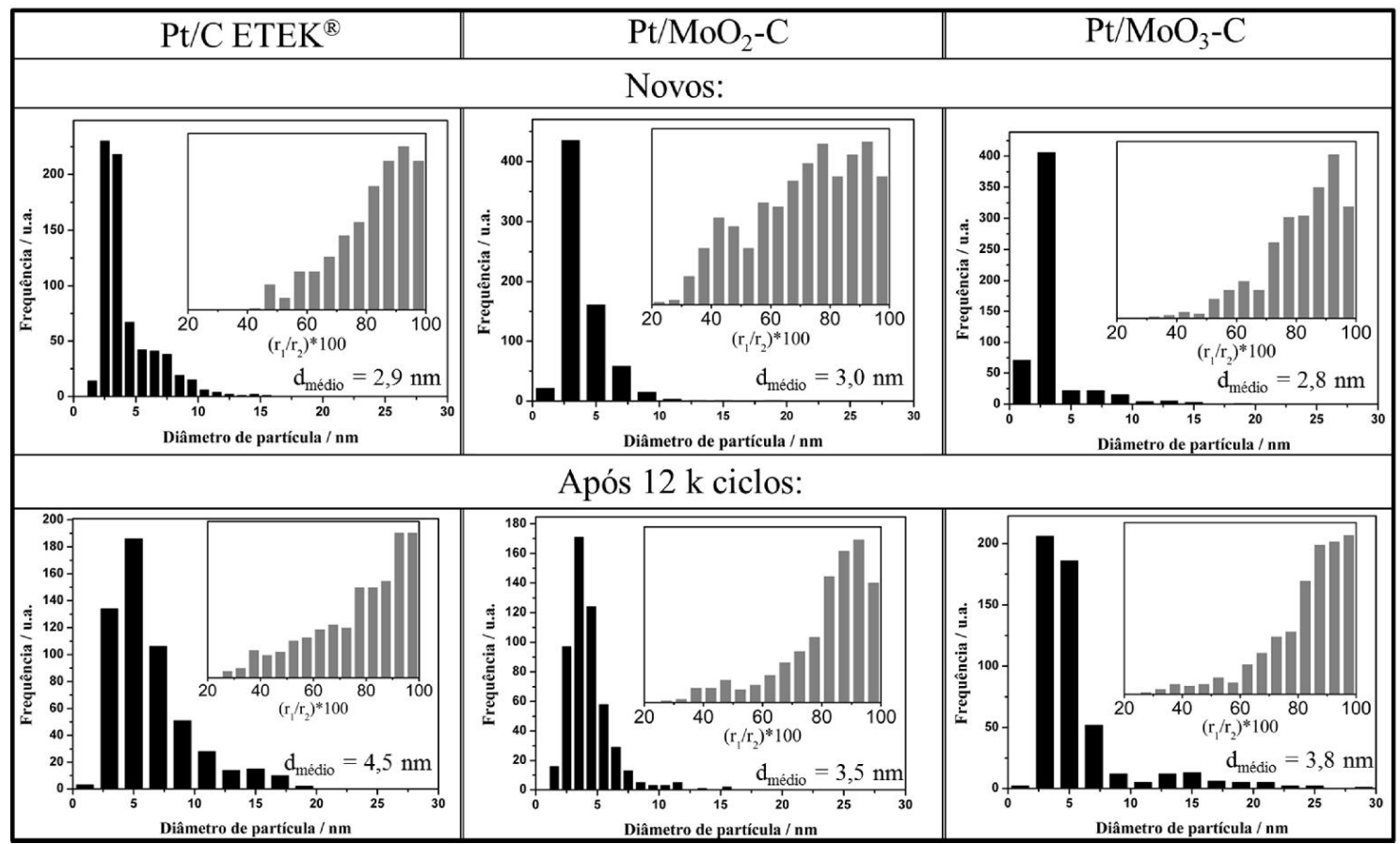


Analisando os histogramas da Figura 26 observa-se que inicialmente $\mathrm{Pt} / \mathrm{MoO}_{2}-\mathrm{C}$ e $\mathrm{Pt} / \mathrm{MoO}_{3}-\mathrm{C}$ possuem distribuição de tamanhos de partículas homogênea em uma pequena faixa de tamanho, apesar de alguns aglomerados terem sido observados. $\mathrm{O}$ catalisador $\mathrm{Pt} / \mathrm{C}$ também possui certa homogeneidade, porém a distribuição possui uma faixa maior de tamanhos. Após os 12000 ciclos, observa-se um claro aumento na faixa de tamanhos de partículas em todos os catalisadores, evidenciando aumento da proporção de nanopartículas maiores. Apesar disso, os perfis dos histogramas continuam essencialmente os mesmos, exceto para $\mathrm{Pt} / \mathrm{MoO}_{3}-\mathrm{C}$, para o qual uma porção considerável de partículas de maior tamanho é formada.

Examinando os insertos em cada histograma da Figura 26 é possível detectar diversas variações na morfologia das nanopartículas. Os resultados de $\mathrm{Pt} / \mathrm{C}$ indicam que as partículas antes do envelhecimento são essencialmente esféricas e que o ciclo de degradação leva a um aumento da proporção de partículas mais alongadas. Esse fenômeno pode ser atribuído à processos tais como coalescência e fusão de nanopartículas, que tornam as partículas maiores e mais alongadas que as anteriores. Os resultados para $\mathrm{Pt} / \mathrm{MoO}_{2}-\mathrm{C}$ mostram que as nanopartículas recém-preparadas são menos esféricas comparadas às de $\mathrm{Pt} / \mathrm{C}$ e $\mathrm{Pt} / \mathrm{MoO}_{3}-\mathrm{C}$. Porém, ao contrário do ocorrido com as partículas de $\mathrm{Pt} / \mathrm{C}$, as de $\mathrm{Pt} / \mathrm{MoO}_{3}-\mathrm{C}$ e, particularmente, as de $\mathrm{Pt} / \mathrm{MoO}_{2}-\mathrm{C}$, tiveram seu grau de esfericidade aumentado após o envelhecimento eletroquímico. De acordo com Vion-Duty et al. [54] o mecanismo de dissolução e re-deposição de partículas de menor diâmetro denominado "Ostwald ripening eletroquímico" resulta em um aumento da proporção de partículas esféricas, porém com tamanho maior do que as partículas originais. Desse modo, a priori, pode-se considerar que um dos mecanismos de dissolução que ocorre nestes materiais, mais particularmente em $\mathrm{Pt} / \mathrm{MoO}_{2}-\mathrm{C}$, é o de Ostwald ripening, não podendo ser descartado, entretanto, a possibilidade de ocorrência de outros mecanismos de degradação.

Analisando as imagens de TEM na Figura 25, observa-se a formação de nanopartículas de platina equiaxiais em $\mathrm{Pt} / \mathrm{MoO}_{3}-\mathrm{C}$ após o envelhecimento eletroquímico. A Figura 27 apresenta outras imagens de TEM que resultaram da busca de maior evidências desse efeito. De acordo com Mabuchi et al. [140], a existência de grãos equiaxiais pode indicar a ocorrência de um processo de re-cristalização do material. Ferreira et al. [50] também encontraram os mesmos tipos de nanopartículas após a degradação do catalisador Pt/Vulcan no cátodo de uma PEMFC. O protocolo de envelhecimento foi bastante similar ao utilizado no presente trabalho, ou seja, ciclagem de potencial no intervalo de $0,6-1,0 \mathrm{~V}$ com velocidade de varredura de $20 \mathrm{mV} \mathrm{s}^{-1}$. Os autores sugerem que esse efeito deve-se à 
reprecipitação das espécies de platina dissolvidas através da reação com o gás $\mathrm{H}_{2}$ advindo do ânodo pelo processo denominado de crossover [50]. Como já mencionado, o teste de degradação utilizado neste trabalho foi realizado em meia-células e, portanto, não há como atribuir a formação destas partículas pela reação sugerida acima. Sendo assim, o mecanismo de Ostwald ripening eletroquímico parece ter o papel majoritário na degradação desse catalisador e na formação destas partículas.

Figura 27 - Micrografias obtidas após o envelhecimento eletroquímico do catalisador $\mathrm{Pt} / \mathrm{MoO}_{3}-\mathrm{C}$. O esquema também apresentado ilustra mecanismo de degradação responsável pela formação das nanopartículas de platina equiaxiais.

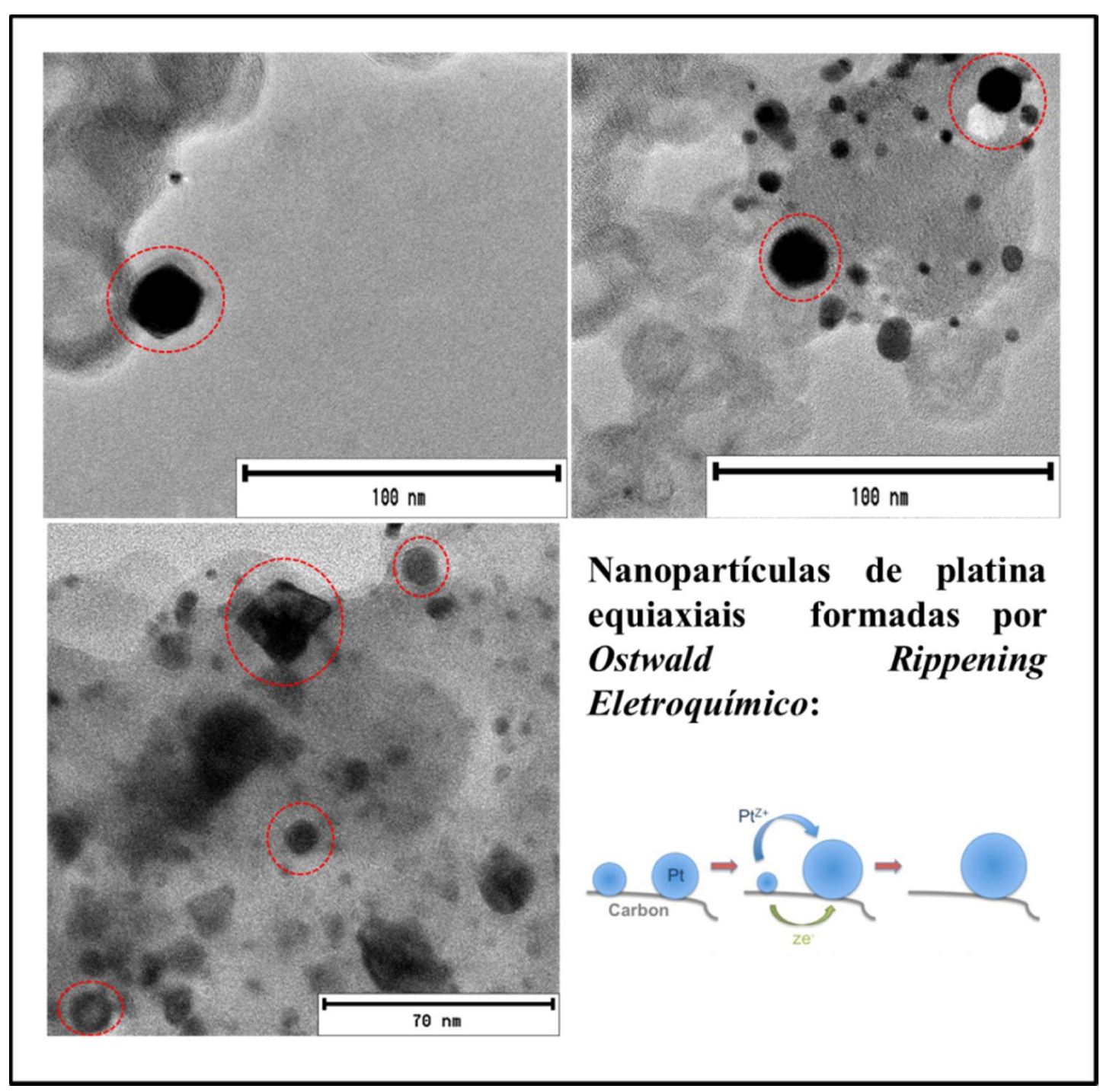

Em resumo, conclui-se que os mecanismos de degradação de NPs para $\mathrm{Pt} / \mathrm{MoO}_{2}-\mathrm{C}$ e $\mathrm{Pt} / \mathrm{MoO}_{3}$-C tais como a migração de cristalito seguida de coalescência e a corrosão do suporte 
catalítico se ocorreram, foi em extensão bem menor do que o de Ostwald ripening. Os insertos nos histogramas (Figura 26) dão suporte a esta conclusão de modo que a diminuição da proporção de partículas com baixa esfericidade, característica das nanopartículas formadas após coalescência de cristalitos, é diminuída tanto para $\mathrm{Pt} / \mathrm{MoO}_{3}-\mathrm{C}$ quanto para $\mathrm{Pt} / \mathrm{MoO}_{2}-\mathrm{C}$. No caso da Pt/C comercial (Figura 26) observa-se que a proporção de NPs de Pt esféricas diminuiu (diminuição do grau de esfericidade). Portanto, para $\mathrm{Pt} / \mathrm{C}$, além do Ostwald ripening, a migração de cristalitos e consequente coalescência pode estar envolvida no processo de degradação deste material. Analisando as curvas voltamétricas obtidas após o teste de degradação (Figura 24), observa-se que a região da dupla-camada elétrica permanece intacta, de modo que a formação de NPs com diâmetro mais elevado não deve ser acompanhada pela corrosão do carbono.

Além do mecanismo Ostwald ripening e a migração e coalescência de cristalitos (para o caso de Pt/C comercial) responsáveis pelo crescimento das NPs de Pt, acredita-se que grande parte da diminuição da área ativa de platina seja também devida ao descolamento e a dissolução das mesmas seguida de migração para o seio da solução [57]. A ciclagem rápida entre 0,6 e 1,0 V deveria facilitar que as NPs de Pt de baixo tamanho que por ventura são dissolvidas, sejam re-precipitadas no eletrodo [55]. No entanto, os dados mostram que grande parte da carga de platina é perdida com consequente diminuição da $A_{P t}$ (Tabela 10). Este fenômeno pode ser observado qualitativamente pelas micrografias de TEM (Figura 25). Como não foi possível realizar a técnica IL-TEM (Identical Location-TEM) [55,58], onde é possível comparar uma região específica do catalisador antes e após o envelhecimento eletroquímico, não é possível saber a extensão dessa perda de NPs de Pt, porém observa-se que todos os catalisadores tiveram uma diminuição na densidade de NPs de Pt por área de suporte.

A Figura 28 apresenta as curvas de polarização potenciodinâmicas para a RRO nos catalisadores novos e após 12000 ciclos $(0,6-1,0 \mathrm{~V})$. O número de elétrons envolvidos na RRO para cada catalisador foi calculado utilizando a equação de Levich (Equação 4.1) do mesmo modo já discutido. Em concordância com os resultados já apresentados, a Tabela 11 mostra que a RRO nos catalisadores ocorre pelo envolvimento de 4 elétrons. Portanto, apesar da diminuição da corrente cinética da reação, os materiais mostraram-se eficientes na conversão de $\mathrm{O}_{2}$ em $\mathrm{H}_{2} \mathrm{O}$. O mecanismo pelo qual a RRO se passa é desconhecido, ou seja, não se pode afirmar se é direto ou indireto. Apesar disto, a magnitude das correntes limites difusionais obtidas para todos os catalisadores indicam que caso $\mathrm{H}_{2} \mathrm{O}_{2}$ seja formado, o mesmo é imediatamente reduzido à $\mathrm{H}_{2} \mathrm{O}$. 
Figura 28 - Curvas de polarização para a RRO obtida potenciodinamicamente a velocidade de $5 \mathrm{mV} \mathrm{s}^{-2}$, em $0,5 \mathrm{M} \mathrm{H}_{2} \mathrm{SO}_{4}, \omega=1600 \mathrm{rpm}$, dos catalisadores $\mathrm{Pt} / \mathrm{MoO}_{3}-\mathrm{C}, \mathrm{Pt} / \mathrm{MoO}_{2}-\mathrm{C}$ e $\mathrm{Pt} / \mathrm{C}$ ETEK novos e em definidos números de ciclagens do teste de envelhecimento acelerado aplicado. As correntes foram normalizadas pela área geométrica do eletrodo, $0,196 \mathrm{~cm}^{2}$.Os insertos são aproximações da região de transferência de carga e possuem intervalo de potenciais de $0,83-0,92 \mathrm{~V} v s$. ERH.

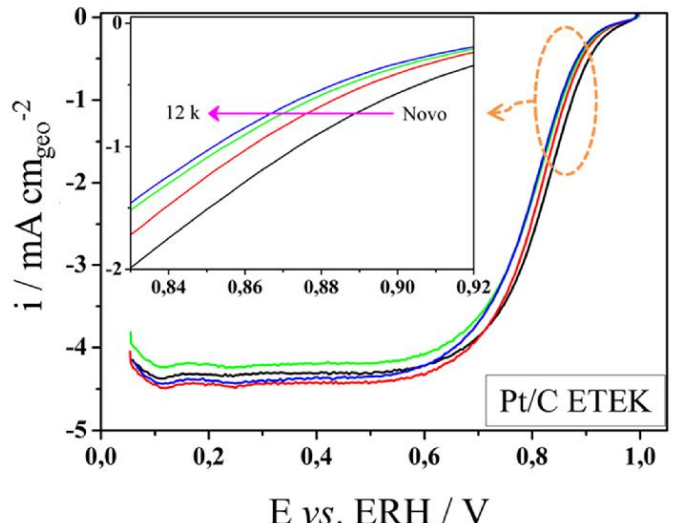

$\mathrm{E} v s . \mathrm{ERH} / \mathrm{V}$

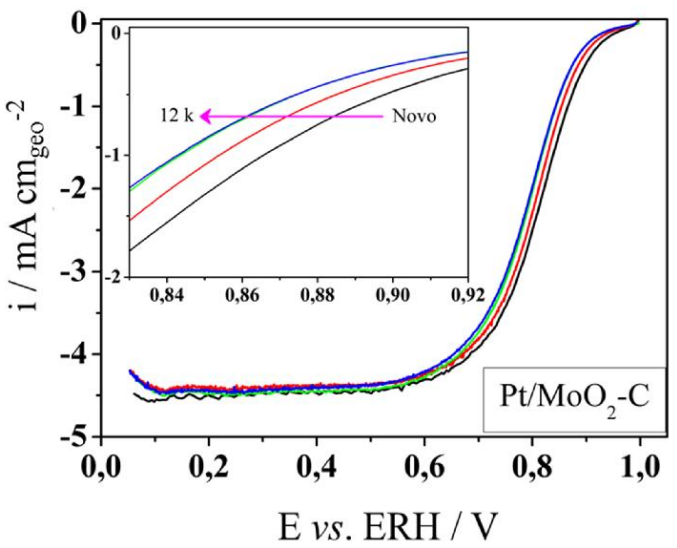

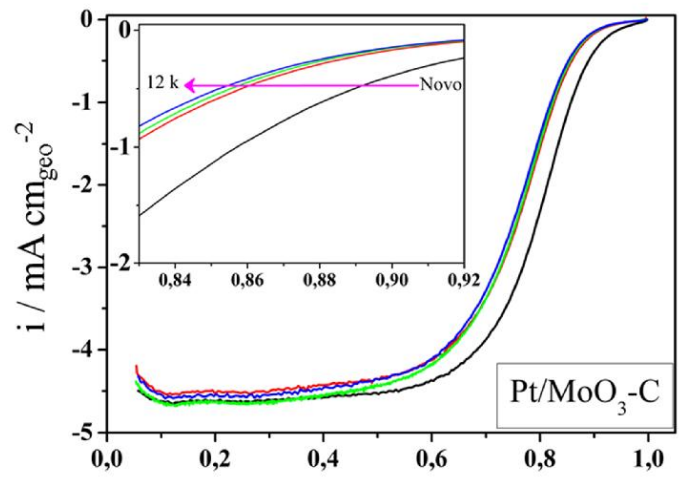

$\mathrm{E} v s . \mathrm{ERH} / \mathrm{V}$

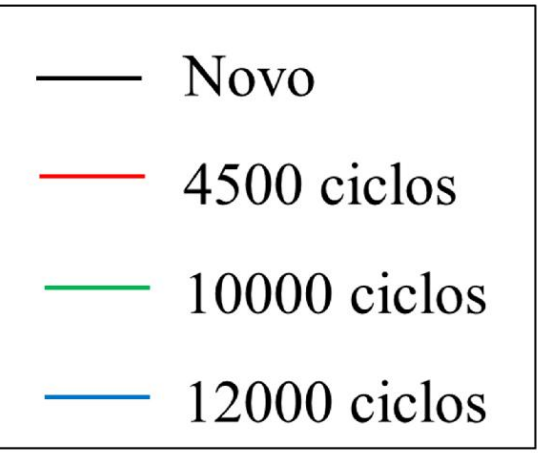

O fator em maior destaque nas curvas de polarização de todos os eletrocatalisadores é o deslocamento de correntes cinéticas para menores valores (insertos na Figura 28). Analisando esses dados em conjunto com os obtidos por TEM (Figura 26), pode-se atribuir que o decréscimo das correntes decorre do aumento do tamanho médio das partículas e a redução do seu número em cada catalisador após o envelhecimento eletroquímico que, consequentemente ocasiona perdas de áreas ativas, como observado por voltametria cíclica (Figura 24). De acordo com a (Figura 28, inserto referente à $\mathrm{Pt} / \mathrm{C}$ ), o catalisador $\mathrm{Pt} / \mathrm{C}$ comercial apresentou uma constante taxa de degradação, proporcional ao número de ciclos aplicados no envelhecimento eletroquímico. O catalisador $\mathrm{Pt} / \mathrm{MoO}_{2}-\mathrm{C}$ apresentou as maiores diminuições de correntes cinéticas (também proporcionais ao número de ciclos) nos primeiros 10000 ciclos, sendo que após os 2000 ciclos posteriores não houve alteração significativa no 
valor de corrente (Figura 28, inserto referente a $\mathrm{Pt} / \mathrm{MoO}_{2}-\mathrm{C}$ ). O catalisador $\mathrm{Pt} / \mathrm{MoO}_{3}-\mathrm{C}$ apresentou uma diminuição de corrente acentuada nos primeiros 4500 ciclos e pouca variação nos demais ciclos aplicados (Figura 28, inserto referente a $\mathrm{Pt} / \mathrm{MoO}_{3}-\mathrm{C}$ ).

Tabela 11 - Número de elétrons envolvidos, correntes cinéticas (normalizadas pela área eletroativa de Pt) obtidas em potencial de $0,9 \mathrm{~V}$ e coeficientes de Tafel $b_{1}$ e $b_{2}$ obtidos para a RRO nos eletrodos $\mathrm{Pt} / \mathrm{MoO}_{3}-\mathrm{C}, \mathrm{Pt} / \mathrm{MoO}_{2}-\mathrm{C}$ recém-preparados e $\mathrm{Pt} / \mathrm{C}$ comercial em intervalos definidos de ciclagem eletroquímica

\begin{tabular}{|c|c|c|c|c|c|}
\hline Materiais & Número de ciclos & $\mathbf{n}_{\text {elétrons }}$ & $i_{0,9 \mathrm{v}} / \mathbf{m A} \mathbf{c m}_{\mathbf{P t}}^{-2}$ & $b_{1} / \mathbf{m V} \operatorname{dec}^{-1}$ & $\mathbf{b}_{2} / \mathrm{mV} \operatorname{dec}^{-1}$ \\
\hline \multirow{4}{*}{$\mathrm{Pt} / \mathrm{MoO}_{3}-\mathrm{C}$} & Novo & 4,10 & 49,0 & 87 & 120 \\
\hline & 4500 & - & 31,6 & - & - \\
\hline & 10000 & - & 34,7 & - & - \\
\hline & 12000 & 3,81 & 32,4 & 83 & 118 \\
\hline \multirow{4}{*}{$\mathrm{Pt} / \mathrm{MoO}_{2}-\mathrm{C}$} & Novo & 3,93 & 29,5 & 87 & 120 \\
\hline & 4500 & - & 33,1 & - & - \\
\hline & 10000 & - & 33,9 & - & - \\
\hline & 12000 & 3,90 & 33,9 & 83 & 118 \\
\hline \multirow{4}{*}{ Pt/C ETEK ${ }^{\circledR}$} & Novo & 3,98 & 33,1 & 87 & 120 \\
\hline & 4500 & - & 32,4 & - & - \\
\hline & 10000 & - & 33,1 & - & - \\
\hline & 12000 & 3,90 & 30,9 & 83 & 118 \\
\hline
\end{tabular}

Os diagramas de Tafel obtidos após o envelhecimento eletroquímico estão apresentados na Figura 29, sendo os valores de $b_{1}$ e $b_{2}$ apresentados na Tabela 11. Observa-se que as inclinações $b_{1}$ e $b_{2}$ sofreram alterações mínimas em relação aos resultados da Figura 
23, indicando que os modos de adsorção das espécies oxigenadas na superfície de platina e sua intensidade não foram alterados. Ou seja, a adsorção de $\mathrm{O}_{2}$ em baixos sobrepotenciais segue a isoterma de Temkin (altos recobrimentos) e em altos sobrepotenciais segue a isoterma de Langmuir (baixos recobrimentos) [34,130,135].

Figura 29 - Diagrama de Tafel dos eletrocatalisadores $\mathrm{Pt} / \mathrm{MoO}_{2}-\mathrm{C}, \mathrm{Pt} / \mathrm{MoO}_{3}-\mathrm{C}$ e $\mathrm{Pt} / \mathrm{C}$ ETEK corrigidos por transporte de massa e as correntes normalizadas pela área ativa de $\mathrm{Pt}$ dos respectivos eletrodos, para a $\mathrm{RRO}$ em solução $0,5 \mathrm{M}$ de $\mathrm{H}_{2} \mathrm{SO}_{4}, \omega=1600 \mathrm{rpm}$, à temperatura de $25^{\circ} \mathrm{C}$, após o envelhecimento eletroquímico.

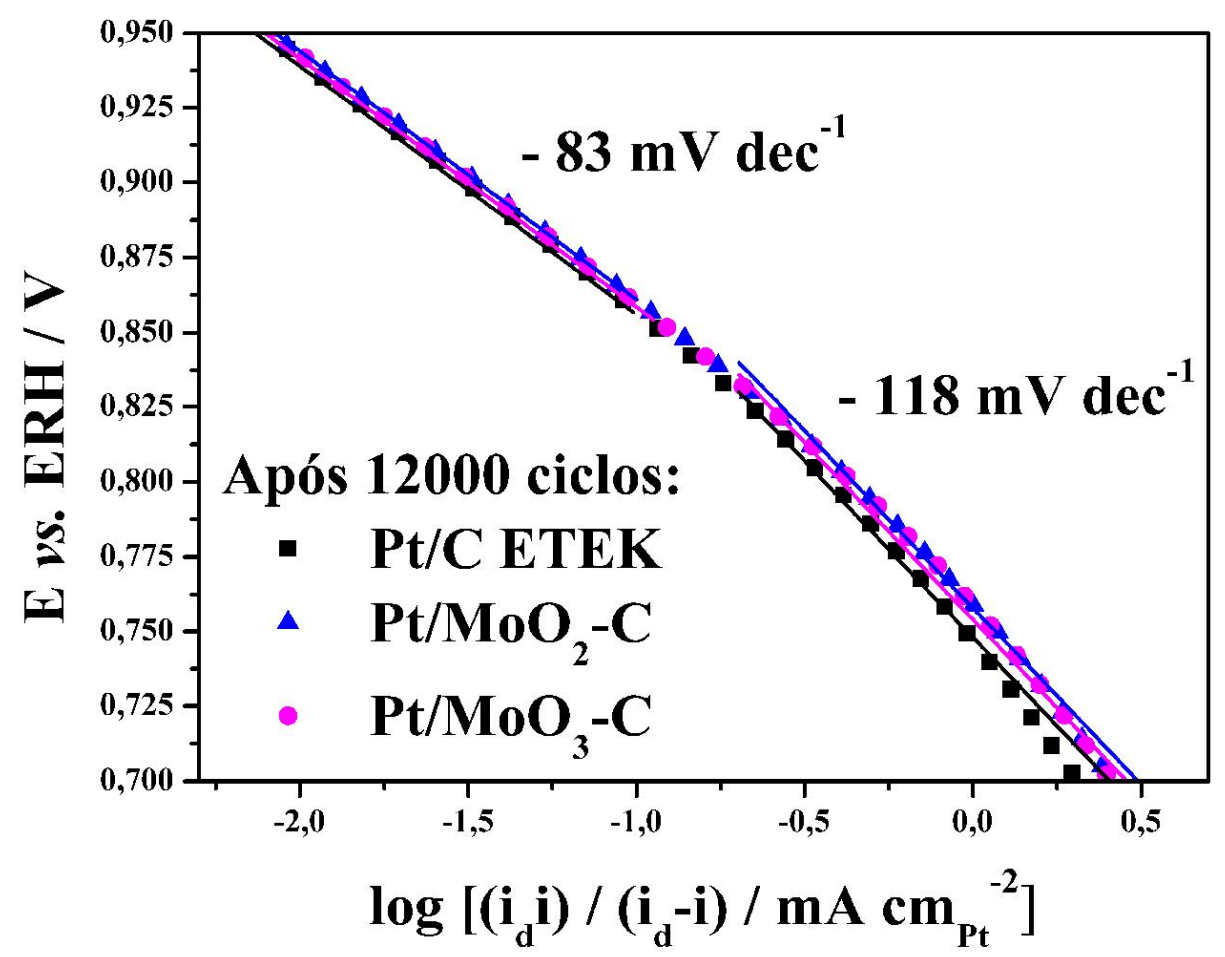

$\mathrm{Na}$ Tabela 11, são apresentados os valores de $\mathrm{i}_{0,9} \mathrm{v}$ obtidos ao longo do processo de ciclagem, até se completar 12000 ciclos. A análise das correntes normalizadas pela área eletroativa de $\mathrm{Pt}\left(\mathrm{i}_{0,9} \mathrm{~V}\right)$ permite avaliar o comportamento catalítico intrínseco de cada material (atividade específica), antes e após o teste de degradação. Para fins de comparação as atividades específicas foram determinadas em potencial fixo de 0,9 V vs. ERH, pois este está localizado em uma região onde não há influência de processos difusionais [34,133]. Estes valores encontram-se na Tabela 11. Verifica-se que o catalisador $\mathrm{Pt} / \mathrm{C}$ comercial manteve sua atividade específica relativamente constante até os primeiros 10000 ciclos. Após 12000 ciclos, o valor de $\mathrm{i}_{0,9} \mathrm{~V}$ diminuiu cerca de $7 \%$ do valor inicial. A possível causa desta pequena perda de atividade pode estar relacionada com a formação de partículas com estruturas que 
dificultam a dessorção dissociativa de $\mathrm{OH}_{\mathrm{ads}}$, etapa determinante da $\mathrm{RRO}$ em potenciais próximos a $0,9 \mathrm{~V}$.

$\mathrm{O}$ catalisador $\mathrm{Pt} / \mathrm{MoO}_{3}-\mathrm{C}$ apresentou inicialmente a maior atividade específica, cerca de 48 \% maior que a de Pt/C ETEK, atribuída a possíveis efeitos sinérgicos metal/suporte (seção 4.2.3). Resultados de XPS mostram que $\mathrm{Pt} / \mathrm{MoO}_{3}-\mathrm{C}$ recém-preparado possui maior proporção de platina na forma metálica, que é ativa para a RRO. Em contrapartida, $\mathrm{Pt} / \mathrm{MoO}_{3}-$ C apresentou uma elevada diminuição de atividade após as ciclagens eletroquímicas, evidenciada por uma queda de cerca de $34 \%$ do valor de $i_{0,9} \mathrm{v}$ (Tabela 11). Estes resultados estão em parte de acordo com os apresentados por Çakar et al. [88], que afirmam que o $\mathrm{MoO}_{3}$ aumenta a área ativa de Pt e incrementa sua atividade frente a RRO. De fato a atividade específica de Pt é aumentada, porém a possível impregnação das NPs de Pt diretamente no $\mathrm{MoO}_{3}$ acarreta na diminuição da área ativa, devido às características semicondutoras deste óxido [122,123]. Apesar do incremento na atividade da platina ocasionado pela presença deste óxido, estes resultados demonstram que as espécies de $\mathrm{MoO}_{3}$ presentes no suporte catalítico não estabilizaram as NPs de Pt, como de fato foi observado pelos resultados obtidos por TEM (Figura 27). $\mathrm{Pt} / \mathrm{MoO}_{3}-\mathrm{C}$ foi o único material que após a ciclagem apresentou nanopartículas de platina equiaxiais, ou seja, partículas com elevado grau de cristalinidade. Estas partículas apresentam tamanhos grandes e formatos bem distintos das demais, o que pode ter sido a possível causa da considerável perda de atividade do material $\mathrm{Pt} / \mathrm{MoO}_{3}-\mathrm{C}$. Contudo, comparando-se os valores de $\mathrm{i}_{0,9 \mathrm{~V}}$ após os 12000 ciclos, este material ainda apresentou atividade superior à $\mathrm{Pt} / \mathrm{C}$ (cerca de $5 \%$ maior).

$\mathrm{O}$ catalisador $\mathrm{Pt} / \mathrm{MoO}_{2}-\mathrm{C}$ foi o que apresentou maior estabilidade da atividade específica frente ao envelhecimento eletroquímico. De acordo com a Tabela 11, as correntes em $0,9 \mathrm{~V}$ permaneceram essencialmente constantes após todos os passos da ciclagem. De fato, a $\mathrm{i}_{0,9} \mathrm{v}$ teve seu valor aumentado comparado ao valor obtido para o material recémpreparado de cerca de $15 \%$. Como mencionado na seção 4.2.1, apesar dos dados de XPS mostrarem que a superfície das partículas de $\mathrm{MoO}_{2}$ possuem majoritariamente espécies de

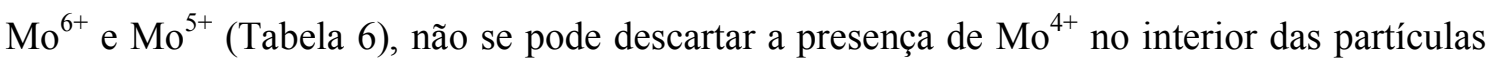
na forma de $\mathrm{MoO}_{2}$, mesmo que com menor grau de cristalinidade. Essa possibilidade é reforçada pelo resultado de EDX obtido para $\mathrm{Pt} / \mathrm{MoO}_{2}-\mathrm{C}$ recém-preparado (Tabela 4), o qual mostra que não ocorreu perda alguma de Mo após a impregnação de NPs de Pt. Dessa forma, é possível correlacionar as características promotoras de atividade frente a RRO das NPs de Pt pelas espécies de $\mathrm{Mo}^{6+}$, com as características promotoras de estabilidade química e física das NPs de Pt pelo suporte $\mathrm{MoO}_{2}$, mantendo sua integridade catalítica após os 12000 ciclos entre 
0,6 - 1,0 V. As espécies de $\mathrm{Mo}^{6+}$ em contato com as NPs de Pt podem ter ocasionado o aprimoramento da atividade catalítica que se manteve até o final da ciclagem porque as espécies de $\mathrm{MoO}_{2}$ devem ter reduzido a taxa de aglomeração das NPs de Pt. O histograma apresentado na Figura 26 comprova esta sugestão, pois mostra que após os 12000 ciclos não houve alargamento pronunciado da distribuição de tamanho dos cristalitos do $\mathrm{Pt} / \mathrm{MoO}_{2}-\mathrm{C}$ comparado aos histogramas de $\mathrm{Pt} / \mathrm{MoO}_{3}-\mathrm{C}$ e $\mathrm{Pt} / \mathrm{C}$; além disso, o histograma indica que houve um aumento significativo na porcentagem de NPs de Pt com elevado grau de esfericidade (inserto na Figura 26 referente ao $\mathrm{Pt} / \mathrm{MoO}_{2}-\mathrm{C}$ ). Portanto, apesar da diminuição de área ativa em todos os catalisadores (Tabela 10) após o envelhecimento eletroquímico, o suporte catalítico $\mathrm{MoO}_{2}-\mathrm{C}$ evitou que as partículas de platina remanescentes sofressem demasiada aglomeração, como foi observado para o $\mathrm{Pt} / \mathrm{MoO}_{3}-\mathrm{C}$ e o Pt/C. 


\section{CONCLUSÕES}

Os suportes catalíticos apresentaram elevada cristalinidade, observada por DRX (Figura 10), comprovando a formação das estruturas dos óxidos almejadas. Ao analisar-se as áreas eletroativas de Pt (Tabela 8), acredita-se que o caráter semicondutor do $\mathrm{MoO}_{3}$ teve influência nas NPs de Pt, inativando-as por meio de problemas de condução eletrônica. Porém, apesar deste fato, o catalisador $\mathrm{Pt} / \mathrm{MoO}_{3}-\mathrm{C}$ apresentou a maior atividade específica frente à RRO (Tabela 9), explicado por efeitos sinérgicos metal/suporte. A interação entre metal/suporte foi evidenciada pelos resultados de XANES apresentados na Figura 18, onde a variação na magnitude da "linha branca" em potencial de $0,5 \mathrm{~V}$ comparada à de $\mathrm{Pt} / \mathrm{C}$ indica que de fato as espécies de óxido de molibdênio depositadas no carbono em $\mathrm{Pt} / \mathrm{MoO}_{3}-\mathrm{C}$ e $\mathrm{Pt} / \mathrm{MoO}_{2}-\mathrm{C}$ estão muito próximas às NPs de $\mathrm{Pt}$.

Quando investigada a estabilidade dos materiais frente ao teste de degradação eletroquímico acelerado, observou-se que, a princípio, nenhum dos óxidos de molibdênio diminuem a extensão da degradação da platina. O principal mecanismo de degradação atribuído ao desgaste dos materiais recém-preparados, em particular do $\mathrm{Pt} / \mathrm{MoO}_{2}-\mathrm{C}$, foi o de Ostwald ripening eletroquímico. A degradação do catalisador por migração seguida de coalescência de cristalitos de platina e a corrosão do suporte catalítico, se ocorreram, foi em menor extensão. No caso da Pt/C comercial, observou-se que a proporção de NPs de Pt esféricas diminuiu (diminuição do grau de esfericidade). Portanto, para $\mathrm{Pt} / \mathrm{C}$, além do Ostwald ripening, a migração de cristalitos e consequente coalescência pode estar envolvida no processo de degradação deste material.

Analisando-se as atividades específicas frente à RRO para cada catalisador antes e após o envelhecimento eletroquímico, foi observado que $\mathrm{Pt} / \mathrm{MoO}_{2}-\mathrm{C}$ apresentou-se como o material mais estável dentre os demais. Essa estabilidade foi atribuída ao sinergismo entre as espécies de $\mathrm{Mo}^{6+}$ na superfície do $\mathrm{MoO}_{2}-\mathrm{C}$ com as NPs de Pt, que acentua a atividade específica frente à $\mathrm{RRO}$, e também às espécies de $\mathrm{MoO}_{2}$ que podem ter contribuído para redução da taxa de aglomeração das NPs de Pt, fato comprovado pelo histograma apresentado na Figura 26, o qual mostra que após os 12000 ciclos não houve alargamento pronunciado da distribuição de tamanho dos cristalitos de $\mathrm{Pt} / \mathrm{MoO}_{2}-\mathrm{C}$ comparado aos histogramas de $\mathrm{Pt} / \mathrm{MoO}_{3}-\mathrm{C}$ e Pt/C. 


\section{REFERÊNCIAS BIBLIOGRÁFICAS}

[1] BOSSEL, U. The birth of the fuel cell, 1835-1845: including the first publication of the complete correspondence from 1839 to 1868 between Christian Friedrich Schoenbein, discoverer of the fuel cell effect, and William Robert Grove, inventor of the fuel cell. 7th ed. Oberrohrdorf: European Fuel Cell Forum, 2000. 1v.

[2] CARRETTE, L.; FRIEDRICH, K. A.; STIMMING, U. Fuel cells - fundamentals and applications. Fuel Cells, v. 1, p. 5-39, 2001.

[3] CARTER, D.; WING, J. The fuel cell industry review 2013. Fuel Cell Today, p. 1-46, 2013.

[4] WINTER, M.; BRODD, R. J. What are batteries, fuel cells, and supercapacitors?. Chem. Rev., v. 104, p. 4245-4269, 2004.

[5] KIROS, Y.; SCHWARTZ, S. Long-term hydrogen oxidation catalysts in alkaline fuel cells. J. Power Sources, v. 87, p. 101-105, 2000.

[6] BRENSCHEIDT, TH.; JANOWITZ, K.; SALGE, H.-J.; WENDT, H.; BRAMMER, F. Performance of ONSI PC25 PAFC cogeneration plant. Int. J. Hydrogen Energy, v. 23, p. 53-56, 1998.

[7] THOMAS, S. C.; REN, X.; GOTTESFELD, S.; ZELENAY, P. Direct methanol fuel cells: progress in cell performance and cathode research. Electrochim. Acta, v. 47, p. 3741-3748, 2002.

[8] REN, X.; ZELENAY, P.; THOMAS, S.; DAVEY, J.; GOTTESFELD, S. Recent advances in direct methanol fuel cells at Los Alamos National Laboratory. J. Power Sources, v. 86, p. $111-116,2000$.

[9] KAMARUDIN, S. K.; DAUD, W. R. W.; HO, S. L.; HASRAN, U. A. Overview on the challenges and developments of micro-direct methanol fuel cells (DMFC). J. Power Sources, v. 163, p. 743-754, 2007.

[10] KAMARUDIN, S. K.; ACHMAD, F.; DAUD, W. R. W. Overview on the application of direct methanol fuel cell (DMFC) for portable electronic devices. Int. J. Hydrogen Energy, v. 34, p. 6902-6916, 2009. 
[11] DILLON, R.; SRINIVASAN, S.; ARICÒ, A. S.; ANTONUCCI, V. International activities in DMFC R\&D: status of technologies and potential applications. J. Power Sources, v. 127, p. 112-126, 2004.

[12] WASMUS, S.; KÜVER, A. Methanol oxidation and direct methanol fuel cells: a selective review. J. Electroanal. Chem., v. 461, p. 14-31, 1999.

[13] WANG, Y.; CHEN, K. S.; MISHLER, J.; CHO, S. C.; ADROHER, X. C. A review of polymer electrolyte membrane fuel cells: Technology, applications, and needs on fundamental research. Appl. Energy, v. 88, p. 981-1007, 2011.

[14] BORUP, R.; MEYERS, J.; PIVOVAR, B.; KIM, Y. S.; MUKUNDAN, R.; GARLAND, N.; MYERS, D.; WILSON, M.; GARZON, F.; WOOD, D.; ZELENAY, P.; MORE, K.; STROH, K.; ZAWODZINSKI, T.; BONCELLA, J.; MCGRATH, J. E.; INABA, M.; MIYATAKE, K.; HORI, M.; OTA, K.; OGUMI, Z.; MIYATA, S.; NISHIKATA, A.; SIRONA, Z.; UCHIMOTO, Y.; YASUDA, K.; KIMIJIMA, K-I.; IWASHITA, N. Scientific aspects of polymer electrolyte fuel cell durability and degradation. Chem. Rev., v. 107, p. 3904-3951, 2007.

[15] WROBLOWA, H. S.; YEN-CHI-PAN; RAZUMNEY, G. Electroreduction of oxygen: a new mechanistic criterion. J. Electroanal. Chem., v. 69, p. 195-201, 1976.

[16] SEPA, D. B.; VOJNOVIC, M. V.; DAMJANOVIC, A. Reaction intermediates as a controlling factor in the kinetics and mechanism of oxygen reduction at platinum electrodes. Electrochim. Acta, v. 26, p. 781-793, 1981.

[17] KATSOUNAROS, I.; SCHNEIDER, W. B.; MEIER, J. C.; BENEDIKT, U.; BIEDERMANN, P. U.; AUER, A. A.; MAYRHOFER, K. J. J. Hydrogen peroxide electrochemistry on platinum: towards understanding the oxygen reduction reaction mechanism. Phys. Chem. Chem. Phys., v. 14, p. 7384-7391, 2012.

[18] ARENZ, M.; MAYRHOFER, K. J. J.; STAMENKOVIC, V.; BLIZANAC, B. B.; TOMOYUKI, T.; ROSS, P. N.; MARKOVIC, N. M. The effect of the particle size on the kinetics of CO electrooxidation on high surface area Pt catalysts. J. Am. Chem. Soc., v. 127, p. 6819-6829, 2005.

[19] MARKOVIĆ, N. M.; GASTEIGER, H. A.; GRGUR, B. N.; ROSS, P. N. Oxygen reduction reaction on $\mathrm{Pt}(111)$ : effects of bromide. J. Electroanal. Chem., v. 467, p. 157-163, 1999. 
[20] MARKOVIĆ, N. M.; SCHMIDT, T. J.; STAMENKOVIĆ, V.; ROSS, P. N. Oxygen reduction reaction on $\mathrm{Pt}$ and $\mathrm{Pt}$ bimetallic surfaces: a selective review. Fuel Cells, v. 1, p. 105-116, 2001.

[21] STAMENKOVIC, V.; MUN, B. S.; MAYRHOFER, K. J. J.; ROSS, P. N.; MARKOVIC, N. M.; ROSSMEISL, J.; GREELEY, J.; NØRSKOV, J. K. Changing the activity of electrocatalysts for oxygen reduction by tuning the surface electronic structure. Angew. Chem. Int. Ed., v. 45, p. 2897-2901, 2006.

[22] STAMENKOVIC, V. R.; FOWLER, B.; MUN, B. S.; WANG, G.; ROSS, P. N.; LUCAS, C. A.; MARKOVIĆ, N. M. Improved oxygen reduction activity on $\mathrm{Pt}_{3} \mathrm{Ni}(111)$ via increased surface site availability. Science, v. 315, p. 493-497, 2007.

[23] HOLEWINSKI, A.; LINIC, S. Elementary mechanisms in electrocatalysis: revisiting the ORR tafel slope. J. Electrochem. Soc., v. 159, p. H864-H870, 2012.

[24] NESSELBERGER, M.; ROEFZAAD, M.; HAMOU, R. F.; BIEDERMANN, P. U.; SCHWEINBERGER, F. F.; KUNZ, S.; SCHLOEGL, K.; WIBERG, G. K. H.; ASHTON, S.; HEIZ, U.; MAYRHOFER, K. J. J.; ARENZ, M. The effect of particle proximity on the oxygen reduction rate of size-selected platinum clusters. Nat. Mater., v. 12, p. 919-924, 2013.

[25] PAULUS, U. A.; WOKAUN, A.; SCHERER, G. G.; SCHMIDT, T. J.;

STAMENKOVIC, V.; MARKOVIC, N. M.; ROSS, P. N. Oxygen reduction on high surface area Pt-based alloy catalysts in comparison to well defined smooth bulk alloy electrodes.

Electrochim. Acta, v. 47, p. 3787-3798, 2002.

[26] MARKOVIC, N.; GASTEIGER, H.; ROSS, P. N. Kinetics of oxygen reduction on $\mathrm{Pt}(\mathrm{hkl})$ electrodes: implications for the crystallite size effect with supported Pt electrocatalysts. J. Electrochem. Soc., v. 144, p. 1591-1597, 1997.

[27] PAULUS, U. A.; SCHMIDT, T. J.; GASTEIGER, H. A.; BEHM, R. J. Oxygen reduction on a high-surface area $\mathrm{Pt} / \mathrm{Vulcan}$ carbon catalyst: a thin-film rotating ring-disk electrode study. J. Electroanal. Chem., v. 495, p. 134-145, 2001.

[28] MARKOVIĆ, N. M.; GASTEIGER, H. A.; ROSS, P. N. Oxygen reduction on platinum low-index single-crystal surfaces in sulfuric acid solution: rotating ring-Pt(hkl) disk studies. $\mathbf{J}$. Phys. Chem., v. 99, p. 3411-3415, 1995. 
[29] STAMENKOVIC, V.; MARKOVIC, N. M.; ROSS Jr., P. N. Structure-relationships in electrocatalysis: oxygen reduction and hydrogen oxidation reactions on $\operatorname{Pt}(111)$ and $\operatorname{Pt}(100)$ in solutions containing chloride ions. J. Electroanal. Chem., v. 500, p. 44-51, 2001.

[30] MAYRHOFER, K. J. J.; BLIZANAC, B. B.; ARENZ, M.; STAMENKOVIC, V. R.; ROSS, P. N.; MARKOVIC, N. M. The impact of geometric and surface electronic properties of Pt-catalysts on the particle size effect in electrocatalysis. J. Phys. Chem. B., v. 109, p. 14433-14440, 2005.

[31] PAULUS, U. A.; WOKAUN, A.; SCHERER, G. G.; SCHMIDT, T. J.; STAMENKOVIC, V.; RADMILOVIC, V.; MARKOVIC, N. M.; ROSS, P. N. Oxygen reduction on carbon-supported Pt-Ni and Pt-Co alloy catalysts. J. Phys. Chem. B., v. 106, p. 4181-4191, 2002.

[32] DAMJANOVIC, A.; GENSHAW, M. A.; BOCKRIS, J. O'M. The role of hydrogen peroxide in oxygen reduction at platinum in $\mathrm{H}_{2} \mathrm{SO}_{4}$ solution. J. Electrochem. Soc., v. 114, p. 466-472, 1967.

[33] MARKOVIĆ, N. M.; ADŽIĆ, R. R.; CAHAN, B. D.; YEAGER, E. B. Structural effects in electrocatalysis: oxygen reduction on platinum low index single-crystal surfaces in perchloric acid solutions. J. Electroanal. Chem., v. 377, p. 249-259, 1994.

[34] TICIANELLI, E. A.; GONZÁLEZ, E. R. Eletroquímica: princípios e aplicações. $2^{\mathrm{a}}$ ed. São Paulo: Editora da Universidade de São Paulo, 2005. 232 p.

[35] ADŽIĆ, R. R.; WANG, J. X. Configuration and site of $\mathrm{O}_{2}$ adsorption on the $\mathrm{Pt}(111)$ electrode surface. J. Phys. Chem. B., v. 102, p. 8988-8993, 1998.

[36] YEAGER, E. Recent avances in the science of electrocatalysis. J. Electrochem. Soc., v. 128, p. 160C-171C, 1981.

[37] YEAGER, E. Dioxygen electrocatalysis: mechanisms in relation to catalyst structure. J. Mol. Catal., v. 38, p. 5-25, 1986.

[38] KINOSHITA, K. Particle size effects for oxygen reduction on highly dispersed platinum in acid electrolytes. J. Electrochem. Soc., v. 137, p. 845-848, 1990.

[39] SHENG, W.; CHEN, S.; VESCOVO, E.; SHAO-HORN, Y. Size influence on the oxygen reduction reaction activity and instability of supported Pt nanoparticles. J.

Electrochem. Soc., v. 159, p. B96-B103, 2012. 
[40] HIGUCHI, E.; UCHIDA, H.; WATANABE, M. Effect of loading level in platinumdispersed carbon black electrocatalysts on oxygen reduction activity evaluated by rotating disk electrode. J. Electroanal. Chem., v. 583, p. 69-76, 2005.

[41] SERRANO, E.;RUS, G.; GARCÍA-MARTÍNEZ, J. Nanotechnology for sustainable energy. Renew. Sustain. Energy Rev., v. 13, p. 2373-2384, 2009.

[42] JAMES, B. D.; SPISAK, A. B. Mass production cost estimation of direct $\mathbf{H}_{2}$ PEM fuel cell systems for transportation applications: 2012 update. Washington, D.C.: U.S. DOE-EERE, 2012. 1v.

[43] PAPAGEORGOPOULOS, D. An introduction to the 2010 fuel cell pre-solicitation workshop. 2010. Disponível em:

$<$ https://www1.eere.energy.gov/hydrogenandfuelcells/pdfs/fuelcell_pre-

solicitation_wkshop_mar10_papageorgopoulos.pdf>. Acesso em: 18 maio 2014.

[44] SAHA, M. S.; NEBURCHILOV, V.; GHOSH, D.; ZHANG, J. Nanomaterials-supported Pt catalysts for proton exchange membrane fuel cells. Wiley Interdiscip. Rev. Energy Environ., v. 2, p. 31-51, 2013.

[45] RABIS, A.; RODRIGUEZ, P.; SCHMIDT, T. J. Electrocatalysis for polymer electrolyte fuel cells: recent achievements and future challenges. ACS Catal., v. 2, p. 864-890, 2012.

[46] POLLET, B. G.; STAFFELL, I.; SHANG, J. L. Current status of hybrid, battery and fuel cell electric vehicles: from electrochemistry to market prospects. Electrochim. Acta, v. 84, p. 235-249, 2012.

[47] YUAN, X.-Z.; LI, H.; ZHANG, S.; MARTIN, J.; WANG, H. A review of polymer electrolyte membrane fuel cell durability test protocols. J. Power Sources, v. 196, p. 9107 9116, 2011.

[48] MILLER, M.; BAZYLAK, A. A review of polymer electrolyte membrane fuel cell stack testing. J. Power Sources, v. 196, p. 601-613, 2011.

[49] PEIGHAMBARDOUST, S. J.; ROWSHANZAMIR, S.; AMJADI, M. Review of the proton exchange membranes for fuel cell applications. Int. J. Hydrogen Energ., v. 35, p. 9349-9384, 2010. 
[50] FERREIRA, P. J.; O', G.J. la; SHAO-HORN, Y.; MORGAN, D.; MAKHARIA, R.; KOCHA, S.; GASTEIGER, H. A. Instability of Pt/C electrocatalysts in proton exchange membrane fuel cells. J. Electrochem. Soc., v. 152, p. A2256-A2271, 2005.

[51] STEELE, B. C. H.; HEINZEL, A. Materials for fuel-cell technologies. Nature, v. 414, p 345-352, 2001.

[52] SHARMA, S.; POLLET, B. G. Support materials for PEMFC and DMFC electrocatalysts - a review. J. Power Sources, v. 208, p. 96-119, 2012.

[53] OHMA, A.; SHINOHARA, K.; IIYAMA, A.; YOSHIDA, T.; DAIMARU, A. Membrane and catalyst performance targets for automotive fuel cells by FCCJ membrane, catalyst, MEA WG. ECS Trans., v. 41, p. 775-784, 2011.

[54] VION-DURY, B.; CHATENET, M.; GUÉTAZ, L.; MAILLARD, F. Determination of aging markers and their use as a tool to characterize $\mathrm{Pt} / \mathrm{C}$ nanoparticles degradation mechanism in model PEMFC cathode environment. ECS Trans., v. 41, p. 697-708, 2011.

[55] NIKKUNI, F. R.; TICIANELLI, E. A.; DUBAU, L.; CHATENET, M. Identical-location transmission electron microscopy study of $\mathrm{Pt} / \mathrm{C}$ and $\mathrm{Pt}-\mathrm{Co} / \mathrm{C}$ nanostructured electrocatalyst aging: effects of morphological and compositional changes on the oxygen reduction reaction activity. Electrocatalysis, v. 4, p. 104-116, 2013.

[56] FERNANDES, A. C.; PAGANIN, V. A.; TICIANELLI, E. A. Degradation study of Ptbased alloy catalysts for the oxygen reduction reaction in proton exchange membrane fuel cells. J. Electroanal. Chem., v. 648, p. 156-162, 2010.

[57] SHAO-HORN, Y.; SHENG, W. C.; CHEN, S.; FERREIRA, P. J.; HOLBY, E. F.; MORGAN, D. Instability of supported platinum nanoparticles in low-temperature fuel cells. Top. Catal., v. 46, p. 285-305, 2007.

[58] ZANA, A.; SPEDER, J.; ROEFZAAD, M.; ALTMANN, L.; BAUMER, M.; ARENZ, M. Probing degradation by IL-TEM: the influence of stress test conditions on the degradation mechanism. J. Electrochem. Soc., v. 160, p. F608-F615, 2013.

[59] SPEDER, J.; ZANA, A.; SPANOS, I.; KIRKENSGAARD, J. K. K.; MORTENSEN, K.; HANZLIK, M.; ARENZ, M. Comparative degradation study of carbon supported proton exchange membrane fuel cell electrocatalysts - the influence of the platinum to carbon ratio on the degradation rate. J. Power Sources, v. 261, p. 14-22, 2014. 
[60] SHAO, Y.; YIN, G.; GAO, Y. Understanding and approaches for the durability issues of Pt-based catalysts for PEM fuel cell. J. Power Sources, v.171, p. 558-566, 2007.

[61] SHAO, Y.; YIN, G.; WANG, Z.; GAO, Y. Proton exchange membrane fuel cell from low temperature to high temperature: material challenges. J. Power Sources, v. 167, p. 235$242,2007$.

[62] SHENG, W.; CHEN, S.; VESCOVO, E.; SHAO-HORN, Y. Size influence on the oxygen reduction reaction activity and instability of supported Pt nanoparticles. J.

Electrochem. Soc., v. 159, p. B96-B103, 2012.

[63] WANG, X.; KUMAR, R.; MYERS, D. J. Effect of voltage on platinum dissolution. Electrochem. Solid-State Lett., v. 9, p. A225-A227, 2006.

[64] YASUDA, K.; TANIGUCHI, A.; AKITA, T.; IOROI, T.; SIROMA, Z. Platinum dissolution and deposition in the polymer electrolyte membrane of a PEM fuel cell as studied by potential cycling. Phys. Chem. Chem. Phys., v. 8, p. 746-752, 2006.

[65] FU, Q.; WAGNER, T. Interaction of nanostructured metal overlayers with oxide surfaces. Surf. Sci. Rep., v. 62, p. 431-498, 2007.

[66] ZHOU, J.; ZHOU, X.; SUN, X.; LI, R.; MURPHY, M.; DING, Z.; SUN, X.; SHAM, T.$\mathrm{K}$. Interaction between Pt nanoparticles and carbon nanotubes - an X-ray absorption near edge structures (XANES) study. Chem. Phys. Lett., v. 437, p. 229-232, 2007.

[67] ANTOLINI, E.; GONZALEZ,E. R. Ceramic materials as supports for low-temperature fuel cell catalysts. Solid State Ionics, v. 180, p. 746-763, 2009.

[68] SHAO, Y.; LIU, J.; WANG, Y.; LIN, Y. Novel catalyst support materials for PEM fuel cells: current status and future prospects. J. Mater. Chem., v. 19, p. 46-59, 2009.

[69] CAMACHO, B. R.; MORAIS, C.; VALENZUELA, M. A.; ALONSO-VANTE, N. Enhancing oxygen reduction reaction activity and stability of platinum via oxide-carbon composites. Catal. Today, v. 202, p. 36-43, 2013.

[70] HABER, J.; LALIK, E. Catalytic properties of $\mathrm{MoO}_{3}$ revisited. Catal. Today, v. 33, p. 119-137, 1997. 
[71] BRÜCKMAN, K.; HABER, J.; WILTOWSKI, T. Active sites for reactions of olefin molecules at surfaces of molybdate catalysts. J. Catal., v. 106, p. 188-201, 1987.

[72] BRÜCKMAN, K.; GRABOWSKI, R.; HABER, J.; MAZURKIEWICZ, A.;

SŁOCZYŃSKI, J. The role of different $\mathrm{MoO}_{3}$ crystal faces in elementary steps of propene oxidation. J. Catal., v. 104, p. 71-79, 1987.

[73] OYAMA, S. T. Crystal face anisotropy of propylene oxidation on molybdenum trioxide. Bull. Chem. Soc. Jpn., v. 61, p. 2585-2594, 1988.

[74] BADAWY, W. A.; AL-KHARAFI, F. M. Corrosion and passivation behaviors of molybdenum in aqueous solutions of different pH. Electrochim. Acta, v. 44, p. 693-702, 1998.

[75] SAJI, V. S.; LEE, C.-W. Molybdenum, molybdenum oxides, and their electrochemistry. ChemSusChem., v. 5, p. 1146-1161, 2012.

[76] BOJINOV, M.; BETOVA, I.; RAICHEFF, R. Transpassivity of molybdenum in $\mathrm{H}_{2} \mathrm{SO}_{4}$ solution. J. Electroanal. Chem., v 381, p. 123-131, 1995.

[77] BOJINOV, M.; BETOVA, I.; RAICHEFF, R. A model for the transpassivity of molybdenum in acidic sulphate solutions based on ac impedance measurements.

Electrochim. Acta, v. 41, p. 1173-1179, 1996.

[78] TSURU, T. Anodic dissolution mechanisms of metals and alloys. Mater. Sci. Eng., v. A146, p. 1-14, 1991.

[79] ITAGAKI, M.; SUZUKI, T.; WATANABE, K. Channel flow double electrode study on anodic dissolution of molybdenum in sulfuric acid solution. Electrochim. Acta, v. 42, p. 1081-1086, 1997.

[80] WIKSTROM, L. L.; NOBE, K. The electrochemical behavior of molybdenum. J. Electrochem. Soc., v. 116, p. 525, 1969.

[81] SUGIMOTO, W.; OHNUMA, T.; MURAKAMI, Y.; TAKASU, Y. Molybdenum oxide/carbon composite electrodes as electrochemical supercapacitors. Electrochem. SolidState Lett., v. 4, p. A145-A147, 2001. 
[82] KIM, H.; POPOV, B. N. Characterization of hydrous ruthenium oxide/carbon nanocomposite supercapacitors prepared by a colloidal method. J. Power Sources, v. 104, p. $52-61,2002$.

[83] JUSTIN, P.; RAO, G. R. Methanol oxidation on $\mathrm{MoO}_{3}$ promoted Pt/C electrocatalyst. Int. J. Hydrogen Energy, v. 36, p. 5875-5884, 2011.

[84] YU, W.; TU, W.; LIU, H. Synthesis of nanoscale platinum colloids by microwave dielectric heating. Langmuir, v. 15, p. 6-9, 1999.

[85] HO, V. T. T.; PAN, C.-J.; RICK, J.; SU, W.-N.; HWANG, B.-J. Nanostructured $\mathrm{Ti}_{0.7} \mathrm{Mo}_{0.3} \mathrm{O}_{2}$ support enhances electron transfer to Pt: high-performance catalyst for oxygen reduction reaction. J. Am. Chem. Soc., v. 133, p. 11716-11724, 2011.

[86] ALONSO-VANTE, N.; CATTARIN, S.; MUSIANI, M. Electrocatalysis of $\mathrm{O}_{2}$ reduction at polyaniline + molybdenum-doped ruthenium selenide composite electrodes. J.

Electroanal. Chem., v. 481, p. 200-207, 2000.

[87] LUQUE, G. C.; FERNÁNDEZ, J. L. Electrocatalysis of oxygen reduction at electrodeposited molybdenum phosphate-based films. J. Power Sources, v. 203, p. 57-64, 2012.

[88] ÇAKAR, İ.; ÖZDOKUR, K. V.; DEMIR, B.; YAVUZ, E.; DEMIRKOL, D.O.; KOÇAK, S.; TIMUR, S.; ERTAŞ, F. N. Molybdenum oxide/platinum modified glassy carbon electrode: A novel electrocatalytic platform for the monitoring of electrochemical reduction of oxygen and its biosensing applications. Sensors Actuators B Chem., v. 185, p. 331-336, 2013.

[89] CHEN, G.; WANG, Z.; XIA, D. Electrochemically codeposited palladium/molybdenum oxide electrode for electrocatalytic reductive dechlorination of 4-chlorophenol. Electrochem. Commun., v. 6, p. 268-272, 2004.

[90] ELEZOVIĆ, N. R.; BABIĆ, B. M.; RADMILOVIĆ, V. R.; GOJKOVIĆ, S. LJ.; KRSTAJIĆ, N. V.; VRAČAR, LJ. M. Pt/C doped by $\mathrm{MoO}_{\mathrm{x}}$ as the electrocatalyst for oxygen reduction and methanol oxidation. J. Power Sources, v. 175, p. 250-255, 2008.

[91] ELEZOVIC, N. R.; BABIC, B. M.; RADMILOVIC, V. R.; VRACAR, LJ. M.; KRSTAJIC, N. V. Synthesis and characterization of $\mathrm{MoO}_{\mathrm{x}}-\mathrm{Pt} / \mathrm{C}$ and $\mathrm{TiO}_{\mathrm{x}}-\mathrm{Pt} / \mathrm{C}$ nano-catalysts for oxygen reduction. Electrochim. Acta, v. 54, p. 2404-2409, 2009. 
[92] YAN, Z.; XIE, J.; JING, J.; ZHANG, M.; WEI, W.; YIN, S. $\mathrm{MoO}_{2}$ nanocrystals down to $5 \mathrm{~nm}$ as Pt electrocatalyst promoter for stable oxygen reduction reaction. Int. J. Hydrogen Energy, v. 37, p. 15948-15955, 2012.

[93] TICIANELli, E. A.; GONZALEZ, E. R.; PINHEIRO, A. L. N.; PEREZ, J. Processo de obtenção de catalisador de platina dispersa ancorada em substrato através da redução por ácido. BR n. PI 9702816-9 B1, 02 set. 1997.

[94] WEST, A. R. Solid state chemistry and its applications. New York: Wiley, 1984. 734 p.

[95] CHEKCELL. Programa de computador. 2010. Disponível em: $<$ http://www.iucr.org/resources/other-directories/software/chekcell>. Acesso em: 25 maio 2014.

[96] GASTEIGER, H. A.; KOCHA, S. S.; SOMPALLI, B.; WAGNER, F. T. Activity benchmarks and requirements for Pt, Pt-alloy, and non-Pt oxygen reduction catalysts for PEMFCs. Appl. Catal. B Environ., v. 56, p. 9-35, 2005.

[97] MAYRHOFER, K. J. J.; STRMCNIK, D.; BLIZANAC, B. B.; STAMENKOVIC, V.; ARENZ, M.; MARKOVIC, N. M. Measurement of oxygen reduction activities via the rotating disc electrode method: from Pt model surfaces to carbon-supported high surface area catalysts. Electrochim. Acta, v. 53, p. 3181-3188, 2008.

[98] MITSUSHIMA, S.; KAWAHARA, S.; OTA, K.; KAMIYA, N. Consumption rate of pt under potential cycling. J. Electrochem. Soc., v. 154, p. B153, 2007.

[99] CHEN, S.; GASTEIGER, H. A.; HAYAKAWA, K.; TADA, T.; SHAO-HORN, Y. Platinum-alloy cathode catalyst degradation in proton exchange membrane fuel cells: nanometer-scale compositional and morphological changes. J. Electrochem. Soc., v. 157, p. A82, 2010.

[100] YANO, H.; AKIYAMA, T.; BELE, P.; UCHIDA, H.; WATANABE, M. Durability of $\mathrm{Pt} /$ graphitized carbon catalysts for the oxygen reduction reaction prepared by the nanocapsule method. Phys. Chem. Chem. Phys., v. 12, p. 3806-3814, 2010.

[101] UCHIMURA, M.; KOCHA, S. S. The impact of cycle profile on PEMFC durability. ECS Trans., v. 11, p. 1215-1226, 2007. 
[102] SUNU, S. S.; PRABHU, E.; JAYARAMAN, V.; GNANASEKAR, K. J.; SESHAGIRI, T. K.; GNANASEKARAN, T. Electrical conductivity and gas sensing properties of MoO3. Sensors Actuators B Chem., v. 101, p. 161-174, 2004.

[103] SWANSON, H. E.; FUYAT, R. K.; UGRINIC, G. M. Standard X-ray diffraction powder patterns. Washington, D.C.: Nat. Bur. Stand. (U.S.), 1954 circ. 539, v. 3, p. 30.

[104] MORRIS, M. C.; McMURDIE, H. F.; EVANS, E. H.; PARETZKIN, B.; PARKER, H. S.; PANAGIOTOPOULOS, N. C. Standard X-ray diffraction powder patterns.

Washington, D.C.: Nat. Bur. Stand. (U.S.), 1981. seç. 18, p. 44.

[105] AGUIAR, A. C. R.; OLIVI, P. Characterization and voltammetric behavior of $\mathrm{Pt}_{\mathrm{y}} \mathrm{Mo}_{\mathrm{z}} \mathrm{O}_{\mathrm{x}} / \mathrm{C}$ electrodes prepared by the thermal decomposition of polymeric precursors. $\mathbf{J}$.

Power Sources, v. 195, p. 3485-3489, 2010.

[106] MARTÍNEZ, S.; MARTINS, M. E.; ZINOLA, C. F. Surface metal modifiers for methanol electrooxidation on platinum, molybdenum and tungsten. Int. J. Hydrogen Energy, v. 35, p. 5343-5355, 2010.

[107] IOROI, T.; FUJIWARA, N.; SIROMA, Z.; YASUDA, K.; MIYAZAKI, Y. Platinum and molybdenum oxide deposited carbon electrocatalyst for oxidation of hydrogen containing carbon monoxide. Electrohem. Commun., v. 4, p. 442-446, 2002.

[108] ZHANG, H.; WANG, Y.; FACHINI, E. R.; CABRERA, C. R. Electrochemically codeposited platinum/molybdenum oxide electrode for catalytic oxidation of methanol in acid solution. Electrochem. Solid-State Lett., v. 2, p. 437-439, 1999.

[109] WANG, Y.; FACHINI, E. R.; CRUZ, G.; ZHU, Y.; ISHIKAWA, Y.; COLUCCI, J. A.; CABRERA, C. R. Effect of surface composition of electrochemically codeposited platinum/molybdenum oxide on methanol oxidation. J. Electrochem. Soc., v. 148, p. C222C226, 2001.

[110] MACHIDA, K.; ENYO, M. Structural and electrochromic properties of tungsten and molybdenum trioxide electrodes in acidic media. J. Electrochem. Soc., v. 137, p. 1169-1175, 1990.

[111] SWANSON, H. E.; TATGE, E. Standard X-ray diffraction powder patterns.

Washington, D.C.: Nat. Bur. Stand. (U.S.), 1953. circ. 539, v. 1, p. 31. 
[112] MUKERJEE, S.; URIAN, R. C.; LEE, S. J.; TICIANELLI, E. A.; McBREEN, J. J. Electrocatalysis of $\mathrm{CO}$ tolerance by carbon-supported PtMo electrocatalysts in PEMFCs. J. Electrochem. Soc., v. 151, p. A1094-A1103, 2004.

[113] LU, Y. C.; CLAYTON, C. R. An XPS study of the passive and transpassive behavior of molybdenum in deaerated 0.1 M HCl. Corros. Sci., v. 29, p 927-937, 1989.

[114] MOULDER, J. F.; STICKLE, W. F.; SOBOL, P. E.; BOMBEN, K. D. Handbook of X-ray photoelectron spectroscopy: a reference book of standard spectra for identification and interpretation of XPS data. Eden Prairie, Minnesota: Perkin-Elmer, 1992. 192 p.

[115] CHOI, J.-G.; THOMPSON, L. T. XPS study of as-prepared and reduced molybdenum oxides. Appl. Surf. Sci., v. 93, p. 143-149, 1996.

[116] BEŁTOWSKA-BRZEZINSKA, M.; WĘSIERSKI, T.; ŁUCZAK, T.; CAMRA, J. Catalytic effect of molybdenum oxo-species on reduction of allyl alcohol at a Pt electrode in strongly acidic solutions. Electrochim. Acta, v. 63, p. 89-99, 2012.

[117] CORRADINI, P. G.; ANTOLINI, E.; PEREZ, J. Structural and electrochemical characterization of carbon supported Pt-Pr catalysts for direct ethanol fuel cells prepared using a modified formic acid method in a $\mathrm{CO}$ atmosphere. Phys. Chem. Chem. Phys., v. 15, p. 11730-11739, 2013.

[118] MUKERJEE, S.; SRINIVASAN, S.; SORIAGA, M. P. Role of structural and electronic properties of $\mathrm{Pt}$ and $\mathrm{Pt}$ alloys on electrocatalysis of oxygen reduction. $\mathbf{J}$. Electrochem. Soc., v. 142, p. 1409-1422, 1995.

[119] LOPES, P. P. Aproveitamento de etanol em células a combustível: eletrocatálise da reação de oxidação direta e da oxidação do hidrogênio contaminado por CO obtido por sua reforma. 2013. 150 f. Tese (Doutorado em Físico-Química) - Instituto de Química de São Carlos, Universidade de São Paulo, São Carlos, 2013.

[120] BROWN, M.; PEIERLS, R. E.; STERN, E. A. White lines in x-ray absorption. Phys. Rev. B, v. 15, p. 738-744, 1977.

[121] LYTLE, F. W.; SAYERS, D. E.; STERN, E. A. Determination of s and d contributions to the $L_{2,3}$ extended x-ray absorption fine structure. Phys. Rev. B, v. 15, p. 2426-2428, 1977. 
[122] GREINER, M. T.; CHAI, L.; HELANDER, M. G.; TANG, W.-M.; LU, Z.-H. Metal/metal-oxide interfaces: how metal contacts affect the work function and band structure of $\mathrm{MoO}_{3}$. Adv. Funct. Mater., v. 23, p. 215-226, 2013.

[123] SEBENIK, R. F.; BURKIN, A. R.; DORFLER, R. R.; LAFERTY, J. M.; LEICHTFRIED, G.; MEYER-GRÜNOW, H.; MITCHELL, P. C. H.; VUKASOVICH, M. S.; CHURCH, D. A.; RIPER, G. G. V.; GILLILAND, J. C.; THIELKE, S. A. Molybdenum and molybdenum compounds. In: ULLMANN F.; BELLUSSI, G. (Ed.). Ullmann's

Encyclopedia of Industrial Chemistry. 7th ed. Weinheim: Wiley-VCH, 2011. v. 23, p. 521566.

[124] LALIK, E.; DAVID, W. I. F.; BARNES, P.; TURNER, J. F. C. Mechanisms of reduction of $\mathrm{MoO}_{3}$ to $\mathrm{MoO}_{2}$ reconciled? J. Phys. Chem. B, v. 105, p. 9153-9156, 2001.

[125] HU, B.; MAI, L.; CHEN, W.; YANG, F. From $\mathrm{MoO}_{3}$ nanobelts to $\mathrm{MoO}_{2}$ nanorods: structure transformation and electrical transport. ACS Nano, v. 3, p. 478-482, 2009.

[126] ZECEVIC, S. K.; WAINRIGHT, J. S.; LITT, M. H.; GOJKOVIC, S. LJ.; SAVINELL, R. F. Kinetics of $\mathrm{O}_{2}$ reduction on a Pt electrode covered with a thin film of solid polymer electrolyte. J. Electrochem. Soc., v. 144, p. 2973-2982, 1997.

[127] KATSOUNAROS, I.; CHEREVKO, S.; ZERADJANIN, A. R.; MAYRHOFER, K. J. J. Oxygen electrochemistry as a cornerstone for sustainable energy conversion. Angew.

Chem. Int. Ed. Engl., v. 53, p. 102-121, 2014.

[128] WATANABE, M.; TRYK, D. A.; WAKISAKA, M.; YANO, H.; UCHIDA, H. Overview of recent developments in oxygen reduction electrocatalysis. Electrochim. Acta, v. 84, p. 187-201, 2012.

[129] HOLEWINSKI, A.; LINIC, S. Elementary mechanisms in electrocatalysis: revisiting the ORR tafel slope. J. Electrochem. Soc., v. 159, p. H864-H870, 2012.

[130] MURTHI, V. S.; URIAN, R. C.; MUKERJEE, S. Oxygen reduction kinetics in low and medium temperature acid environment: correlation of water activation and surface properties in supported Pt and Pt alloy electrocatalysts. J. Phys. Chem. B, v. 108, p. $11011-$ 11023, 2004.

[131] SCHMIDT, T. J.; GASTEIGER, H. A.; STÄB, G. D.; URBAN, P. M.; KOLB, D. M.; BEHM, R. J. Characterization of high-surface-area electrocatalysts using a rotating disk electrode configuration. J. Electrochem. Soc., v. 145, p. 2354-2358, 1998. 
[132] GILEADI, E. Electrode kinetics for chemists, chemical engineers, and materials scientists. Weinheim: VCH, 1993. 597 p.

[133] SANTOS, L. G. R. De A. Eletrocatálise da reação de redução de oxigênio em meio ácido em ligas de platina dispersa em carbono. 2008. 103 f. Tese (Doutorado em FísicoQuímica) - Instituto de Química de São Carlos, Universidade de São Paulo, São Carlos, 2008.

[134] BARD, A. J.; FAULKNER, L. R. Electrochemical methods: fundamentals and applications. $2^{\text {nd }}$ ed. New York: Wiley, 2001. 833 p.

[135] DAMJANOVIC, A.; BRUSIC, V. Electrode kinetics of oxygen reduction on oxidefree platinum electrodes. Electrochim. Acta, v. 12, p. 615-628, 1967.

[136] NØRSKOV, J. K.; ROSSMEISL, J.; LOGADOTTIR, A.; LINDQVIST, L.; KITCHIN, J. R.; BLIGAARD, T.; JÓNSSON, H. Origin of the overpotential for oxygen reduction at a fuel-cell cathode. J. Phys. Chem. B, v. 108, p. 17886-17892, 2004.

[137] STAMENKOVIĆ, V.; SCHMIDT, T. J.; MARKOVIĆ, N. M.; ROSS, P. N. Surface composition effects in electrocatalysis: kinetics of oxygen reduction on well-defined $\mathrm{Pt}_{3} \mathrm{Ni}$ and $\mathrm{Pt}_{3}$ Co alloy surfaces. J. Phys. Chem. B, v. 106, p. 11970-11979, 2002.

[138] DARLING, R. M.; MEYERS, J. P. Kinetic model of platinum dissolution in PEMFCs. J. Electrochem. Soc., v. 150, p. A1523, 2003.

[139] DARLING, R. M.; MEYERS, J. P. Mathematical model of platinum movement in PEM fuel cells. J. Electrochem. Soc., v. 152, p. A242, 2005.

[140] MABUCHI, M.; YAMADA, Y.; SHIMOJIMA, K.; WEN, C. E.; CHINO, Y.; NAKAMURA, M.; ASAHINA, T.; IWASAKI, H.; AIZAWA, T.; HIGASHI, K. The grain size dependence of strength in the extruded AZ91 Mg alloy. In: KAINER, K. U. (Ed.). Magnesium alloys and their applications. Weinheim: Wiley-VCH, 2006. p. 280-284. 